\title{
La formación del profesorado de ciencias en contextos de diversidad
}

Una mirada desde la mediación con las TIC y la construcción de diseños didácticos

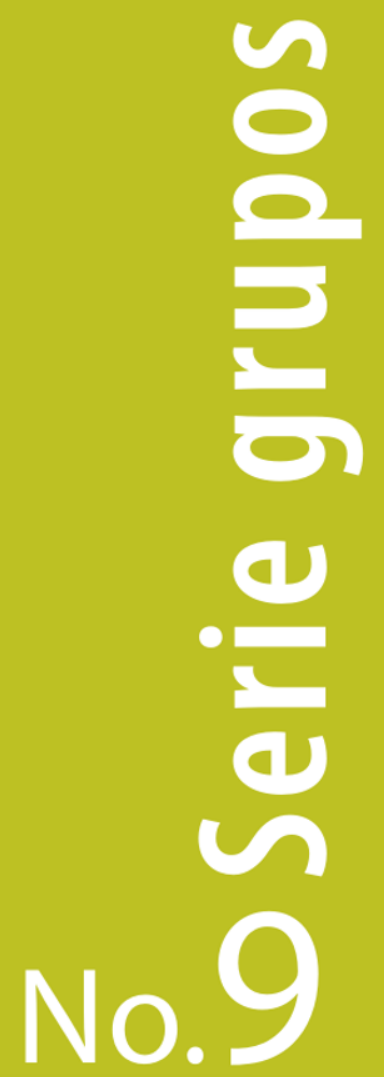

Área de Ciencias Naturales

Colombia, Chile y México

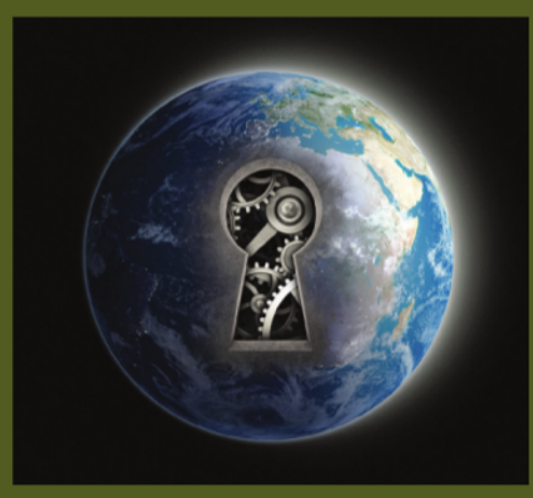

Álvaro García Martínez

Cristian Merino Rubilar Diana Patricia Rodríguez Pineda Rubinsten Hernández Barbosa Flor de María Reyes Cárdenas Leonardo Enrique Abella Peña Juan Carlos Guevara Bolaños

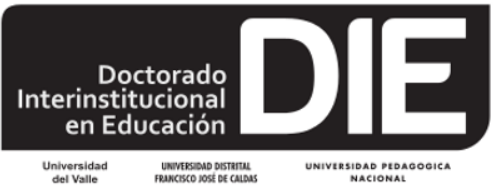




\section{La formación del profesorado de ciencias en contextos de diversidad.}

\section{Una mirada desde la mediación con las TIC y la construcción de diseños didácticos.}

\section{Área de Ciencias Naturales Colombia, Chile y México}

\begin{abstract}
Álvaro García Martínez
Cristian Merino Rubilar

Diana Patricia Rodríguez Pineda

Rubinsten Hernández Barbosa

Flor de María Reyes Cárdenas

Leonardo Enrique Abella Peña

Juan Carlos Guevara Bolaños
\end{abstract}

Universidad Distrital Francisco José de Caldas, Colombia.

Pontificia Universidad Católica de Valparaíso, Chile.

Universidad Pedagógica Nacional, México.

Universidad Distrital Francisco José de Caldas, Colombia.

Universidad Pedagógica Nacional, México.

Universidad Distrital Francisco José de Caldas, Colombia.

Universidad Distrital Francisco José de Caldas, Colombia.

Colaboradores:

Mario Lorenzo Flores López, Universidad Pedagógica Nacional, México.

David Contreras, Marcela Arellano y Roxana Jara, Pontificia Universidad Católica de Chile, Chile.

Víctor Astaburuaga, Pontificia Universidad Católica de Chile, Chile.

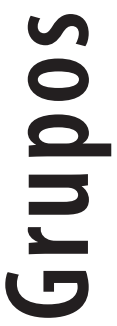




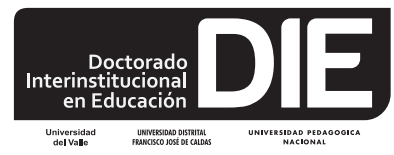

Comité Editorial Interinstitucional-CAIDE

Carlos Javier Mosquera Suárez

Director nacional

Alexander Ruíz Silva

Coordinador DIE,

Universidad Pedagógica Nacional

Sandra Soler Castillo

Directora DIE,

Universidad Distrital Francisco José de Caldas

\section{Jaime Humberto Leiva \\ Coordinador DIE \\ Universidad del Valle}

\section{Comité Editorial CADE}

\section{Sandra Soler Castillo}

Presidenta CADE

William Manuel Mora Penagos

Representante grupos de investigación: Interculturalidad, Ciencia y Tecnología-INTERCITEC, y del Grupo Didáctica de la Química-DIDAQUIm, del Énfasis de Educación en Ciencias.

Dora Inés Calderón

Representante de los grupos de investigación:

Moralia, Estudios del Discurso, Filosofía y Enseñanza de la Filosofía, Grupo de investigación

Interdisciplinaria en Pedagogía de Lenguaje y las Matemáticas-GIIPLyM y Jóvenes, Culturas y Poderes, del Énfasis de Lenguaje y Educación.

Martín Eduardo Acosta Gempeler

Representante de los grupos de investigación:

Grupo de Investigación Interdisciplinaria en

Pedagogía de Lenguaje y las Matemáticas

GIIPLyM, Matemáticas Escolares Universidad Distrital-mESCUD y Edumat, del Énfasis de Educación Matemática.

Bárbara García Sánchez

Representante de los grupos de investigación: Formación de Educadores, del énfasis de Historia de la Educación, Pedagogía y Educación Comparada.
UNIVERSIDAD DISTRITAL

FRANCISCO JOSÉ DE CALDAS

\section{Roberto Vergara Portela}

Rector (E)

Universidad Distrital Francisco José de Caldas

\section{Borys Bustamante Bohórquez}

Vicerrector Académico

Universidad Distrital Francisco José de Caldas

ISBN impreso: 978-958-8832-81-4

ISBN digital: 978-958-8832-82-1

Primera edición, 2014

(C) U. Distrital Francisco José de Caldas

\section{Preparación Editorial}

Doctorado Interinstitucional en Educación Sede Universidad Distrital Francisco José de Caldas

http://die.udistrital.edu.co

\section{Elban Gerardo Roa Díaz}

Asistente Editorial

eventosdie@udistrital.edu.co

\section{Fondo de publicaciones}

U. Distrital Francisco José de Caldas

Cra. 19 No. 33-39. Piso 2.

PBX: (57+1) 3238400, ext. 6203

publicaciones@udistrital.edu.co

Corrección de estilo

\section{Luisa Juliana Avella Vargas}

Impreso en Javegraf

Bogotá, Colombia, 2014

Prohibida la reproducción total o parcial de la presente obra por cualquier medio sin permiso escrito de la Universidad Distrital Francisco José de Caldas. 


\section{La formación del profesorado de ciencias en contextos de diversidad.}

\section{Una mirada desde la mediación con las TIC y la construcción de diseños didácticos.}

\section{Área de Ciencias Naturales \\ Colombia, Chile y México}

\begin{tabular}{r|l} 
Álvaro García Martínez & Universidad Distrital Francisco José de Caldas, Colombia. \\
Cristian Merino Rubilar & Pontificia Universidad Católica de Valparaíso, Chile. \\
Diana Patricia Rodríguez Pineda & Universidad Pedagógica Nacional, México. \\
Rubinsten Hernández Barbosa & Universidad Distrital Francisco José de Caldas, Colombia. \\
Flor de María Reyes Cárdenas & Universidad Pedagógica Nacional, México. \\
Leonardo Enrique Abella Peña & Universidad Distrital Francisco José de Caldas, Colombia. \\
Juan Carlos Guevara Bolaños & Universidad Distrital Francisco José de Caldas, Colombia.
\end{tabular}

Colaboradores:

Mario Lorenzo Flores López, Universidad Pedagógica Nacional, México. David Contreras, Marcela Arellano y Roxana Jara, Pontificia Universidad Católica de Chile, Chile. Víctor Astaburuaga, Pontificia Universidad Católica de Chile, Chile. 


\section{Contenido}

Introducción

7

1. La formación mediada por tecnologías en ambientes de diversidad

1.1. Acceso y uso de las TIC en poblaciones vulnerables en Latinoamérica

1.2. Hacia la comprensión de la formación del profesorado desde la diversidad

1.3. El proceso de formación del profesorado de ciencias

2. Orientaciones en la formación del profesorado de ciencias en ambientes mediados por las TIC

2.1. Dimensiones de la profesión docente mediada por las TIC $\quad 30$

2.2. Recomendaciones pedagógicas y técnicas en procesos de formación mediados por las TIC

a. Recomendaciones para formadores de profesores 40

b. Recomendaciones para estudiantes para profesor $\quad 42$

c. Recomendaciones generales de orden técnico y de aplicación $\quad 43$

3. Orientaciones para la elaboración de diseños didácticos en los campos estructurantes de la Ciencia Escolar

3.1. El diseño en la práctica del formador de profesores

3.2. Desde el diseño universal de aprendizaje hacia los diseños particulares 
4. Orientaciones para el desarrollo de la gestión y la evaluación mediante el diseño de unidades didácticas en ciencias naturales

4.1. Orientaciones para el desarrollo de la gestión didáctica $\quad 67$

4.2. Orientaciones para el desarrollo de la evaluación didáctica 72

5. Ejemplo de unidades didácticas para la ciencia escolar 77

5.1. Unidad didáctica «Seres vivos» para estudiantes de primaria en contextos de diversidad cultural: medio indígena

77

5.2. Unidad didáctica «Cambio químico» en contextos de diversidad

5.3. Unidad didáctica «La Materia» para estudiantes de primaria en contextos de diversidad 
Las Tecnologías de la Información y de la Comunicación (TIC) se han transformado en un elemento de innovación dentro del conocimiento humano. Aplicadas directamente a la disciplina académica, las TIC se han ganado un espacio debido al creciente interés por este tipo de herramientas de parte de los docentes.

El siglo xxı ha logrado imponer tecnologías que se desarrollan potencialmente, presentando herramientas que son cada vez más rápidas, cómodas y portátiles. Las TIC han incidido fuertemente en la educación, y el docente ya las considera como una herramienta útil para realizar su trabajo en el aula; además, las considera y usa como medio que facilita el aprendizaje de los estudiantes.

No obstante, al día de hoy, en Latinoamérica el uso de tic no es masivo. Su implementación aún está en una etapa inicial, esto es debido a diversos factores: falta de dotación de equipos, problemas con las redes y sistemas limitados de formación docente, aspecto que está íntimamente unido al poco seguimiento al implementar este tipo de tecnologías en las instituciones educativas y a los métodos y procedimientos empleados en la cualificación. En una escuela, el profesor que no ha sido preparado lo suficiente en el uso de las TIC difícilmente logrará utilizarlas adecuadamente, y sus metodologías de aula serán, probablemente, idénticas a las que existían previas a la implementación.

En ese sentido, hay que anotar que existe una gran diferencia entre conocer una herramienta y dominarla; el dominio se logra, por ejemplo, al conocer las ventajas y desventajas que posee una herramienta determinada en conexión directa a los contenidos y las necesidades de los estudiantes. El dominio de las TIC es el que otorga al docente de aula tomar decisiones que tiendan a la efectividad del proceso educativo, ya que las TIC no son solo un conjunto de herramientas, sino que además son orientables hacia un área u otra dependiendo de factores variables propias del proceso.

Dentro de una escuela existen diferentes actores que se interrelacionan socialmente. Cada uno posee funciones determinadas que aportan hacia los logros institucionales. En el contexto del trabajo con TIC en la escuela, el equipo directivo toma una gran responsabilidad debido a que asume la mediación de implementar estas herramientas, y la reacción de los dife- 
rentes actores. Por ello es fundamental comprender que toda acción debe propender hacia el cumplimiento de metas comunes.

La incorporación de TIC puede generar debate, lo cual es necesario para que no se convierta en una imposición jerárquica, sino que sea producto de acuerdos construidos de manera colectiva y participativa. No solo la incorporación debe ser el motivo de discusión y reflexión, sino que también los procesos de acercamiento, reformulación, uso, práctica y articulación metodológica de estas tecnologías en el aula. Las actividades ligadas a estos procesos no deben ser focalizadas de manera aislada en su uso, sino que de manera paulatina, al establecimiento en su totalidad.

Es importante considerar las diversas percepciones y actitudes que pueden existir al interior de una comunidad escolar en relación con las TIC. No todos los docentes, por ejemplo, tendrán el mismo nivel de disposición frente a una implementación de este tipo. Es por eso que se hace imprescindible la realización de actividades que permitan, en primera instancia, conocer el estado inicial de las percepciones frente al proceso y las actitudes que se tienen frente a un tema. Este aspecto a considerar se hace extensivo a todos los miembros de la institución y las familias. La idea es que todos puedan encontrar el sentido didáctico que tiene la incorporación de herramientas de este tipo, que se pueda lograr una profunda reflexión acerca de las fortalezas que adquiere el proceso educativo al usar Tıc en el aula, de la importancia de tener disposición frente a posibles cambios y las múltiples posibilidades de uso que este tipo de herramientas tienen para apoyar los procesos de enseñanza y aprendizaje.

Existen diferentes tipos de actividades que se pueden realizar para los fines descritos anteriormente, las cuales podrán ser consideradas por las instituciones. Estas actividades no son excluyentes entre sí; inclusive, podrían ser reformuladas para estar acordes al contexto educativo de cada institución. Es de gran importancia que el equipo directivo asuma la realización de estas actividades, las cuales, a modo de ejemplo, se listan a continuación:

- Actividades de indagación por parte de los estudiantes, para que ellos identifiquen actividades cotidianas que realizan utilizando la tecnología.

- Proyectos de aula en donde los estudiantes puedan utilizar herramientas tecnológicas para elaborar sus indagaciones, ya sea en una presentación, en la búsqueda misma, en la fabricación de algún producto, etc.

- Recopilar información mediante entrevistas y/o encuestas en relación con las experiencias con TIC por parte de los docentes y los estudiantes, a fin de considerarlas previas a la implementación. 
- Elaboración de propuestas iniciales de incorporación de tıc en el aula, para poder dar paso a un uso progresivo en las actividades lectivas.

El sistema educativo, en la necesidad de incorporar a las personas con capacidades diversas, ha ideado fórmulas bajo las cuales todos los estudiantes, hombres y mujeres, con o sin alguna discapacidad, puedan estar en un aula con sus pares sin que se considere mayormente su condición. Los primeros intentos de ello se han descrito bajo el concepto de integración. Este concepto se ha centrado constantemente en la discapacidad presente en la persona, más que en sus habilidades y fortalezas. Ha sido la experiencia la que permite llegar a una concepción nueva, la inclusión.

La inclusión ha sido definida por la Real Academia de la Lengua Española como «acción y efecto de incluir»; a su vez, incluir se define como «poner algo dentro de otra cosa o dentro de sus límites». Ambas definiciones se ven profundamente limitadas cuando tratamos de aplicar el concepto a un ámbito socioeducativo. En una escuela se trabaja con estudiantes, sujetos, personas, las cuales son formadas en las diferentes disciplinas del conocimiento humano, cuyas características individuales no siempre obedecen a una homogeneidad. De hecho, la diferencia es parte esencial e innegable de dichos actores del proceso educativo.

En ausencia de la inclusión, se tiende a pensar de manera homogénea respecto a quienes asisten a un establecimiento educativo. Siendo así, existirán ciertos estudiantes que podrían estar en desigualdad de condiciones. Justamente, la presencia de dicha inclusión educativa confronta a la homogeneidad utópica aludida, que se traduce en una heterogeneidad visible en la sociedad, a la viva presencia de la diversidad en el aula, en donde no es posible concebir a los otros como sujetos idénticos. Así, aparece el concepto de diversidad, bajo el cual se logra resignificar la inclusión.

Según Blanco (1999):

La inclusión implica que todos los niños de una determinada comunidad aprendan juntos independientemente de sus condiciones personales, sociales o culturales. Se trata de lograr una escuela en la que no existan "requisitos de entrada" ni mecanismos de selección o discriminación de ningún tipo; una escuela que modifique substancialmente su estructura, funcionamiento y propuesta pedagógica para dar respuesta a las necesidades educativas de todos y cada uno de los niños y niñas, incluidos aquellos que presentan una discapacidad. 
Este concepto, el cual ha surgido desde una apreciación filosófica y socioantropológica, se ha logrado incorporar en el ámbito socioeducativo debido a la presencia de sujetos que poseen una discapacidad y el requerimiento imperante de otorgar una formación que atienda a las necesidades que ellos presentan.

Estas personas, que están presentes en el sistema actual, demandan profundamente el derecho a ser educados bajo los principios de calidad y equidad. La integración no ha podido hacerse responsable de dar respuesta a dicha demanda, puesto que muchas veces integrar a un estudiante es acentuar la diferencia. En la inclusión, es el contexto quien se adapta al sujeto, por ende las diferencias no separan a una u otra persona, sino que se transforma en su motivo de unidad. El contexto responde a las necesidades, y la discapacidad ya no es la que predomina a la hora de considerar un proceso de enseñanza y aprendizaje efectivo, sino que se dejan ver las habilidades presentes, además de los potenciales logros que tiene cada estudiante, sin importar alguna condición existente de cualquier tipo.

El aprovechamiento de las tecnologías en la inclusión educativa contribuye a modificar el enfoque tradicional prevaleciente en muchos ámbitos del proceso formativo. En el caso de la población en contexto de diversidad, estas brechas se ven acentuadas debido a la discapacidad en sí, y además al hecho de que la comunidad escolar no realiza esfuerzos concernientes a condiciones de equidad. La escuela, en general, tiende a replicar prácticas pedagógicas que presuponen un principio de homogeneidad, y que dejan a ciertos estudiantes lejos de lograr procesos efectivos y significativos.

Teniendo en cuenta el contexto anterior, este documento contiene algunas orientaciones para el uso del material desarrollado en el área de Ciencias Naturales del Proyecto ALTER-NATIVA, el cual va dirigido a la formación de profesores que atienden poblaciones en contexto de diversidad con incorporación de las TIC. Es importante anotar que las actividades que se proponen son una posibilidad distinta de asumir la enseñanza de las ciencias naturales, lo que a su vez implica reflexión y evaluación constante de la práctica de los docentes de esta área; que los compromete también con los desarrollos tecnológicos actuales, lo cual conlleva a analizar y canalizar sus esfuerzos para diseñar y gestionar mecanismos que permitan la incorporación de las TIC en sus prácticas, pues se considera que estas permiten colaborar en la construcción de mundos posibles, cercanos a los ideales de participación, igualdad y equidad (Merino, Contreras \& Borja, 2013). 
Estas orientaciones específicas atienden básicamente dos asuntos: por un lado, cobijan algunas recomendaciones, las cuales son una propuesta de uso para aprovechar al máximo el material que se propone en el estudio de las ciencias naturales para las poblaciones participantes -sordos, indígenas y desplazados-. Para el desarrollo de las actividades planteadas, es necesario que los estudiantes para profesor y profesores de escuelas, colegios y universidades del área de Ciencias Naturales, como posibles usuarios de este material, las perciban como un recurso que tiene un potencial, y que para su desarrollo, se hace necesario tener presente el diseño y estructura didáctica, los objetivos temáticos, la infraestructura, los recursos tecnológicos, las necesidades y características de las poblaciones con quien se vaya a utilizar, entre otros aspectos. Y por otro, estas orientaciones tienen como propósito ofrecer elementos para la formación de profesores de ciencias naturales en su acción pedagógica y didáctica; se involucran las prácticas profesionales de diseño y elaboración de objetos didácticos y de los Objetos Virtuales de Aprendizaje (Ova) como casos específicos de estos.

Tomando como referencia lo anterior, se plantea como objetivo central de este texto el presentar algunas orientaciones que son necesarias para tener en cuenta a la hora incorporar las TIC en la formación de profesores de ciencias. De tal manera que los objetivos específicos serían los siguientes: a) establecer unas orientaciones que sean consideradas a la hora de usar los recursos virtuales, como los ova que fueron diseñados como parte del proyecto ALTER-NATIVA en el área de ciencias naturales; b) favorecer el aprendizaje de las ciencias naturales en las poblaciones objeto de estudio a través del uso de las TIC; c) resaltar la importancia que tiene el uso de las TIC para concebir el aprendizaje como un sistema de interacción y no como transmisión de información solamente, d) aportar a la reflexión y formación de docentes con una cultura tecnológica que les permita afrontar su labor pedagógica y didáctica en ámbitos de diversidad; e) proporcionar unos elementos teóricos y de uso de las TIC que admitan la planeación, el diseño, desarrollo, uso y evaluación de ova dentro de un Ambiente Virtual de Aprendizaje (AVA). 


\section{La formación mediada por tecnologías en ambientes de diversidad}

Existen múltiples proyectos y políticas gubernamentales en Latinoamérica que apuntan a la inclusión de las tecnologías, ya sea para facilitar procesos formativos o como 'competencia' a instalar en todos y todas los ciudadanos como parte de las aspiraciones de los ministerios de educación respectivos. A continuación revisamos algunos de estos aspectos, que creemos son primordiales para dar sustento a los ejemplos que son abordados más adelante en este libro.

\subsection{Acceso y uso de las tecnologías en poblaciones vulnerables en Latinoamérica}

Para Latinoamérica o América Latina (AL) y el Caribe, región con profundos desequilibrios económicos y sociales, la transición hacia el emergente paradigma de la sociedad de la información puede significar una inédita oportunidad de explorar nuevos rumbos hacia un desarrollo con equidad que incluya al conjunto de su ciudadanía (Hernández \& Calcagno, 2003, p. 1). A pesar de la conciencia política y económica por parte de todos los gobiernos de AL acerca de la necesidad universal de las TIC, existen brechas tanto en la disponibilidad de equipos, como en la conectividad y acceso a internet, que están asociadas a las condiciones de desigualdad socioeducativa y geográfica; el acceso a internet presenta diferencias significativas entre los países de la región, y al interior de ellos, entre el sector urbano y el rural; y en el ámbito educativo, entre las instituciones que albergan estudiantes de estratos socioeconómicos altos y las que albergan poblaciones más vulnerables, comúnmente asociadas a escuelas privadas y públicas respectivamente (SITEAL, 2010).

\section{a. En relación al acceso}

Un factor social, cultural y pedagógico a favor de incorporar a todas las poblaciones de AL al uso comprensivo de las TIC, es la existencia de organizaciones y comunidades que diseñan los productos tecnológicos y sus diferentes accesorios obedeciendo a las siguientes reglas:

- Uso equitativo: el diseño es útil y comercializable para todas las personas, independientemente de las habilidades que estas posean. 
- Flexibilidad en su uso: el diseño se adecúa a una amplia gama de capacidades y preferencias individuales.

- Simple e intuitivo: el diseño es fácil de entender a pesar de la experiencia del usuario, sus conocimientos, las competencias lingüísticas o el nivel de concentración que se tenga.

- Información fácil de percibir: el diseño comunica la información necesaria de manera eficaz, a pesar de las condiciones ambientales o de la capacidad sensorial del usuario.

- Tolerancia a errores: el diseño minimiza los riesgos y las consecuencias negativas de acciones no deseadas o accidentales.

- Bajo esfuerzo físico: el diseño puede ser utilizado de manera eficiente y cómoda con un mínimo de esfuerzo físico.

- Dimensiones y espacios apropiados: el tamaño y espacio del material es apropiado para su alcance, manipulación y uso, de acuerdo con el enfoque con el que fue creado en independencia de la estatura, complexión, postura o movilidad del usuario (Torres, 2009).

El cumplimiento de estas reglas obliga a tomar en cuenta contextos, modos y medios apropiados para las distintas poblaciones potencialmente usuarias del producto diseñado. En relación con el uso de TIC en el diseño del aprendizaje, aparece como condición necesaria que «la implementación de las TIC debe comenzar en las aulas de formación de docentes. Así emergerán nuevas generaciones de profesores que construyan y aprovechen tales mediaciones en los desafíos que da su entorno institucional» (Anthony \& Clark, 2011).

\section{b. En relación con la formación docente}

En AL se evidencia la necesidad de incorporar las TIC en los procesos pedagógicos, en especial en la formación inicial docente (SITEAL, 2010). Por tanto, el reto en la formación de profesores consiste en incluir una formación profesional orientada a la comprensión, apropiación crítica y exploración de las TIC, sus objetos y sus nuevos lenguajes en los contextos educativos de AL. Este análisis nos sitúa en la exigencia de revisar las propuestas de formación de profesores y de los currículos y prácticas académicas en la educación superior y el papel que en estos procesos juegan las TIC, de tal modo que se pueda comprender y responder a este reto. Urge incorporar dentro de las competencias profesionales de los docentes aquellas que, por una parte, les posibilite conocer las herramientas tecnológicas digitales y de comunicación, y por otra, las competencias pedagógicas a partir de la implementación de actividades innovadoras, que faciliten diversas estrate- 
gias de acceso a la interacción con los saberes y conocimientos propios de los espacios educativos.

Por tanto, los procesos de formación de docentes deben tener presente la formación de docentes mediadores y diseñadores de ambientes de aprendizaje, ya que en última instancia -y es relevante decir que no en primera instancia-, es el profesor quien diseña e implementa un proceso de aprendizaje que va a transformar información en conocimiento significativo, donde los niños y jóvenes participan con sus conocimientos, emociones, expectativas y realidades, y donde las computadoras pueden solo jugar un rol secundario y lo principal será la posibilidad de generar la interacción entre estudiantes, docentes y saberes, sin importar las características de los participantes.

Además, es importante en la formación de los docentes insistir en reconocer que la labor pedagógica requiere una permanente acción reflexionada sobre la diversidad en sus diferentes expresiones en el espacio escolar y la relación de la diversidad y el diseño de ambientes de aprendizaje, en los que las nuevas tecnologías favorecen estrategias de enseñanza y aprendizaje en general; las TIC como herramientas, permiten la superación de los retos propios de la diversidad: se convierten en ojos para los ciegos y oídos para los sordos. En consecuencia, conformar aulas con un alto grado de interacción, participación y por ende de aprendizaje compartido, se debe convertir en búsqueda permanente del profesor.

\section{c. Reconocimiento de la diversidad}

La diversidad cultural implica aspectos políticos, jurídicos, epistémicos, ontológicos y axiológicos, que son difíciles de separar a la hora de analizar su configuración en el marco de la cultura. En el caso de la educación, la compresión de la diversidad cultural implica compromisos y aperturas de todos los actores que conforman la institución escolar. Independiente del espacio, hay dos formas en las que se puede manifestar el compromiso al que se hace referencia: la primera, se refiere a la actitud de una acción abierta a la diferencia y a lo heterogéneo; y la segunda, asume la condición de lo diverso y heterogéneo en cuanto a lo cognitivo, a las concepciones y cosmovisiones del sujeto.

Hablar de diversidad poblacional en educación es reconocer la condición humana de los sujetos participantes en el acto educativo, es reconocer la configuración de cada sujeto como única y específica, no somos iguales. 
Estas diferencias tienen dos grandes vertientes en la diversidad humana que son de tipo biológico y socio-cultural. Por ejemplo, en el caso de la población invidente, Camargo y Da Silva (2006) analizan las dificultades entre profesores en formación y alumnos invidentes en clase de mecánica, y reportan que el principal problema son todos los significados que se obtienen en representaciones (o información) visuales, por lo que se deben proponer representaciones no visuales para poder obtener los mismos contenidos, y que la comunicación es la barrera principal.

En el año 2010, Camargo reporta el análisis de una clase de Física realizada con estudiantes invidentes, basada en evidencia auditiva y la interpretación de la misma por parte de los estudiantes. Se encontró efectivo el uso de la información auditiva (en lugar de la observación de un fenómeno) y se concluyó que las experiencias de física presentadas para alumnos no videntes necesitan estar organizadas de forma que se potencien al máximo todas las posibilidades (tacto, olfato, audición, quinestésica) de obtener información del fenómeno. A esta conclusión llegan también Costa, Neves y Barone (2006) en su investigación en enseñanza de la física para personas invidentes: la enseñanza de las ciencias considera la observación (la visión) como un elemento importante para su comprensión, por lo que se deben buscar alternativas factibles que permitan al estudiante con limitación visual obtener la información que requiere. Recomiendan el uso de recursos didácticos adaptados -computadora o tecnología específicamente adecuadapara la población invidente.

El reconocimiento de este amplio abanico de condiciones humanas significa que las particularidades que constituyen la diversidad, como la entendemos hoy, son una cuestión pública. Ya no se trata de una educación para formar ciudadanos iguales, por lo que las particularidades étnicas, religiosas, lingüísticas, sensoriales y económicas, son susceptibles de atención educativa dando sentido a la noción de educación para todos sin menoscabo de las particularidades. No se trata de formar ciudadanos iguales mediante la educación, sino de atender equitativamente, según sus condiciones particulares, a las diversas poblaciones.

\section{d. Las TIC y la educación en la diversidad}

Las TIC están llamadas a tener un papel relevante en la educación, no solo como instrumento de apoyo en el aula, sino como un elemento innovador que presenta nuevas maneras de afrontar la educación en la diversidad. 
En lo que corresponde a la comunidad indígena, Quero y Madueño (2006) desarrollaron y aplicaron un software educativo contextualizado dentro de una comunidad indígena Wayuu en Venezuela para incentivar la lectura y escritura wayuunaiki en escuelas indígenas, evidenciando que los niños muestran interés por un software que se escucha y lee en su idioma. Por su parte, Becerra (2012) refiere que en el proceso de apropiación de las TIC por estudiantes indígenas, se encuentra que hay acceso y uso de la computadora e internet (aunque no alcanzan el nivel de apropiación deseado de las TIC). Recomienda tomar en cuenta las necesidades especiales culturales y de lenguaje para el uso de las TIC, así como apoyar investigaciones que guíen los esfuerzos por incluirlas en el sistema educativo.

Por ejemplo, el gobierno de California cambió todos los libros de texto de ciencias y matemáticas del High School por versiones digitales gratuitas; esto posibilita que personas en vulnerabilidad socio-económica o con limitaciones físicas tengan un mejor acceso a una biblioteca gigantesca.

Además, la atención a la diversidad hace que la normatividad juegue un papel importante, la provee de un marco institucional. Por ejemplo, respecto a la incorporación de TIC en la formación de profesores, el gobierno Chileno presenta Competencias y Estándares TIC para la Profesión Docente (MINEDUC, 2011), los cuales prevén patrones o criterios que permitirán emitir en forma apropiada juicios sobre el desempeño docente de los futuros educadores y fundamentar las decisiones (ya sea en estudiantes con o sin NEE), que deben tomarse en torno a:

- Conocer las implicancias del uso de tecnologías en educación y sus posibilidades para apoyar su sector curricular.

- Planear y diseñar ambientes de aprendizaje con tıc para el desarrollo curricular.

- Utilizar las TIC en la preparación de material didáctico para apoyar las prácticas pedagógicas con el fin de mejorar su futuro desempeño laboral.

- Implementar experiencias de aprendizaje con uso de tıc para la enseñanza del currículum.

- Evaluar recursos tecnológicos para incorporarlos en las prácticas pedagógicas.

- Evaluar los resultados obtenidos en el diseño, implementación y uso de tecnología para la mejora en los aprendizajes y desarrollo de habilidades cognitivas.

- Apoyar los procesos de enseñanza y aprendizaje a través del uso de entornos virtuales. 
- Conocer aspectos relacionados con el impacto y papel de las TIC en la forma de entender y promocionar la inclusión en la sociedad del conocimiento.

- Identificar y comprender aspectos éticos y legales asociados a la información digital y a las comunicaciones a través de las redes de datos (privacidad, licencias de software, propiedad intelectual, seguridad de la información y de las comunicaciones).

- Manejar los conceptos y funciones básicas asociadas a las TIC y el uso de computadores personales.

- Utilizar herramientas de productividad (procesador de textos, hoja de cálculo, presentador) para generar diversos tipos de documentos.

- Manejar conceptos y utilizar herramientas propias de Internet, Web y recursos de comunicación sincrónicos y asincrónicos, con el fin de acceder y emplear las tecnologías para apoyar las tareas administrativo-docentes.

- Desarrollar habilidades para incorporar reflexivamente las tecnologías en su práctica docente.

- Utilizar las tecnologías para la comunicación y colaboración con iguales, y con la comunidad educativa en general, con miras a intercambiar reflexiones, experiencias y productos que coadyuven a su actividad docente.

Desde esta perspectiva la atención a la diversidad es exigente. Por ejemplo, creatividad e interdisciplinariedad deben hacer presencia a la hora de construir materiales educativos. Hay que articular diseño artístico con funcionalidad incluyente. Esta última condición lleva a las difíciles cuestiones de accesibilidad, usabilidad y comprensibilidad, entre otras.

Igualmente hay que tener en cuenta que el uso de las TIC, que desarrolla habilidades intelectuales que permiten disponer y elaborar nuevos bienes culturales, no ponga en riesgo la educación en y para la diversidad al intentar eliminar o dejar de lado en la educación el uso de tecnologías propias de las comunidades y de las poblaciones. Una opción para controlar el riesgo, es apostar por sinergias de tecnologías; así, atender la diversidad implica también atender a las tecnologías diversas.

\section{e. Las comunidades de práctica y la constitución de la identidad}

Para el desarrollo del proyecto y la Red ALTER-NATIVA, de la cual compartimos en este libro parte de sus productos, se asumió la estrategia metodológica de comunidades de práctica (Wenger, 2001). En términos generales, esta metodología se caracteriza por la configuración de una comunidad hu- 
mana constituida por personas que comparten una preocupación o una pasión por un quehacer y quieren aprender a hacerlo mejor, de manera colectiva, a medida que interactúan con regularidad en ese dominio; esta dinámica permite el desarrollo de una identidad definida por el actuar de la comunidad. Por ello, en la comunidad se generan prácticas (con sus actores), formas de organización y resultados compartidos. La constitución de la identidad no es una cuestión que se deba solo a la voluntad personal; la identidad se constituye y dinamiza en la relación que los individuos establecen entre sí y con las comunidades; estas aportan a los individuos significados, tipos de prácticas específicas y estables, y algo importante, distintos tipos de reconocimiento. Por tanto, la constitución de la identidad es una cuestión de pertenencia a comunidades (Wenger, 2001). Aunque existen muchas estrategias colaborativas, la de las comunidades de práctica asume también la cuestión de la identidad.

Como ya se dijo anteriormente, pertenecer a una comunidad de práctica implica participar localmente con otros miembros de la comunidad configurando un propósito compartido y su consecución; pero también implica vincular esa participación local, que desarrolla una forma particular de práctica, a modos y estilos de práctica más globales. De este vínculo emerge una tensión entre las prácticas local y global, que se puede tramitar en términos de los dos procesos que constituyen la identidad: el proceso de identificación y el de negociación de significados.

Cuando alguien dice soy reciclador, estudiante, hijo, etc., se está identificando como miembro de una comunidad que realiza una práctica. De un profesor que afirma: soy profesor que usa las TIC para atender la diversidad existente en el aula, se espera que despliegue una práctica efectiva de atención a la diversidad poniendo en juego las TIC. Las comunidades son las que valoran o evalúan la práctica específica que lleva a cabo una persona. Entonces podrán identificarla como experta o como novata; dirán de ella «usted es...», asignándole presencia, estatus y roles según ese reconocimiento. Al valorar la práctica, la comunidad propone rutas de existencia, de exigencia y de aprendizaje. Ser en una comunidad de práctica conlleva aprender las prácticas características de esa comunidad. Con lo dicho, en ALTER-NATIVA los formadores de profesores que atiendan la diversidad, ayudarán a los futuros profesores a aprender en la práctica; la práctica de diseñar, gestionar y evaluar para que se haga altamente probable el aprendizaje de los escolares sin desmedro -pero con estímulo- de la diversidad. 


\section{f. Contextos educativos de interacción del docente}

La participación del profesor en actividades que lo hacen integrante de una comunidad de práctica que acoge la diversidad, le permite identificar la práctica de enseñar como una práctica profesional, altamente compleja e importante para la construcción de mundos posibles cercanos a los ideales de igualdad, equidad y reconocimiento de la diversidad, ampliando las posibilidades de acción en los contextos educativos. ALTER-NATIVA ha identificado algunos requerimientos ineludibles para que la formación de profesores les permita tener alta probabilidad de éxito cuando incorporen en su práctica profesional la atención a la diversidad. Para conocer estos aspectos ineludibles en la formación de profesores en las áreas de matemáticas, ciencias naturales y lenguaje y comunicación, consultar los documentos de Referentes Curriculares de cada una de estas áreas según su interés. Dentro de estos requerimientos aparece la constitución de una identidad dirigida, entre otras direcciones necesarias, a la actuación comprensiva desde la diversidad y para la protección y evolución de la diversidad. Para las universidades que hacen parte de ALTER-NATIVA y forman profesores, y de manera particular para los formadores de dichos profesores, es importante tener una posición informada acerca de la constitución y dinamización de la identidad profesional tanto de los estudiantes para profesor como de los profesores en ejercicio.

\section{g. Integración de las tIC en diseños didácticos}

El proyecto y la red ALTER-NATIVA adoptan la perspectiva de Aprender a Enseñar, que señala que este es un proceso paulatino de incorporación en una comunidad de práctica que tiene como objetivo proveer al estudiante para profesor de instrumentos de la práctica de enseñar. Esto se logrará desarroIlando experiencias con un cierto tipo de conocimiento característico de su profesión:

- El conocimiento profesional del profesor.

- Identificando la profesión de enseñar como una actividad altamente compleja, necesaria e importante para la construcción de mundos posibles, cercanos a los ideales de igualdad, equidad y reconocimiento de la diversidad.

En esta medida, integrar tecnologías al marco de la formación de profesores presupone considerar las formas en que dichas tecnologías contribuyen al desarrollo de entornos educativos y ambientes de aprendizaje que potencien otras formas de enseñar y aprender, de interacción comunicativa y de 
transformación de las prácticas pedagógicas, es decir, otros tipos de contextos educativos más incluyentes y diversos. Así que la incorporación de las TIC en el ámbito educativo se enmarca en la perspectiva denominada uso inclusivo o incluyente, que se afirma en la valoración de la diversidad como elemento que potencia y enriquece aprendizajes, ya que el uso se focaliza tanto en lo que le aportan a los sujetos en términos de proveer posibilidades de acceso, expresión y de construcción de conocimientos, como en lo que aportan a las transformaciones de los contextos educativos, favoreciendo la construcción de ambientes de aprendizaje y desarrollo profesional que minimicen los obstáculos para la interacción, la participación, la negociación de significados y la comunicación. Cuando las tecnologías se insertan en el contexto educativo y se hacen interactuar con la perspectiva de formar en y para la diversidad, aparecen diferentes énfasis o funciones que podríamos sintetizar -solo desde la intencionalidad analítica- en dos polos diferentes: aquellas que no cuestionan el statu quo de las prácticas de formación (adaptativas) y aquellas que potencian su transformación (innovadoras).

Para Alter-NATIVA, la segunda será la función que esperamos asociar a la propuesta de formación de profesores. Adoptando la perspectiva de reconocer la diversidad como un hecho connatural al acto educativo, y las TIC como herramientas con potencial didáctico innovador, acogemos la propuesta de Diseño Universal del Aprendizaje (DUA) como respuesta a la necesidad de garantizar el acceso universal al aprendizaje de todas las personas, basado en una serie de principios que compartimos plenamente -los cuales detallaremos más adelante en el apartado de «Orientaciones para la elaboración de diseños didácticos en los campos estructurantes de la Ciencia Escolar»-, que orientan el diseño de las propuestas de formación de profesores y que exigen la incorporación del trabajo de ingenieros y tecnólogos en las áreas de sistemas, electrónica y telecomunicaciones para el trabajo en el contexto de la educación. Lo anterior dará como resultado la conformación de equipos interdisciplinarios que trabajen en y para la diversidad en educación con incorporación tecnológica.

\section{h. Un ambiente de aprendizaje para la formación didáctica requerida}

Para ayudar a los futuros profesores a ingresar, permanecer y dominar la práctica requerida, sus formadores pueden diseñarles ambientes de aprendizaje que abordan actividades auténticas de esa práctica.

Para la comunidad ALTER-NATIVA, la cuestión no es solo diseñar para que los niños videntes o los niños ciegos aprenden un concepto. Se trata de 
diseñar para que los niños, en cualquier condición sensorial, lingüística, cultural o socioeconómica, interactuando juntos aprendan dicho concepto y otros procesos de pensamiento que les aporten para su desempeño futuro como ciudadanos. ¿Qué ayudas TIC propone ALTER-NATIVA para posibilitar que niños ciegos, sordos, desplazados, indígenas o con cualquier tipo de diversidad, interactúen plenamente con niños videntes, con audición normal o citadinos, para resolver tareas similares a las antes propuestas? Las investigaciones, analizadas desde los contenidos propios del área de Ciencias Naturales, han establecido que los niños invidentes pueden descubrir el mundo de la ciencia usando medios que privilegien la información auditiva y los materiales táctiles con volumen. Se han usado propuestas de libros con texturas y Braille para desarrollar contenidos que tienen que ver con células, hongos, animales y biología marina, entre otros. En cuanto a los niños sordos se sugiere, además de la lectura labio-facial, el uso de actividades visuales y táctiles. De la misma manera que para la población ciega, es necesario tener presente en todo caso, que para los alumnos con déficit auditivo, los objetivos a lograr son los mismos que para el resto de alumnos, siempre encaminados a potenciar su máximo desarrollo en las áreas cognitiva, social, afectiva y motora.

\subsection{Hacia la comprensión de la formación del profesorado desde la diversidad}

Día a día se hace más importante el estudio y análisis de los procesos de formación de los profesores de ciencias como elemento central del mejoramiento de la educación de una sociedad. En este contexto, las políticas de desarrollo de un país, cada vez se encuentran más obligadas a contemplar la formación docente cuando se habla de una intención de mejoramiento de la calidad de la educación, situación que se evidencia un poco más en países desarrollados (en Estados Unidos, la National Council of Accreditation for Teacher Education-NCATE) y muy poco en aquellos que no lo son.

A pesar de lo anterior, los intentos gubernamentales por mejorar la educación en general, y en nuestro caso particular en ciencias naturales, se han orientado principalmente hacia cambios de currículo, de sistemas de evaluación, de materiales curriculares e incorporación de las TIC, entre otros; pero es muy poco lo que se ha generado en torno a la formación del profesorado. En nuestros países es casi inexistente este tipo de medidas a nivel gubernamental, lo cual se refleja en las políticas de desarrollo educativo. Pareciera existir un principio implícito, y es que al intentar modificar los 
«currículos» mediante la presentación de estándares y de sistemas diferentes de evaluación, se diera de manera directa una transformación en la enseñanza desde la perspectiva del profesorado, lo cual además de no ser del todo cierto, es algo muy difícil de lograr. Y es de difícil consecución, porque se requiere de procesos y programas de formación que atiendan a las exigencias de las comunidades académicas, y a la vez a los requerimientos sociales y culturales de formación y de la escuela; es aquí donde se hace evidente una tensión, siempre existente, entre las políticas estatales, las demandas de la academia y las necesidades de la sociedad y la escuela.

Considerando estas observaciones, desde la comunidad académica se ve la necesidad de generar mejores procesos de formación del profesorado para enriquecer la educación de nuestros niños y niñas, y desde la comunidad ALTER-NATIVA se toma como central esta idea, pensando también en una educación para otras poblaciones no contempladas dentro de los procesos formales de educación.

Una adecuada formación del profesorado de ciencias permite que nuestros estudiantes, entre otros indicadores, desarrollen procesos de aprendizaje más acordes con los avances científicos y tecnológicos; con mejores habilidades para comunicarse adecuadamente en el ámbito de las ciencias, en espacios que así se lo exijan dentro de su actuar cotidiano de ciudadano; con mayor respeto y reconocimiento del otro y sus ideas, aceptando nuestra diversidad cultural; a actuar sobre el medio que le rodea de forma consciente y responsable; a asumir posiciones basadas en principios éticos y a aprender a trabajar de forma cooperativa pero también de forma autónoma «aprendiendo a aprender», aún fuera de la escuela.

Desde estas exigencias de formación, se ha venido contribuyendo para que en la Didáctica de las Ciencias la formación de profesores se convierta en una línea de investigación de gran reconocimiento, lo cual se evidencia en las publicaciones que lo toman como un eje vital de desarrollo para la educación en ciencias. Así, en el Handbook editado por Gabel (1994), el capítulo Research on Science Teaching Education hace referencia a investigaciones sobre la formación del profesorado de ciencias; igualmente, en el editado por Fraser y Tobin bajo el título International Handbook of Science Education (1998), se encuentra el apartado «Teacher Development in Science Education», dedicado por completo a mostrar avances en las investigaciones sobre la formación inicial y continuada de los profesores de ciencias. En la obra editada por Perales y Cañal (2000) se abordan aspectos importantes en la actualidad, relacionados con investigaciones en 
formación de profesores; lo mismo sucede en el Handbook of Research on Science Education (Abell \& Lederman, 2007) y en el Handbook of Research on Teacher Education (Cochran-Smith, Feiman-Nemser \& McIntyre, 2008). De otro lado, en los congresos más importantes de la educación en ciencias a nivel mundial (ESERA, Enseñanza de las Ciencias, etc.) aparece una sección dedicada a esta línea.

La formación del profesorado ha pasado por diferentes perspectivas para ser desarrollada y ha estado ligada a ciertos modelos pedagógicos de tradición. Se destacan aquellas visiones que solo contemplaban la formación centrada en cursos y conferencias cortas desarrolladas en ambientes externos a la institución y soportadas en referentes teóricos sobre el deber ser del profesor. Estas experiencias de formación se caracterizaban porque al profesor se le formaba en algunos aspectos teóricos y metodológicos propios de la actividad docente, que al intentar ser replicadas en el aula presentaban dificultades, ya que eran diseñadas desde fuera de la escuela y en contextos diferentes a los que se aplicarían posteriormente. La formación desde una perspectiva academicista tenía un fuerte énfasis en el conocimiento de los contenidos disciplinares más que en los propios de la pedagogía, y menos, de las didácticas específicas.

En esta línea se plantearon procesos de formación ligados al qué deben saber y saber hacer los profesores de ciencias, dando la imagen de generación de listados de aspectos que deberían ser cumplidos por parte de un profesor para poder ejercer adecuadamente sus actividades docentes.

Al pensar en lo que debe enfatizar un programa de formación de profesores, Valcárcel y Sánchez (2000) plantearon cuatro grandes metas que se mencionan a continuación:

1. Mejorar el conocimiento de los profesores en relación con la asignatura que enseñan, especialmente en lo que respecta al contenido de enseñanza y al conocimiento didáctico del contenido.

2. Cambiar las concepciones y prácticas docentes de los profesores hacia enfoques coherentes con presupuestos constructivistas.

3. Formar al profesor como diseñador de proyectos curriculares e investigador de su actuación docente en el aula.

4. Desarrollar actitudes y prácticas docentes más colaborativas, críticas y autónomas.

Estas metas han orientado diversos programas de formación y actualmente resultan pertinentes a la hora de pensar en el tema. Desde la primera, 
surgen programas e investigaciones que tienen como denominador común que las decisiones del programa han sido tomadas por los expertos a partir de un diagnóstico de necesidades que muestra la insuficiencia de los conocimientos científicos o disciplinares de los profesores para una enseñanza eficaz (García-Martínez, 2009); de allí se derivan estudios centrados en el Pedagogical Content Knowledge (РСК) (Shulman,1986), posteriormente denominados, en el contexto iberoamericano, Conocimiento Didáctico del Contenido (CDC). A partir de la segunda meta, se presentan programas centrados en la promoción de un cambio didáctico (Mosquera \& Furió, 2008), basados en presupuestos teóricos de cambio conceptual desde corrientes psicológicas, en donde no solo se busca el estudio de las concepciones y prácticas docentes, sino también su cambio.

Otras propuestas de programas de formación orientadas desde la tercera y cuarta meta, tienen como elemento común el diagnóstico y resolución de problemas del aula, el trabajo cooperativo, el diseño y desarrollo del currículo y la reflexión en y sobre la práctica. Se pretende además cambiar el modelo didáctico hacia presupuestos constructivistas, formando al profesor como investigador de su acción docente y hacerlo profesionalmente más crítico y autónomo (Marx, Freeman, Krajcik \& Blumenfeld, 1998; Gil, Furió \& Gavidia, 1998).

Esta área de trabajo ha venido evolucionando en las orientaciones teóricas y metodológicas, por lo cual la perspectiva en los programas ha venido cambiando y, con ella, la terminología. Por ejemplo, términos como Teacher Education o Teacher Training han venido desapareciendo por las implicaciones que acarrea su uso, y aunque algunos autores lo emplean aún, para evitar ser ubicados en la imagen clásica reduccionista hacen las respectivas aclaraciones (Cochran-Smith, 1991). En los últimos años se emplea el término desarrollo del profesor o desarrollo profesional del profesorado (Teacher Development o Teacher Professional Development) (Couso, 2002, Hewson, 2007; García-Martínez, 2009; Simon \& Campbell, 2011). Esta última perspectiva asume:

el desarrollo profesional del profesorado como una serie de procesos sucesivos de autorregulación metacognitiva que llevan a un crecimiento en los ámbitos que orientan la profesión docente (ámbito personal, de conocimientos y estructuras interpretativas, y el ámbito práctico, todos ellos en el mundo personal del profesor) producto de la comprensión, puesta en práctica y de la relación entre lo que piensan, sienten, y hacen en su aula y en su institución; dichos ámbitos 
se ven influenciados por un ámbito externo (García-Martínez, 2009 y

García-Martínez \& Izquierdo, 2014).

\subsection{El proceso de formación del profesorado de ciencias}

El analizar la formación del profesorado desde la perspectiva del desarrollo profesional docente implica mirar en profundidad los elementos que lo constituyen y las implicaciones de asumirlos. Esta interpretación conlleva el reconocimiento de los procesos sucesivos de autorregulación como un elemento central en la construcción de la profesionalidad del docente, ya que esta se asume como el conocimiento y regulación de nuestras propias actividades cognitivas en el proceso de aprendizaje. Este conjunto de procesos sucesivos, ya que no es uno solo ni pertenece a un solo campo, se fundamenta en la interacción de los ámbitos de formación y desempeño del docente, los cuales se van construyendo y reconstruyendo de forma permanente cuando el profesor o profesora interactúa con los estudiantes, profesores y otros actores de la escuela por su misma actividad docente, sus intereses, emociones y el medio externo a sus actividades cotidianas. A continuación se realiza una breve descripción de los ámbitos que orientan la profesión docente soportados en García-Martínez (2009).

El ámbito personal está formado por valores, creencias, actitudes de tipo ideológico y político que orientan el ejercicio profesional del profesorado. El contexto y su diversidad cultural influyen en la forma como estructuran, orientan y desarrollan la actividad profesional, la forma como interpretan su aula de clase, su papel como orientadores, su papel como líderes académicos e inclusive como gestores de cambios en la escuela. La interpretación que el profesorado tenga sobre las políticas institucionales y gubernamentales orientan lo que se «enseña o deja de enseñar» y la forma de hacerlo; sus criterios se ven soportados en estas ideas personales que orientan su acción profesional.

Cuando se habla del ámbito de conocimientos y estructuras interpretativas, se quiere hacer énfasis en que la actividad profesional docente se centra en el conocimiento, y que este es producto de estructuras complejas para la reflexión, interpretación y acción. Esto implica que la docencia es una actividad intelectual y práctica, por tanto, la formación debe orientarse en la manera como el profesorado construye y emplea diferentes tipos de conocimiento, la forma como los lleva al aula y qué tipo de decisiones toma 
al momento de enfrentarse en sus contextos culturalmente diversos. Es en este ámbito en donde se ubican los conocimientos pedagógicos generales, los conocimientos sobre la diversidad de contextos, la «materia a enseñar» y su conocimiento didáctico del contenido.

El ámbito práctico hace referencia al conocimiento práctico del profesor, a la forma como este se ha construido y al modo como se reconstruye cuando interacciona en sus actividades docentes, con sus estudiantes y su entorno, entre otros. Algunos rasgos que caracterizan el conocimiento práctico de los profesores se pueden resumir en los siguientes enunciados: a) es un conocimiento orientado por la acción; b) está relacionado con la persona y su contexto; c) en gran medida es un conocimiento implícito y tácito; d) estos conocimientos están integrados: los conocimientos formales o científicos, los conocimientos del día a día, incluyendo normas y valores, al mismo tiempo que los experienciales, son parte del conocimiento práctico; y e) está soportado en las creencias del profesor (Van Driel, Beijaard \& Verloop, 2001).

Como se ha mencionado, el ámbito externo hace referencia a los aspectos que influyen en la profesión y que tienen su origen en elementos que están fuera de la actividad docente. Estos son de diversa naturaleza, pero se destacan los siguientes: los procedimientos y requerimientos de certificación o evaluación institucional; los programas y proyectos, su desarrollo y evaluación; las características propias de la institución, el diseño curricular, su desarrollo y evaluación; las agendas y agencias de investigación y seguimiento; el tipo de contratación del profesor y los mismos formadores de profesores o coordinadores de los programas de formación, entre otros.

Estos ámbitos son elementos básicos a la hora de pensar en cómo formar profesores, puesto que dan orientaciones sobre los procesos a desarrollar en dicho ejercicio, las metodologías más pertinentes, las metas de la formación, la estructura de un programa de formación y los contenidos a tener en cuenta.

Al reflexionar en la formación de profesores de ciencias que tendrán como objeto de estudio e interacción las comunidades culturalmente diversas, se ha previsto el analizar este proceso no como una sumatoria o yuxtaposición de partes, sino como un proceso sistémico, contextualizado, reflexivo, crítico y de construcción en comunidad, el cual puede ser desarrollado en contextos reales, con poblaciones con las que diariamente trabaja el profesorado. 


\section{Orientaciones en la formación del profesorado de ciencias en ambientes mediados por las TIC}

Diversos son los esfuerzos de los diferentes Ministerios de Educación de Latinoamérica para abordar la apropiación educativa de las TIC. En algunos casos, como es el de Chile, se ha concretado en dos obras: "Competencias TIC en la profesión docente», dedicada a los docentes en servicio, y «Estándares de formación TIC», destinada a la Formación Inicial Docente (FID). En este contexto, a continuación se exponen algunas ideas de estas dos obras que consideramos relevantes para la formación inicial y continua del profesorado en ciencias con mediación tecnológica ${ }^{1}$ en los países que forman parte de este proyecto.

Estas orientaciones se relacionan fundamentalmente con cambios en el entorno social, en los estudiantes y en la educación, y sigue la dinámica de las actualizaciones que otros países e instituciones han realizado o se encuentran realizando. Parte de estas orientaciones tienen referenciales de interés, especialmente el de la UNESCO. Creemos que las siguientes orientaciones, que presentamos agrupadas en cinco dimensiones (pedagógica; técnica; de gestión; social, ética y legal; y de responsabilidad y desarrollo profesional) y que consideran funciones de planificación y preparación de la enseñanza, la creación de ambientes propicios para el aprendizaje, la enseñanza propiamente dicha, la evaluación y la reflexión sobre la propia práctica docente, son necesarias para retroalimentar y enriquecer el quehacer incorporando las TIC.

Dado el carácter general de la afirmación anterior, se ha optado por especificar en cinco dimensiones la relación del docente con las TIC. Las dimensiones corresponden a las funciones clave que desarrolla un docente en cuanto a integrar TIC en su trabajo, ya sea si en su aula exista presencia o no de estudiantes con NEE. Así, se postula que un docente que integra las TIC, es un docente que:

1. Se preocupa por promover y desarrollar apropiadas experiencias de aprendizaje de los/as estudiantes (dimensión pedagógica).

2. Conoce y maneja bien las tecnologías disponibles para apoyar su función (dimensión técnica o instrumental).

1 MINEDUC (2011). Competencias y estándares tIC para la formación docente. Chile. 
3. Utiliza las TIC para mejorar la gestión curricular en su ámbito de acción (dimensión de gestión).

4. Se sirve de las TIC como un medio de inclusión social, de atención a la diversidad, realizando una actuación ética y legal respecto a su uso y cuidando la salud y del medio ambiente (dimensión social, ética y legal).

5. Reconoce su responsabilidad para que los estudiantes tengan un aprendizaje cada vez más eficiente y actual usando o incorporando las TIC, y que como docente asume responsablemente su propia actualización y desarroIlo profesional con las potencialidades que presentan las TIC para su quehacer profesional (dimensión responsabilidad y desarrollo profesional).

Si deseamos incluir estas dimensiones al quehacer del docente para diseñar dispositivos diferenciadores en el marco de la diversidad de aula con estudiantes con Necesidades Educativas Especiales (NEE), lo que nos queda es considerar los marcos del Diseño Universal de Aprendizaje (DUA), los cuales abordaremos más adelante. A continuación realizamos una breve descripción de las dimensiones de la profesión docente mediada por tecnología.

\subsection{Dimensiones de la profesión docente mediada por las TIC}

A continuación se describen las cinco dimensiones que son necesarias para retroalimentar y enriquecer el quehacer docente incorporando las TIC.

\section{a. Dimensión pedagógica}

Los desafíos actuales exigen que los docentes integren las TIC en sus labores cotidianas, tanto por el valor propio que ellas tienen en el desarrollo del conocimiento, la sociedad, el trabajo y todas las dimensiones de la vida personal y ciudadana, como también por la importancia de favorecer la ampliación de las capacidades de todos los seres humanos (docentes y estudiantes, en el caso de la escuela). Estas constituyen, hace ya algún tiempo, parte inherente a una cultura que los estudiantes viven en forma natural y cotidiana.

En el plano pedagógico, existe suficiente evidencia de que la incorporación de las TIC y su uso por parte de los docentes puede propiciar y desarrollar las potencialidades que tienen los nuevos medios para favorecer aprendizajes de calidad; esta incorporación debiera ocurrir en el contexto educativo con propósitos y objetivos curriculares bien definidos. 
El propósito de esta dimensión apunta a integrar las TIC a los procesos de enseñanza y aprendizaje con el fin de agregar valor al proceso mismo y para apoyar el desarrollo de los estudiantes. Para efecto de esta dimensión se han considerado tres orientaciones, la primera de ellas relacionada con la incorporación de las TIC al diseño de experiencias de aprendizaje; la segunda, a su implementación; y la tercera, relacionada con la incorporación de sistemas de información en línea y de comunicación mediada por computadores en la implementación de experiencias de aprendizaje. La evaluación se ha integrado explícitamente en las primeras dos orientaciones a fin de ser considerada durante todo el proceso de enseñanza y aprendizaje.

A continuación presentamos algunos de los aspectos que apuntan la integración de tecnología, que pueden ser utilizadas bajo ambientes con estudiantes con o sin NEE. Invitamos a que cada docente pueda hacer su propio diseño, por ejemplo para poblaciones sordas y ciegas, entre otras.

\section{Orientación}

1.1. Integrar TIC en la planificación de ambientes y experiencias de aprendizaje de los sectores curriculares para agregar valor al aprendizaje y al desarrollo integral de los estudiantes.

\section{Criterio}

1.1.1. Planifica ambientes y experiencias de aprendizaje utilizando resultados de estudios, buenas prácticas o estrategias exitosas respecto al uso de TIC.

1.1.2. Interpreta el contexto para planificar el uso de TIC en el diseño de actividades de aprendizaje y de acuerdo con los recursos disponibles.

1.1.3. Selecciona o adapta recursos digitales para potenciar el aprendizaje de los estudiantes, de acuerdo con las oportunidades y normativas materiales y humanas del contexto de desempeño.

1.1.4. Diseña estrategias de evaluación utilizando recursos digitales pertinentes a los aprendizajes esperados. 


\begin{tabular}{l} 
Orientación \\
\hline 1.2. Integrar tIC en la implementa- \\
ción de ambientes y experiencias \\
de aprendizaje de los sectores \\
curriculares para agregar valor al \\
aprendizaje y al desarrollo inte- \\
gral de los estudiantes.
\end{tabular}

\section{Criterio}

1.2.1. Implementa TIC en los ambientes y las experiencias de aprendizaje, acorde al contexto y los recursos tecnológicos disponibles.

1.2.2. Propicia en los estudiantes el desarrollo del pensamiento crítico y otras funciones cognitivas de orden superior mediante la integración de las TIC en el desarrollo de actividades de aprendizaje.

1.2.3. Desarrolla un ambiente de trabajo motivante y fomenta una disposición positiva hacia la incorporación y uso de las TIC en el proceso educativo.

1.2.4. Usa TIC para evaluar, de acuerdo con su pertinencia, los aprendizajes de los estudiantes en los sectores curriculares.

1.2.5. Usa TIC para retroalimentar los resultados de la evaluación para que los estudiantes ajusten, propongan y acuerden mejoras para sus propios procesos de aprendizaje.

1.3. Incorporar sistemas de información en línea y de comunicación mediada por computadores en la implementación de experiencias de aprendizaje con los estudiantes.
1.3.1. Desarrolla experiencias para facilitar el aprendizaje instrumental de sistemas electrónicos de información y de comunicación mediada por computadores, pertinentes a las características de los estudiantes y del contexto.

1.3.2. Desarrolla experiencias para el aprendizaje de estrategias de búsqueda, localización, selección y almacenamiento de recursos de información disponibles en sistemas electrónicos.

1.3.3. Desarrolla experiencias de aprendizaje que faciliten en los estudiantes la comprensión y reflexión de los alcances de la interacción en modalidades de comunicación mediadas por computadores. 


\section{b. Dimensión técnica}

La incorporación de las TIC en la educación es un proceso que requiere, además del equipamiento adecuado, que los docentes dispongan de oportunidades reales para familiarizarse con estas tecnologías, adquirir seguridad en la operación instrumental de los sistemas y construir un dominio personal con estos medios que les permita implementar y ejecutar con confianza las actividades de aprendizaje, y apoyar al estudiantado en su manejo informático.

Esta dimensión está implícita en las otras dimensiones, dado que en el contexto planteado de la incorporación de las TIC en la educación, se supone en todos los casos la utilización de recursos digitales y tecnológicos. Para este referencial, el énfasis de esta dimensión está en orientar y facilitar procesos de inducción al uso de los sistemas y herramientas actuales y emergentes.

\section{Orientación Criterio}

2.1. Usar instrumentalmente recursos tecnológicos, digitales y espacios virtuales en los procesos de enseñanza y aprendizaje.
2.1.1. Usa recursos tecnológicos y digitales para los procesos de enseñanza aprendizaje y para otras tareas docentes.

2.1.2. Usa recursos digitales de apoyo a los procesos de enseñanza aprendizaje y de gestión curricular en la planificación y realización de clases.

2.1.3. Construye espacios virtuales de colaboración, usándolos para fines pedagógicos.
2.2. Operar sistemas digitales de comunicación y de información pertinentes y relevantes para los procesos de enseñanza y aprendizaje.
2.2.1. Formula e implementa estrategias de búsqueda, localización y selección de recursos de información a través de sistemas en línea.

2.2.2. Usa sistemas digitales de comunicación para interactuar con sus estudiantes y otros actores del sistema educacional, siguiendo protocolos propios de esta modalidad. 


\section{c. Dimensión de gestión}

El concepto actual de gestión involucra todas las prácticas realizadas en un establecimiento educacional para asegurar el cumplimiento del ciclo curricular, desde la sustentabilidad del diseño e implementación de una propuesta pedagógica consistente, hasta la evaluación de sus resultados, ello considerando la coherencia con el Proyecto Educativo Institucional (PEI) y los aprendizajes de los estudiantes. Dicho esto, la noción de gestión que se utiliza en esta dimensión tiene por foco el desarrollo y/o fortalecimiento de los procesos de aprendizaje de los y las estudiantes.

En este contexto, los docentes cumplen un rol fundamental en la gestión curricular, pues sus prácticas deben asegurar que la implementación curricular se concrete en el aula a través de los procesos de enseñanza aprendizaje y sus aportes a la gestión del establecimiento, en relación con la comunidad y especialmente en la relación escuela-familia, pues también contribuyen en gran medida a su desarrollo.

La gestión curricular que realiza un docente puede beneficiarse en muy buena medida del uso de las TIC. Para ello se han distinguido dos tipos de funciones en las cuales puede usarlas: una relacionada con el uso de TIC para mejorar y renovar procesos de gestión curricular, y otra para mejorar y renovar la gestión institucional.

\section{Orientación \\ Criterio}

3.1. Usar TIC para mejorar y renovar procesos de gestión curricular.
3.1.1. Integra el uso de TIC para potenciar el análisis e interpretación de variables del desempeño académico y de eficiencia interna, y realizar así acciones de mejoramiento.

3.1.2. Usa TIC para programar, administrar y controlar el tiempo dedicado a la labor docente.

3.1.3. Colabora en la gestión de la organización, mantenimiento y actualización de los recursos digitales necesarios para la labor docente dentro de la institución. 


\section{Orientación}

\section{Criterio}

3.1.4. Implementa, mediante el uso de entornos virtuales, estrategias de comunicación y seguimiento del aprendizaje de los estudiantes que faciliten la interacción y el seguimiento de las actividades relacionadas con materias educativas.

3.1.5. Evalúa la pertinencia del uso de TIC para el logro de una gestión curricular adecuada y oportuna, buscando periódicamente su actualización y nuevas oportunidades para aplicarlas (nuevos ámbitos o contextos).
3.2. Usar TIC para mejorar y renovar la gestión institucional en la relación con la comunidad y especialmente en la relación escuela-familia.
3.2.1. Usa TIC para participar en la gestión institucional, en acciones como la planificación e implementación de proyectos, estudios y acciones institucionales colectivas $y$ de cooperación con el PEl, que involucren a la comunidad y especialmente a las familias.

3.2.2. Usa los espacios virtuales existentes en el establecimiento para facilitar y promover la interacción con los padres, madres y apoderados.

3.2.3. Usa TIC para planificar e implementar actividades con los padres, madres y apoderados, para el acompañamiento académico de los estudiantes y para recoger información (formularios on-line, encuestas y otros), para fines educativos. 


\section{d. Dimensión social, ética y legal}

Esta dimensión atraviesa y permea a todas las otras, pero dada su relevancia nos parece aconsejable tratarla en forma independiente. Se entiende que la labor del docente, en este sentido, se refiere principalmente a que sus estudiantes conozcan y se apropien de los aspectos sociales, éticos y legales relacionados con el uso e incorporación de tic en un marco de respeto y compromiso de cuidado de sí mismo, de los demás y del medio ambiente.

Hoy en día se tienen en cuenta las oportunidades -como también las amenazas- asociadas al uso de TIC, realizándose reflexiones éticas, especialmente aquellas relativas al uso responsable, a los derechos y deberes de los actores, a la promoción de las TIC, a la propiedad, y a otros temas que crecientemente ocupan un lugar preponderante en nuestras vidas. Todo esto se relaciona, evidentemente, también con lo legal, que constituye una mirada imprescindible para el trabajo con TIC.

Como último punto, pero no menos importante, la dimensión abarca el aspecto social, que abre un mundo nuevo para las relaciones de cada ser humano en particular y del conjunto de los estudiantes y los docentes en general, y da una atención especial a las nuevas formas de socialización que promueven las TIC, a la equidad, al respeto a la diversidad y al cuidado de la salud de los estudiantes.

\begin{tabular}{ll}
\hline Orientación & Criterio \\
\hline $\begin{array}{l}\text { 4.1. Integrar TIC para promover el } \\
\text { desarrollo de habilidades sociales, } \\
\text { nuevas formas de socialización y } \\
\text { el desarrollo de ciudadanía digi- } \\
\text { tal. }\end{array}$ & $\begin{array}{l}\text { 4.1.1. Promueve, a través de la imple- } \\
\text { mentación de ambientes de aprendi- } \\
\text { zaje con TIC, el desarrollo de habili- } \\
\text { dades sociales para la participación y } \\
\text { el aprendizaje colaborativo y en red. } \\
\text { 4.1.2. Explora con los estudiantes las } \\
\text { nuevas formas de socialización que } \\
\text { promueven las tic y sus implicancias } \\
\text { para el desarrollo y la conformación } \\
\text { de la identidad, propiciando procesos } \\
\text { de reflexión y formación de criterios } \\
\text { para actuar al respecto. }\end{array}$ \\
\end{tabular}




\begin{tabular}{l}
\hline Orientación \\
\hline \\
\hline 4.2. Incorporar TIC conforme a \\
prácticas que favorezcan el res- \\
peto a la diversidad, igualdad de \\
trato y condiciones saludables en \\
el acceso y uso.
\end{tabular}

\section{Criterio}

4.1.3. Incorpora en el diseño e implementación de las actividades con TIC, principios de la ciudadanía digital para el acceso y uso de la información y para la configuración de prácticas sociales digitales.

4.2.1. Integra, en el trabajo con $\mathrm{TIC}$, estrategias que aseguren el acceso equitativo a los recursos tecnológicos y digitales para todos los estudiantes, procurándoles las mejores condiciones disponibles y atendiendo a sus capitales culturales y diversas capacidades.

4.2.2. Incluye procedimientos de prevención y cuidado de la salud de los estudiantes y del ambiente educativo al trabajar con TIC.

4.2.3. Evalúa los logros alcanzados en las acciones implementadas para favorecer el acceso equitativo a los recursos tecnológicos y digitales, y la prevención y cuidado de la salud de los/las estudiantes y del medio ambiente.

4.3. Incorporar TIC conforme a prácticas que favorezcan el cumplimiento de las normas éticas y legales.
4.3.1. Modela y aplica, en las experiencias de aprendizaje en que se utilicen TIC, prácticas de reflexión y de toma de decisiones respecto a dilemas éticos y legales relacionados con su uso.

4.3.2. Modela, planifica e implementa actividades que propicien conductas respetuosas de las normas éticas y legales en el uso de TIC, especialmente en la prevención y tratamiento del acoso (bullying) y de fenómenos relacionados. 


\section{e. Dimensión de desarrollo y responsabilidad profesional}

Las TIC han pasado a ser una herramienta de gran valor y de apoyo al trabajo pedagógico y didáctico, entendiendo que -al igual que en el resto de los ámbitos de la vida- constituyen una parte inherente del quehacer social. En este sentido, son parte de la profesionalidad en el caso de la profesión docente, lo que significa que los docentes modernos no pueden estar ajenos a su comprensión y uso.

En esta dimensión se incluyen dos perspectivas, esto es, las TIC y su potencialidad como herramientas para el desarrollo profesional, vía formación continua, y las TIC como oportunidad para mejorar el desempeño, aportando desde ahí al mejoramiento de los aprendizajes de los estudiantes.

\begin{tabular}{|c|c|}
\hline Orientaciones & Criterios \\
\hline \multirow{3}{*}{$\begin{array}{l}\text { 5.1. Usar TIC en las actividades de } \\
\text { formación continua y de desarrollo } \\
\text { profesional, participando en comu- } \\
\text { nidades de aprendizaje presencial o } \\
\text { virtual y a través de otras estrategias } \\
\text { no formales apropiadas para el de- } \\
\text { sarrollo de este tipo de competen- } \\
\text { cias. }\end{array}$} & $\begin{array}{l}\text { 5.1.1. Selecciona y participa en ac- } \\
\text { tividades de formación continua so- } \\
\text { bre el uso e integración de las TIC en } \\
\text { temas pedagógicos y de contenidos } \\
\text { propios del sector de aprendizaje. }\end{array}$ \\
\hline & $\begin{array}{l}\text { 5.1.2. Participa en comunidades de } \\
\text { aprendizaje presenciales o virtuales } \\
\text { ligadas a su quehacer profesional, } \\
\text { utilizándolas como una oportuni- } \\
\text { dad de aprendizaje y desarrollo } \\
\text { profesional. }\end{array}$ \\
\hline & $\begin{array}{l}\text { 5.1.3. Usa estrategias no formales } \\
\text { para el desarrollo de competencias } \\
\text { TIC, orientando este esfuerzo a la in- } \\
\text { tegración de las TIC en las prácticas } \\
\text { pedagógicas y en los contenidos } \\
\text { propios del sector de aprendizaje. }\end{array}$ \\
\hline $\begin{array}{l}5.2 \text { Aplicar estrategias y procesos } \\
\text { para la gestión de conocimiento } \\
\text { mediado por TIC, con el fin de me- } \\
\text { jorar la práctica docente y el propio } \\
\text { desarrollo profesional. }\end{array}$ & $\begin{array}{l}\text { 5.2.1. Integra las TIC de manera per- } \\
\text { tinente en el quehacer y desarrollo } \\
\text { profesional, usándolas para la ob- } \\
\text { tención, almacenamiento y organi- } \\
\text { zación de información. }\end{array}$ \\
\hline
\end{tabular}




\begin{tabular}{|c|c|}
\hline Orientaciones & Criterios \\
\hline & $\begin{array}{l}\text { 5.2.2. Intercambia con sus pares } \\
\text { reflexiones, experiencias y recursos } \\
\text { sobre y para el uso de las TIC en su } \\
\text { desarrollo profesional. }\end{array}$ \\
\hline & $\begin{array}{l}\text { 5.2.3. Usa tic para la comunicación } \\
\text { y colaboración con sus pares para } \\
\text { fines de gestión curricular. }\end{array}$ \\
\hline \multirow{4}{*}{$\begin{array}{l}\text { 5.3. Reflexionar sobre los resultados } \\
\text { del uso y manejo de TIC en el propio } \\
\text { desarrollo profesional, diseñando e } \\
\text { implementando acciones de mejora. }\end{array}$} & $\begin{array}{l}\text { 5.3.1. Utiliza metodología de aná- } \\
\text { lisis para la reflexión de su práctica } \\
\text { con uso de tIC. }\end{array}$ \\
\hline & $\begin{array}{l}\text { 5.3.2. Participa en instancias de } \\
\text { evaluación y autoevaluación sobre } \\
\text { el manejo instrumental de TIC para } \\
\text { diagnosticar su nivel de dominio y } \\
\text { necesidad de formación. }\end{array}$ \\
\hline & $\begin{array}{l}\text { 5.3.3. Define un itinerario de desa- } \\
\text { rrollo profesional asociado al uso y } \\
\text { manejo de tIC. }\end{array}$ \\
\hline & $\begin{array}{l}\text { 5.3.4. Diseña e implementa accio- } \\
\text { nes de mejoramiento para el que- } \\
\text { hacer profesional a partir de la re- } \\
\text { flexión sobre el uso y manejo de TIC. }\end{array}$ \\
\hline
\end{tabular}

\subsection{Recomendaciones pedagógicas y técnicas en procesos de formación mediados por las TIC}

La enseñanza y el aprendizaje de las ciencias hoy es prioridad para los diferentes organismos gubernamentales y se considera como un factor de base para la movilidad social en el marco de las políticas educativas (UNESCO, 2000). Con preponderancia se desea que los ciudadanos se caractericen por desarrollar una mejor comprensión y apropiación de saberes con sentido, que les permita desenvolverse óptimamente en el mundo en el que viven, no como espectadores, sino como ciudadanos activos en la construcción de su propio proyecto de vida y actuando, a la vez, como coeditores y cogestores del desarrollo sustentable de su comunidad. 
Sin embargo, este objetivo se hace más difícil en la medida en que las poblaciones que conforman el objeto de estudio en este proyecto -en contextos de diversidad- no cuentan con mecanismos y programas institucionalizados que les permita, en condiciones de igualdad e inclusión, acceder a una educación científica acorde con las realidades y avances en este campo. Las TIC son una herramienta que permite al profesorado el diseño de estrategias de trabajo, que considerando la exclusión sufrida por estas poblaciones en virtud a sus diferencias culturales, físicas y cognitivas, pueden ser una buena alternativa en el logro de lo anotado en la parte inicial.

Para este escenario de diversidad se han elaborado las secuencias didácticas de ciencias naturales a partir de los campos estructurantes propios de las disciplinas, mediante el uso de tecnología. El diseño de estas secuencias y algunos ejemplos se presentarán en el último apartado, sin embargo, para que se pueda sacar provecho de ello, a continuación presentamos brevemente algunas recomendaciones de tipo pedagógico y técnico que pueden servir tanto a los profesores formadores de formadores -es decir a los profesores de las facultades de educación y de las normales que forman profesores- como a los estudiantes para profesor e incluso a los profesores en ejercicio, que incursionan en procesos de formación mediados por las TIC.

\section{a. Recomendaciones para formadores de profesores}

Un educador que ejerce su compromiso profesional en medio de la diversidad que este proyecto ha planteado, debe considerar la posibilidad de otras formas de asumir el reto educativo, lo cual implica no solo una reflexión y evaluación constante de su práctica, sino también -dados los desarrollos tecnológicos actuales- analizar y canalizar sus esfuerzos para diseñar y gestionar mecanismos que permitan la incorporación de las TIC en sus prácticas, pues se considera que estas posibilitan colaborar en la construcción de mundos posibles cercanos a los ideales de participación, igualdad y equidad.

El uso de las TIC, dentro de cualquier proceso de formación, requiere inicialmente una fuerte estructura didáctica que permita articular los objetivos de enseñanza y los modos y medios que proveen las TIC. Calderón y León (2010) destacan la importancia de reconocer si el ambiente de aprendizaje proporciona condiciones para que todos los partícipes tengan acceso al conocimiento y actividades propuestas, así como contacto con materiales diseñados para permitir un amplio abanico de aprendizajes cognitivos, afectivos y sociales. Por tanto, conformar aulas con un alto grado de inte- 
racción, participación, y por ende de aprendizaje compartido, se convierte en la búsqueda permanente del formador de profesores.

En este sentido, es pertinente que los formadores de profesores se vayan apropiando poco a poco de este tipo de recursos y medios para que los futuros profesores tengan una imagen de cómo se pueden hacer estas relaciones, bien a través de la implementación de cursos virtuales, uso de pequeños ova, evaluaciones en línea, uso del chat, programas de tutoría remota de forma sincrónica y asincrónica, entre otros.

La unESCO, en los Estándares de Competencia en tIc para docentes, señala que estos, desde su formación, deben desarrollar competencias en la utilización de las TIC que ayuden a mejorar la calidad del sistema educativo y recomienda incrementar la comprensión tecnológica de estudiantes, ciudadanos y fuerza laboral mediante la integración de competencias en TIC en los planes de estudios (UNESCO, 2005).

Por lo anterior, el perfil del docente de educación superior -que cuenta con una amplia trayectoria y práctica educativa- cambia radicalmente en los procesos educativos que incluyen las TIC o que son mediados por entornos virtuales. Ello exige a los docentes transformar sus competencias pedagógicas desarrollando actitudes innovadoras, incorporando nuevas competencias comunicativas no verbales y el dominio de las herramientas tecnológicas digitales, de comunicación, transmisión de contenidos e interacción con sus alumnos.

Una ventaja que ofrecen las TIC es que los materiales medulares ya están diseñados y son óptimos para su uso en el medio; es de vital importancia que el docente esté familiarizado con el material educativo que va a utilizar y además con el equipo tecnológico con el que él y sus estudiantes - para profesor- van a acceder en las sesiones programadas. Por lo anterior, el docente deberá conocer no solo el ova (el recurso digital) sino también el ava (el diseño holístico de la unidad didáctica) para que, además de poder utilizar los recursos tecnológicos, también sea clara y congruente la seriación de actividades dentro y fuera de la plataforma virtual, así como el objetivo de cada actividad y de la totalidad de la unidad didáctica. Además, como sus estudiantes para profesor trabajarán este material en contextos diversos, es también aconsejable que se solicite información sobre sus contextos de docencia y práctica docente y se realicen simulaciones bajo estas condiciones. 


\section{b. Recomendaciones para estudiantes para profesor}

Otra dimensión de las TIC la ofrecen los entornos virtuales de aprendizaje (e-learning), que permiten la educación a distancia a través de espacios de interacción que se integran o bien en las plataformas digitales, en entornos presenciales o en una combinación de ellos. Se ha demostrado que estas herramientas y entornos pueden potenciar la participación de estudiantes en lectura de documentos o textos on-line, participación en foros, construcción colaborativa mediante Wiki's para la realización de documentos comunes y elaboración de documentos de reflexión individual, entre otros. Participar en estos entornos con estas tecnologías es un modo de lograr aprendizaje tecnológico útil para la interacción y acogimiento de la diversidad.

Al estar más próximos a los diferentes avances tecnológicos, generacionalmente hablando, los estudiantes deberían aprovechar esta cercanía para analizar diferentes tipos de tecnologías que se pueden emplear para su formación y para la futura formación de los alumnos de primaria y secundaria, tales como plataformas para videojuegos y redes sociales, entre otras, y cómo estas pueden contribuir a la formación en contextos de diversidad.

Es importante que los estudiantes para profesor conozcan las capacidades y aspectos generales de los equipos tecnológicos ( $p$. ej. encendido y apagado de una computadora o acceso a un programa). Si es necesario, habrá que realizar prácticas adicionales para conocer el equipo y las capacidades y posibilidades de los ova diseñados. También es importante saber que es posible que algunos de sus alumnos tengan un manejo alto de los equipos y que pueden apoyar a la conducción de la sesión si se considera conveniente.

Finalmente vale la pena anotar que, independientemente del nivel de formación, actualmente las TIC son consideradas como un factor no solo de innovación, sino también como componente esencial en los cambios educativos y sociales que se puedan generar en una institución, en un sector educativo o incluso en un país, ya que las tic han desarrollado herramientas educativas diversas que facilitan el aprendizaje. Estos desarrollos potenciales son los que el proyecto ALTER-NATIVA ha considerado fundamentales para su incorporación, uso e integración en las prácticas educativas de las poblaciones objeto de estudio. 


\section{c. Recomendaciones generales de orden técnico y de aplicación}

\section{Aspectos técnicos}

Aunque parece obvio, lo primero a considerar es el modo y tipo de conectividad con que se cuenta, así como la finalidad que se persigue. Por ello, en relación con el uso particular de las presentes orientaciones para la construcción de objetos de aprendizaje accesibles, se requiere tomar en cuenta no sobrepasar los 5MB para el tamaño de archivos de audio, video y texto a fin de no dificultar su descarga y ejecución en equipos informáticos de capacidades mínimas. También es necesario que se tengan alternativas para que en el diseño de los recursos, de manera concreta, se considere la diversidad de las poblaciones y se tenga en cuenta el uso combinado de texto/audio, imagen/audio o texto. Además, es necesario tener presente las indicaciones necesarias de uso y la posibilidad que tiene el docente o el equipo de docentes de una institución, de poder construir sus propios recursos, de acuerdo con sus necesidades, como por ejemplo la elaboración de un video en lengua de señas indígena que explique un audio determinado.

\section{Aspectos de aplicación}

Las condiciones de uso y aplicación de los recursos dependen de una gran variedad de situaciones y factores, que es necesario tener presentes. Entre estos se encuentran:

- Edad de quien lo va a usar.

- Condición física, lingüística, étnica, de género y económica de quien lo va a usar.

- Ambiente geográfico y cultural donde se va a ubicar.

- Formas de interacción que el recurso propicia.

- Bienestar social que genera su uso.

- Tiempo de permanencia del recurso en los espacios sociales e institucionales.

- Condiciones del aula y aspectos de servicios para garantizar que los equipos tecnológicos funcionen adecuadamente (electricidad, temperatura, etc.). 


\section{Orientaciones para la elaboración de diseños didácticos en los campos estructurantes de la Ciencia Escolar}

En este apartado presentamos algunas orientaciones para la elaboración de diseños didácticos, en campos estructurantes en contextos de diversidad mediante el uso de tecnología. Pero antes de ello describiremos brevemente la idea de campo estructurante.

Al retomar la idea de Izquierdo (2005) respecto a que los temas a enseñar en ciencias deberían estructurarse en torno a los de los «modelos» básicos e irreductibles, que agrupan las ideas que fundamentan y permiten interpretar conjuntos de fenómenos que son relevantes para la formación de todas las personas, hemos planteado en el documento «Referentes curriculares con incorporación tecnológica para la formación de profesores en el área de Ciencias Naturales para atender poblaciones en contextos de diversidad» (García-Martínez et al., 2013), que dichos «modelos», pueden organizarse en torno a lo que hemos denominado los campos estructurantes del conocimiento científico, alrededor de los cuales los profesores de ciencias pueden pensar la planificación de su enseñanza para todas las poblaciones, independientemente de su contexto de diversidad.

Ahora bien, los campos estructurantes que permiten articular los modelos fundamentales que el alumnado debe construir para pensar acerca de la ciencia, específicamente de la biología, la física y la química, son correspondientemente Ser Vivo, Interacciones y Cambio Químico.

\subsection{El diseño en la práctica del formador de profesores}

Un hacer natural del formador de profesores, que también es un objeto de su enseñanza, es el diseño didáctico. Diseño que no puede limitarse a distribuir contenidos que son irrelevantes para los alumnos -como afirmaciones sin significado- (Rodríguez et al., 2011), sino que le supone proponer un conjunto de actividades y de tareas que orienten las experiencias en las que participarán los estudiantes para profesor, teniendo como referentes 
generales la diversidad y la incorporación de las TIC desde las perspectivas indicadas en los párrafos anteriores.

Así, el formador de profesores en general y los profesores en particular, han de asumir como una de sus tareas -que delimitan y caracterizan su actuación-, el seleccionar, organizar y planificar las experiencias de aprendizaje necesarias para que una persona aprenda, en particular para que un estudiante para profesor aprenda la práctica de enseñar. Por lo anterior, participar de la tarea del diseño forma parte de la identidad que caracteriza la práctica del formador de profesores, toda vez que se requiere que reflexione antes, durante y después de su acción. La investigación basada en el diseño, que se desarrolla en, sobre y dentro del mismo diseño, ha puesto de manifiesto que para proponer ambientes de aprendizaje se requiere construir, experimentar, evaluar y rediseñar hipótesis de trayectorias de aprendizaje.

\section{a. Tipos de diseño en los que participa un formador de profesores}

Como hemos argumentado, la realización de diseños didácticos es un elemento que configura la identidad del formador de profesores al quedar determinada por su experiencia con objetos y relaciones que constituyen lo que se llama el tejido didáctico que conforma las macro estructuras didácticas, a saber:

- La situación didáctica: estructuralmente es considerada como un sistema regulado de corta duración, durante el cual se produce un fenómeno de aprendizaje o comprensión; discursivamente, la situación didáctica se configura como una situación de comunicación (Calderón, 2005).

- La unidad didáctica: es el sistema más amplio que interrelaciona los actores y los elementos centrales del proceso de enseñanza-aprendizaje -propósitos, contenidos, evaluación e interacciones- con una alta coherencia metodológica interna. Se emplea como instrumento de programación y orientación de la práctica docente y se sitúa en el marco del desarrollo del plan de área para un ciclo escolar (García-Martínez, 2009).

- La secuencia didáctica: es la estructuración curricular de una secuencia temporal de unidades didácticas, a propósito de la orientación dada por unos objetivos de un programa o de una asignatura, y de la necesidad de desarrollar un aprendizaje sobre contenidos en un marco de acción curricular. Es una superestructura de un dominio disciplinar, diseñada curricularmente, que se mueve en tres niveles: la situación planeada, la situación realizada y la situación reconstruida.

- Los dispositivos didácticos: se refiere al componente de la propuesta didáctica que propicia las condiciones para la emergencia de un tipo de 
acción en estudiantes y profesores, que a la vez favorece la manifestación y el desarrollo de procesos de aprendizaje y enseñanza, y es el mediador del proceso enseñanza-aprendizaje; está diseñado y adecuado intencionalmente para tal fin. Gracias a este proceso de diseño, adquiere su carácter de dispositivo didáctico. Encontramos, entre otros, el juego, la resolución de problemas, el proyecto de aula, los talleres (Vergel, Rocha \& León, 2006; Calderón \& León, 2010).

- El ambiente didáctico: es el sistema didáctico configurado por el profesor, y el que, a su vez, configura las relaciones, los escenarios y los instrumentos que intervienen para consolidar un ambiente de aprendizaje. Como ambiente, articula relaciones bio-socio-culturales desde un punto de vista ecológico; como didáctico, ancla en ese ambiente la organización de los procesos de enseñanza y de aprendizaje. Estos procesos se dan entre distintos sujetos y en actos comunicativos, con las condiciones de existencia que los caracteriza.

A manera de ejemplo aportamos la estructura de una Unidad didáctica que, como se dijo anteriormente, se sitúa en el marco del desarrollo del plan de área para un ciclo escolar. Para nuestro caso, es el instrumento de planeación de un espacio de formación semestral.

\section{b. Los objetos virtuales de aprendizaje}

El desarrollo de las TIC ha generado, en el campo de la educación, la necesidad de considerar el diseño de Objetos Virtuales de Aprendizaje (ova) como respuesta a las necesidades de uso de la tecnología para el aprendizaje y la colaboración. Para el proyecto ALTER-NATIVA, el interés por los objetos de aprendizaje se relaciona con dos elementos centrales para la didáctica:

- La posibilidad de materializar las relaciones didácticas aprovechando las tecnologías: entre estudiantes (con distintas condiciones sensoriales, físicas y culturales), contenidos escolares (expresados en distintas representaciones y modos de comunicar) y profesores (que han concebido estas relaciones desde la perspectiva de facilitar y cualificar los aprendizajes).

- La producción colaborativa de propuestas de diseños didácticos con incorporación tıc. Se concibe esta colaboración tanto en la generación de los ova (con la participación de profesores, diseñadores e ingenieros), como en la posibilidad de producir objetos por comunidades de práctica de formadores de profesores, que pueden ser reutilizados por otros profesores.

Para lo anterior, es importante no solo producir los diseños y los OVA, sino también proponer estrategias para el almacenamiento, la búsqueda y 
el uso de estos objetos. Es decir, participar también en la construcción de los repositorios en los que estarán alojados los ova, garantizando su disponibilidad, su adaptabilidad y capacidad de reutilización por otros y en otros contextos. Aunque no hay aún acuerdos entre los expertos sobre una única definición de OVA, consideramos importante destacar las siguientes características:

- Es un todo, una unidad instrumental (documento electrónico, archivo) y una unidad simbólica (portadora de un lenguaje específico y mediadora del aprendizaje).

- $\quad$ Es un medio de aprendizaje que ha sido construido para ese propósito.

- Es reutilizable porque ha sido construido para que otros puedan usarlo. Por lo tanto, debe tener cualidades de durabilidad.

- Es un objeto de la red, porque incluye tanto las redes computacionales como las redes de apoyo, de profesionales y las redes sociales, entre otras.

- Es accesible, el contenido está dispuesto para circular en todo componente de entrada o de salida de la red y para cualquier usuario. En ese sentido, tiene características de adaptabilidad.

Para diseñar un ova es necesario tener en cuenta dos tipos de acciones: la pedagógico-didáctica y la del diseño de la producción, edición y utilización de las tecnologías apropiadas.

\section{c. Sobre el diseño pedagógico-didáctico}

Esta acción es la que involucra la definición y delimitación pedagógica y didáctica, especificando entre otros:

- Quiénes serán los usuarios de este objeto de aprendizaje y qué saben de lo que se pretende que aborden. Las respuestas a estas preguntas nos permitirán delinear las rutas de aprendizaje y sobre todo definir los ámbitos de flexibilidad que se tendrán.

- El enfoque didáctico que se adoptará. Delimitamos la perspectiva de aprendizaje y el tipo de enseñanza que es coherente con ella y cómo el uso de las TIC posibilita dichos procesos. ALTER-NATIVA privilegia el diseño de situaciones de aprendizaje enmarcado en una perspectiva sociocultural, dando especial importancia a las comunidades de práctica en contextos de diversidad.

- Los objetivos de aprendizaje. Dada la perspectiva de aprendizaje adoptada, los objetivos de aprendizaje se plantean en términos de la adquisición de instrumentos de la práctica de enseñar, poniendo especial énfasis en los procesos y menos en los resultados. Un aspecto importante es reconocer 
que se aprende en interacción con los otros, y que estos otros representan la diversidad como valor pedagógico y didáctico.

- Definición de las estrategias de aprendizaje. Se pone especial énfasis en cuatro grandes estrategias: de reflexión sobre la acción o de metacognición, de participación, de negociación de significados y de cosificación. De tal suerte que el papel del profesor privilegiará dos acciones que posibiliten una construcción colectiva de significados y una constitución de identidades: la regulación y la promoción de interacciones, de tal manera que se genere la constitución de las comunidades de aprendizaje.

- De este proceso surgen, naturalmente, las preguntas respecto a por qué otras estrategias propician el uso de las TIC y cuáles de ellas son útiles para promover la diversidad. Por ejemplo, estructuras de clase que combinan los trabajos individuales, en grupos pequeños (de dos, tres, o más personas) y en plenaria, pueden favorecer la construcción individual y colectiva y la discusión.

- El modelo de evaluación. La evaluación se asume como un proceso y como parte del aprendizaje, no como un ejercicio de reproducción (generalmente memorística) de conocimientos. Se promueven procesos de autoevaluación, coevaluación y heteroevaluación.

- Actividades de aprendizaje. Son todas aquellas actividades que se proponen a los y las estudiantes, también denominadas tareas o actividades auténticas. Corresponden a cuestiones acerca de problemas relacionados con las tareas de diseño, y deben hacer un uso intensivo de las tecnologías, por ejemplo de software especializados.

- Delimitación de los entornos en los que se desarrollarán las actividades. Considerar las cualidades de los entornos puede permitir identificar herramientas de comunicación e interacción síncronas y asíncronas, tales como foros, wikis o cualquier otra herramienta de mediación que permita la construcción conjunta a través de la participación y la cosificación.

- Los recursos de comunicación. Los objetos de aprendizaje pueden integrar diferentes recursos para la comunicación, por ejemplo los videos, los traductores entre lenguas, las imágenes, los lectores de pantalla, entre otros. Esta integración tiene que tener como referente la propuesta pedagógica y didáctica, garantizando que el estudiante pueda interactuar con el objeto ya que está disponible y utilizable.

Íntimamente relacionado con la adopción de una perspectiva pedagógica y didáctica, se halla el diseño gráfico y computacional, en el cual se decide, entre otras cuestiones, el tipo de accesibilidad, de imágenes, de letras, de dispositivos tecnológicos, etc. Esta es una tarea de trabajo interdisciplinario entre los ingenieros/diseñadores y los didactas. Una vez terminadas estas dos acciones, se tiene un diseño inicial que debe tener un grado de flexi- 
bilidad que le permita cumplir con las condiciones del diseño universal y con los requerimientos de incorporación de la diversidad, y someterse a los embates de la experimentación.

\subsection{Desde el diseño universal de aprendizaje hacia los diseños particulares}

Como se anunció ya desde el primer apartado de este documento -en el inciso sobre Integración de las TIC en diseños didácticos-, el Diseño Universal de Aprendizaje (DUA) tiene por objetivo justamente reestructurar el currículum, de manera tal que sea accesible y acorde a las necesidades de todos los estudiantes, ya que no necesariamente son los estudiantes con alguna discapacidad quienes se encuentran con estos obstáculos, sino que incluso alumnos sin discapacidad que poseen ritmos y estilos de aprendizaje diversos, pueden fracasar en sus procesos de aprendizaje. Basado en una serie de principios que orientan el diseño de las propuestas de formación de profesores, a continuación damos cuenta de tres principios fundamentales:

- Principio I. Proporcionar múltiples medios de representación (el «¿qué?» del aprendizaje). Los alumnos difieren en el modo en el que perciben y comprenden la información que se les presenta. Por ejemplo, aquellos con deficiencias sensoriales (e.g., sordera o ceguera), dificultades de aprendizaje (dislexia), diferencias culturales o de idioma y demás, pueden requerir diferentes maneras de abordar los contenidos. Otros pueden simplemente captar mejor la información a través de métodos visuales o auditivos que a través de un texto escrito. En realidad, no hay un solo medio que sea el mejor para todos los alumnos; el proporcionar opciones en la representación es esencial. En el caso del trabajo con personas sordas (e.g.), las representaciones con las que se apoya el desarrollo de una actividad deben ser presentadas mediante diversas vías, es decir, si se trata de una exposición oral, se hace fundamental que el expositor se apoye en diferentes clases de textos: escrito, auditivo y visual. De esta forma, la información podrá ser recibida de manera adecuada por parte de todos los estudiantes. Los sordos son esencialmente visuales, por ende al utilizar dicha vía, las brechas disminuyen potencialmente.

- Principio II. Proporcionar múltiples medios de expresión (el «¿cómo?» del aprendizaje). Los estudiantes difieren en el modo en que pueden «navegar en medio del aprendizaje» y expresar lo que saben. Por ejemplo, individuos con discapacidades motoras significativas (parálisis cerebral), aqueIlos que luchan con las habilidades estratégicas y organizativas (déficits 
de la función ejecutiva, TDHA), aquellos con un idioma materno distinto a la lengua de acogida y demás, abordan las tareas del aprendizaje y demuestran su dominio de manera muy distinta. Algunos serán capaces de expresarse correctamente por escrito, pero no oralmente y viceversa. En realidad, no hay un medio de expresión óptimo para todos los estudiantes; proporcionar opciones para expresarse es esencial. Las personas sordas (e.g.) son esencialmente visuales, y por medio de la Lengua de Señas pueden recibir y transmitir información en un contexto social determinado.

En un contexto socioeducativo la Lengua de Señas no siempre está presente, ni en las personas que rodean al individuo sordo, ni en ellos mismos, quienes no siempre se comunican a través de dicha lengua. Cuando la Lengua de Señas está presente en el entorno, se pueden describir diferentes situaciones comunicativas: aquellas en donde docentes y estudiantes poseen un manejo en esta lengua, caso en el cual no se hace necesaria ninguna observación en relación a este principio; también existen aquellas situaciones en las que el docente usa solo una lengua oral y sus estudiantes la de señas, caso en el cual, si no existe un intérprete de Lengua de Señas, es importante que las clases se puedan apoyar en textos escritos y desplegados frente a todos los estudiantes. También es importante que los docentes de aula puedan modular adecuadamente para todos los estudiantes, sobre todo para aquellos que poseen una discapacidad auditiva y su forma de comprensión de enunciados se dé a partir de la lectura labial.

- Principio III. Proporcionar múltiples medios de compromiso (el «ipor qué?» del aprendizaje). Los alumnos difieren marcadamente en la forma en que pueden sentirse implicados y motivados para aprender. Algunos alumnos se «enganchan» o conectan con la espontaneidad y la novedad, mientras que otros se desconectan, incluso se asustan. Al aprender así, no hay un único medio de representación que sea óptimo para todos los estudiantes; proporcionar múltiples medios de compromiso es esencial. Los estudiantes sordos (e.g.) en aula poseen intereses diversos, tal como el resto de los alumnos. Se podrían definir algunos ejes centrales relacionados con su nivel de participación en la Comunidad Sorda y su Identidad. Si se trata de sordos de participación activa con sus pares, sienten atracción por temas relacionados con ellos, es decir, problemáticas que giran en torno a las personas sordas y su Comunidad. Para los estudiantes que poseen pérdidas auditivas y que no necesariamente participan con sus pares, los temas de «enganche» son similares a los de otros estudiantes. El docente debe ser capaz de proponer diversos temas, en función de los diferentes intereses de todos los estudiantes. Siendo así, ellos lograrán sentirse motivados y conectados con la actividad. 
Ya que nuestro propósito es integrar bajo una construcción consensuada y validada de referentes curriculares generales los programas de formación de profesores en las áreas de lenguaje, matemáticas y ciencias, y a partir de ellos proponer diseños didácticos diferenciados para contextos de diversidad incorporando las TIC, es necesario ilustrar con un ejemplo a través de las herramientas que son consideradas del proyecto para el diseño de nuestra unidad.

\begin{tabular}{|c|c|c|c|}
\hline $\begin{array}{l}\text { Nombre del } \\
\text { Producto }\end{array}$ & Imagen & Descripción & Fabricante \\
\hline $\begin{array}{l}\text { Virtual } \\
\text { Magnifying } \\
\text { Glass }\end{array}$ & 包 & $\begin{array}{l}\text { El programa per- } \\
\text { mite ampliar un } \\
\text { área determinada } \\
\text { de la pantalla al- } \\
\text { rededor del pun- } \\
\text { tero del ratón y es } \\
\text { activado con una } \\
\text { combinación de } \\
\text { teclas. }\end{array}$ & $\begin{array}{l}\text { Harri Pyy, } \\
\text { Chris } \\
\text { O'Donnell, } \\
\text { Felipe } \\
\text { Monteiro de } \\
\text { Carvalho }\end{array}$ \\
\hline $\begin{array}{l}\text { Mando Wii } \\
\text { remote plus } \\
\text { para pizarra } \\
\text { digital }\end{array}$ & 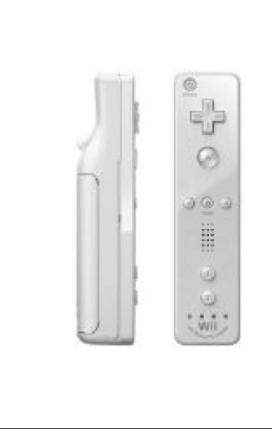 & $\begin{array}{l}\text { Pizarra digital ba- } \\
\text { sada en la utiliza- } \\
\text { ción de un mando } \\
\text { de Nintendo Wii } \\
\text { acoplado a una } \\
\text { computadora con } \\
\text { software controla- } \\
\text { dor, conectada a } \\
\text { un proyector mul- } \\
\text { timedia. }\end{array}$ & Nintendo \\
\hline Wink & \& Wink & $\begin{array}{l}\text { Wink es un soft- } \\
\text { ware para crear } \\
\text { tutoriales interac- } \\
\text { tivos para enseñar } \\
\text { la utilización de } \\
\text { software. }\end{array}$ & DebugMode \\
\hline
\end{tabular}

El kit que propone ALTER-NATIVA abarca herramientas para diversas poblaciones en contexto de diversidad (ciegos, discapacitados, sordos, comunidades indígenas y desplazados, entre otros), por ejemplo, las tres presentadas en la figura anterior podrían aplicarse a la enseñanza de las poblaciones con 
discapacidad auditiva, ya que su principal función es estimular el aprendizaje visual y kinestésico en estudiantes sordos.

A continuación presentamos algunas orientaciones para el diseño de un ova sobre la base de los principios descritos anteriormente.

\section{a. Principio I. Proporcionar múltiples medios de representación (el «¿qué?» del aprendizaje)}

Los alumnos difieren en el modo en que perciben y comprenden la información que se les presenta. Por ejemplo, si consideramos alumnos con deficiencias sensoriales - como la sordera-, cada uno de ellos puede requerir diferentes maneras de abordar los contenidos y de captar mejor la información. Lo hacen mejor a través de métodos visuales que de un texto escrito. En realidad, no hay un solo medio que sea el mejor para todos los estudiantes; el proporcionar opciones en la representación es esencial.

\section{Pauta 1. Proporcionar opciones de percepción}

Para ser eficaz en aulas con diversidad, el currículo debe presentar la información de forma que sea perceptible por todos los estudiantes.

Es imposible aprender la información que el estudiante no puede percibir, y difícil cuando esa información se presenta en formatos que requieren un esfuerzo extraordinario o asistencia. Por tanto, es importante asegurarse de que todos los alumnos perciban la información de igual forma con el fin de reducir las barreras del aprendizaje. Para ello es fundamental: 1) proveer la misma información a través de distintos modos sensoriales, como a través de la vista (Wink y Wii Mote) y del lenguaje de señas; 2) facilitar la información en un formato que permita ser ajustado por el alumno (texto que pueda ser agrandado con Virtual Magnifying Glass).

Las múltiples representaciones no solo aseguran que la información sea accesible a los estudiantes con desventajas particulares sensoriales o perceptivas, sino que sea más accesible a todos los demás. Cuando la misma información, por ejemplo, es presentada de forma hablada y escrita, la representación complementaria mejora la comprensibilidad para la mayoría de los estudiantes. 


\begin{tabular}{|c|c|}
\hline Sugerencia & Descripción \\
\hline $\begin{array}{l}\text { Opciones para personalizar la infor- } \\
\text { mación mostrada }\end{array}$ & $\begin{array}{l}\text { Aquí el uso de las diversas activi- } \\
\text { dades tiene un lenguaje básico y }\end{array}$ \\
\hline \multirow[t]{2}{*}{$\begin{array}{l}\text { La información debe ser mostrada en } \\
\text { un formato flexible, de modo que las } \\
\text { siguientes características perceptivas } \\
\text { puedan ser variadas. }\end{array}$} & $\begin{array}{l}\text { comprensible para el vocabulario } \\
\text { de los estudiantes sordos, donde } \\
\text { mediante el uso de la herramienta } \\
\text { Virtual Magnifying Glass, se flexi- } \\
\text { biliza el foco de atención en una } \\
\text { idea para los estudiantes, que pue- } \\
\text { de ser mediante el zoom de una } \\
\text { imagen o un texto escrito. }\end{array}$ \\
\hline & $\begin{array}{l}\text { Las herramientas de internet selec- } \\
\text { cionadas, fueron diseñadas dentro } \\
\text { de los estándares para mostrar la } \\
\text { información (tamaño de las letras, } \\
\text { color de fondo, contraste entre el } \\
\text { fondo y la imagen). }\end{array}$ \\
\hline $\begin{array}{l}\text { Opciones que facilitan alternativas } \\
\text { para la información oral }\end{array}$ & $\begin{array}{l}\text { La herramienta Wink representa } \\
\text { una alternativa para facilitar el len- } \\
\text { guaje oral; presenta un contenido } \\
\text { o un procedimiento de manera } \\
\text { tutorial y permite relacionar las } \\
\text { indicaciones del profesor con las } \\
\text { acciones que deberán realizar los } \\
\text { estudiantes. Hay que recordar que } \\
\text { el vocabulario de los estudiantes } \\
\text { sordos es básico, ya que no tie- } \\
\text { nen noción de ciertos conceptos } \\
\text { (químicos, biológicos y físicos) por } \\
\text { lo abstractos que son, por lo que } \\
\text { asociar un procedimiento o una } \\
\text { secuencia de imágenes, ayudaría a } \\
\text { conectar el concepto con la activi- } \\
\text { dad que se realizará. }\end{array}$ \\
\hline
\end{tabular}

Pauta 2. Proporcionar opciones para el lenguaje y símbolos

Los estudiantes varían en su destreza con diferentes formas de representación: verbal y no verbal. El vocabulario que puede agudizar y aclarar a un estudiante, puede confundir y extrañar a otro. 
Un dibujo o imagen que posee un significado para unos estudiantes puede llevar un significado muy diferente para otros de distinta cultura o ambiente familiar. El resultado es que las desigualdades aparecen cuando la información es presentada a todos los estudiantes a través de un solo modo de representación.

El uso de la herramienta Wink representa una importante estrategia de introducción, facilita formas de representación alternativas, no solo por accesibilidad, sino para aclararla y hacerla más comprensible a todos los estudiantes.

\begin{tabular}{l} 
Sugerencia \\
\hline $\begin{array}{l}\text { Opciones que explican el } \\
\text { vocabulario y símbolos }\end{array}$
\end{tabular}

\section{Descripción}

Por ejemplo, podemos proponer una actividad que apueste por enseñar el concepto de cambio químico a partir de un modelamiento de ideas, desde la más simple hasta la más compleja, que consiste en plantear, inicialmente, el cambio químico como un proceso temporal o permanente, luego desde la reversibilidad e irreversibilidad, y finalmente en la formación de nuevas sustancias, promoviendo paulatinamente relaciones desde el concepto con actividades de la vida cotidiana (presentadas en imágenes fijas o animadas) a través de los trabajos realizados en clase mediante la herramienta Wii Mote Plus. Es decir, el uso, dentro del vocabulario del estudiante, del concepto de cambio químico mediante las imágenes, favorece entender que corresponde a un proceso permanente, irreversible y donde se forman nuevas sustancias. También cabe destacar que dentro de la enseñanza para estos jóvenes, es recomendable presentar un concepto mediante expresiones complejas que estén compuestas por palabras más simples o símbolos. Ejemplo: irreversible $=$ no reversible, o sin vuelta atrás.

Sin embargo, añadir el concepto de cambio químico dentro del Lenguaje de Señas, o un simbolismo que lo represente, es complicado, puesto que se necesita del apoyo de un intérprete y de un trabajo más profundo dentro de esa área, donde varios conceptos científicos no se pueden presentar mediante el Lenguaje de Señas. 


\begin{tabular}{ll}
\hline Sugerencia & Descripción \\
\hline $\begin{array}{l}\text { Opciones que aclaran la } \\
\text { sintaxis y la estructura }\end{array}$ & $\begin{array}{l}\text { El trabajo desarrollado con la Herramienta } \\
\text { Wink ofrece una alternativa de trabajo median- } \\
\text { te su sistema de tutorial, estableciendo una } \\
\text { estructura fundamental en el modo de trabajo } \\
\text { dentro de las actividades de la clase. Por otra } \\
\text { parte, el Wii Mote Plus ofrece relacionar el con- } \\
\text { cepto más explícitamente mediante la unión del } \\
\text { concepto con procesos que ocurren en la vida } \\
\text { cotidiana, y dando referentes sobre la estructura } \\
\text { de su conocimiento. }\end{array}$ \\
\hline $\begin{array}{l}\text { Opciones que promueven } \\
\text { el entendimiento entre } \\
\text { estudiantes con distintas }\end{array}$ & $\begin{array}{l}\text { Dentro de la medida de lo posible, integrar el } \\
\text { lenguas }\end{array}$ \\
$\begin{array}{l}\text { Concepto descomponiendo las palabras y otor- } \\
\text { gando el significado correspondiente. }\end{array}$ \\
$\begin{array}{l}\text { Oonceptos clave no lin- } \\
\text { güísticos }\end{array}$ & $\begin{array}{l}\text { Aquí el Virtual Magnifying Glass y las activida- } \\
\text { des con el Wii Mote juegan un rol importante, } \\
\text { ya que permiten presentar los conceptos clave } \\
\text { en las ilustraciones o diagramas, que se com- } \\
\text { plementan con equivalentes verbales, explica- } \\
\text { ciones o aumentos. }\end{array}$ \\
\hline
\end{tabular}

\section{Pauta 3. Proporcionar opciones para la comprensión}

El objetivo de la educación no es hacer accesible la información (que es el objetivo de las bibliotecas), pero sí enseñar a los estudiantes cómo transformar el acceso a la información en conocimiento que se pueda utilizar.

Décadas de la información de la ciencia cognitiva han demostrado que la capacidad de transformar la información en conocimiento no es un proceso pasivo sino activo. La construcción de conocimientos útiles, el que es accesible para la futura toma de decisiones, depende no solo de percibir la información activa, sino de «habilidades de procesamiento de la información» tales como atención selectiva, integración de la nueva información con los conocimientos previos, categorización estratégica y memorización activa. Las personas difieren en sus habilidades del procesamiento de la información y en su acceso a los conocimientos previos, a través de los cuales pueden asimilar nueva información. Un buen diseño y presentación de la información, que es responsabilidad de cualquier currículo o metodología de enseñanza, puede proporcionar las rampas cognitivas que son necesarias para garantizar que todos los estudiantes tengan acceso a los conocimientos. 


\begin{tabular}{|c|c|}
\hline Sugerencia & Descripción \\
\hline $\begin{array}{l}\text { Opciones que proporcio- } \\
\text { nan o activan a fondo el } \\
\text { conocimiento }\end{array}$ & $\begin{array}{l}\text { Anclando la enseñanza, activando el co- } \\
\text { nocimiento previo relevante. Por ejemplo, } \\
\text { utilizando imágenes visuales, conceptos in- } \\
\text { cluyentes, rutinas con el Wii Mote, donde } \\
\text { los alumnos puedan realizar una actividad } \\
\text { de exploración. La enseñanza previa de los } \\
\text { conceptos que son prerrequisitos, se realiza } \\
\text { a través de demostraciones o tutoriales me- } \\
\text { diante el programa Wink. }\end{array}$ \\
\hline \multirow[t]{2}{*}{$\begin{array}{l}\text { Opciones que ponen de } \\
\text { relieve las características } \\
\text { críticas, las grandes ideas } \\
\text { y las relaciones }\end{array}$} & $\begin{array}{l}\text { El programa Virtual Magnifying Glass resalta } \\
\text { o destaca elementos clave en las actividades } \\
\text { con el fin de enfocar la atención de los alum- } \\
\text { nos en aquella área de interés. }\end{array}$ \\
\hline & $\begin{array}{l}\text { Por ejemplo, el programa Wink permite en- } \\
\text { fatizar las actividades con Wii Mote para } \\
\text { destacar características críticas, usando cla- } \\
\text { ves y apoyos de distinto tipo para llamar la } \\
\text { atención (e.g. señalética con signo de pre- } \\
\text { gunta o exclamación). }\end{array}$ \\
\hline $\begin{array}{l}\text { Opciones que orientan } \\
\text { el procesamiento de la } \\
\text { información }\end{array}$ & $\begin{array}{l}\text { El programa Wink otorga instrucciones explí- } \\
\text { citas para cada paso en un proceso secuen- } \\
\text { cial mediante el desarrollo de tutoriales. }\end{array}$ \\
\hline $\begin{array}{l}\text { Opciones que apoyan a la } \\
\text { memoria y la generaliza- } \\
\text { ción (transferencia) }\end{array}$ & $\begin{array}{l}\text { La aplicación Virtua Magnifying Glass pro- } \\
\text { porciona un método para verificar y recor- } \\
\text { dar conceptos importantes, haciendo zoom } \\
\text { sobre la imagen o la idea para facilitar la asi- } \\
\text { milación del contenido. }\end{array}$ \\
\hline
\end{tabular}

\section{b. Principio II. Ofrecer múltiples medios para la acción y la expresión}

Los estudiantes difieren en la forma de navegación y expresión en un entorno de aprendizaje. Por ejemplo, las personas con importantes discapacidades motrices (parálisis cerebral), los que luchan con las estrategias y capacidades organizativas (trastornos de la función ejecutiva, ADHD), los que se enfrentan a barreras del idioma, etc., abordan las tareas del aprendizaje de distinta manera. Algunos pueden ser capaces de expresarse bien con la escritura, pero no en el discurso oral ó viceversa, no existe un medio de expresión óptimo para todos los estudiantes y resulta esencial ofrecerlo. 


\section{Pauta 4. Proporcionar opciones para la acción física}

La propuesta de estas orientaciones es ofrecer un material curricular adecuadamente diseñado para la enseñanza del cambio químico para los estudiantes sordos y que se pueda proporcionar una interfaz eficiente con las tecnologías comunes de ayuda, a través de las cuales las personas con discapacidades puedan navegar o interactuar con un solo interruptor de joystick u otros.

\begin{tabular}{ll}
\hline Sugerencia & Descripción \\
\hline $\begin{array}{l}\text { Opciones en el modo de } \\
\text { respuesta física }\end{array}$ & $\begin{array}{l}\text { Mediante el uso del Wii Mote es posible } \\
\text { proporcionar alternativas para responder } \\
\text { físicamente, indicando los cambios físicos } \\
\text { y químicos según los contenidos revisados } \\
\text { teóricamente en la clase, por ejemplo, tras- } \\
\text { ladando un cuadro marcando con el control } \\
\text { de Wii para indicar qué tipo de cambio co- } \\
\text { rresponde. }\end{array}$ \\
\hline $\begin{array}{l}\text { Opciones en los medios de } \\
\text { navegación }\end{array}$ & $\begin{array}{l}\text { Proporcionar alternativas para interactuar } \\
\text { físicamente con los materiales. A través del } \\
\text { joystick de Wii, es posible que los estudian- } \\
\text { tes participen en las distintas actividades de } \\
\text { aprendizaje. }\end{array}$ \\
\hline $\begin{array}{l}\text { Opciones para acceder a } \\
\text { herramientas y tecnologías } \\
\text { de ayuda }\end{array}$ & $\begin{array}{l}\text { Cada herramienta posee las opciones de } \\
\text { cambio, por ejemplo el control de Wii nece- } \\
\text { sita calibración para ser utilizado, el botón } \\
\text { A sirve para seleccionar y el botón B para } \\
\text { salir del sistema de Wii Mote. La manera en } \\
\text { que los estudiantes pueden acceder a esta } \\
\text { tecnología es mediante el tutorial realizado } \\
\text { con el programa Wink, que ayuda a explicar } \\
\text { cómo funciona el dispositivo. }\end{array}$ \\
\hline & \\
&
\end{tabular}

\section{Pauta 5. Proporcionar opciones de habilidades expresivas y de fluidez}

No existe un medio de expresión igualmente adecuado para todos los estudiantes o para todo tipo de comunicación. Por el contrario, hay medios de comunicación que parecen poco adecuados para algunos tipos de expresión, y para algunos tipos de estudiantes. Si bien un estudiante con dislexia puede sobresalir en la narración de una conversación, puede fallar drásticamente cuando habla de la misma historia por escrito. Otras moda- 
lidades de expresión deben proporcionarse, no solo a nivel del campo de juego entre los estudiantes, sino también para introducirles a toda la gama de medios que son importantes para la comunicación y la alfabetización en nuestra cultura multimedia.

Además, los estudiantes varían en cuanto a la fluidez y la familiarización de las convenciones en cualquier medio. Dentro de los medios, se apoya que la alternativa debe estar disponible para orientar a los estudiantes a que se encuentren en los diferentes niveles de su aprendizaje, y a que aprendan a expresarse competentemente.

\begin{tabular}{ll}
\hline Sugerencia & Descripción \\
\hline $\begin{array}{l}\text { Opciones en los medios para } \\
\text { la comunicación }\end{array}$ & $\begin{array}{l}\text { Dentro de las actividades propuestas en la } \\
\text { secuencia de aprendizaje desarrollada tanto } \\
\text { con Wii Mote como con Wink, se observan } \\
\text { los siguientes medios o formatos: } \\
\text { Texto } \\
\text { Discurso } \\
\text { Dibujo, ilustración, diseño } \\
\text { Multimedia (diseños web que permiten la } \\
\text { interacción con el joystick de Wii) }\end{array}$ \\
\hline $\begin{array}{l}\text { Opciones en las herramien- } \\
\text { tas para la composición y } \\
\text { solución de problemas }\end{array}$ & $\begin{array}{l}\text { por el control de Wii cuentan con un diseño } \\
\text { asistido por el ordenador (CAD), el cual tiene } \\
\text { la corrección de los ejercicios para la resolu- } \\
\text { ción de cada uno de los problemas. }\end{array}$ \\
\hline
\end{tabular}

Opciones para el andamiaje de la práctica y el funcionamiento
A modo de ejemplo, se pueden proporcionar diferentes modelos para emular con el control de Wii, es decir, modelos que muestran los mismos resultados, pero usan diferentes enfoques desde el mismo modelamiento del concepto. Si bien tienen muchas similitudes las actividades que se presentan en la unidad didáctica, se abordan desde distintos enfoques dentro del aprendizaje esperado o lo que se pretende lograr en los estudiantes.

También proporciona diferentes tutores (es decir, uno como profesor y tutores virtuales como el Wink) y utilizan diversas formas para motivar, orientar, informar o comentar. 


\section{Pauta 6. Proporcionar opciones para las funciones ejecutivas}

En el más alto nivel de la capacidad humana para actuar hábilmente, están las denominadas «Funciones ejecutivas», asociadas con la corteza prefrontal del cerebro. Estas capacidades permiten a los seres humanos superar los impulsos y las reacciones a corto plazo en su medio ambiente, establecer los objetivos a largo plazo y el plan estratégico eficaz para alcanzar esos objetivos, supervisar su progreso y, llegado al caso, modificar las estrategias cuando sea necesario.

Resulta de crítica importancia para los educadores tomar conciencia del hecho de que las funciones ejecutivas tienen una capacidad muy limitada y son especialmente vulnerables ante determinados déficits. Esto es así porque la capacidad ejecutiva se reduce cuando:

- La capacidad de las funciones ejecutivas debe ser enfocada a la gestión de las capacidades del «nivel inferior» y las respuestas que no son automáticas o fluidas (debido a la inexperiencia o deficiencia). Por lo tanto, las funciones se toman desde las capacidades del «nivel superior».

- La capacidad ejecutada por sí mismo es reducida debido a un nivel alto de discapacidad o la falta de fluidez mediante las estrategias ejecutadas. La perspectiva del diseño intenta incidir y concentrar sus esfuerzos en ampliar la capacidad ejecutiva de dos maneras:

1. Apoyando las habilidades del nivel inferior a fin de requerir menos competencias ejecutivas.

2. Desarrollando las habilidades y estrategias ejecutivas del alto nivel para que puedan desarrollarse de forma más efectiva.

Otras guías se han dirigido a los procesos de ayuda centrados en las habilidades de bajo nivel. Estas se dirigen a formas de prestar apoyo a las propias funciones ejecutivas.

\begin{tabular}{|c|c|}
\hline Sugerencia & Descripción \\
\hline $\begin{array}{l}\text { Opciones para } \\
\text { guiar el estable- } \\
\text { cimiento efectivo } \\
\text { de objetivos }\end{array}$ & $\begin{array}{l}\text { Las actividades con Wii Mote fueron diseñadas para } \\
\text { ayudar al estudiante en su contextualización, además } \\
\text { para estimar el esfuerzo, los recursos y la dificultad } \\
\text { requerida por una tarea o meta. Por otra parte, Wink } \\
\text { representa un modelo o ejemplo del proceso y del pro- } \\
\text { ducto de establecer objetivos-metas mediante los tu- } \\
\text { toriales, indicándoles a los estudiantes a qué objetivo } \\
\text { deben Ilegar. Dentro de las actividades de Wii hay listas } \\
\text { de comprobación para ayudar a establecer objetivos. }\end{array}$ \\
\hline
\end{tabular}




\begin{tabular}{|c|c|}
\hline Sugerencia & Descripción \\
\hline $\begin{array}{l}\text { Opciones que } \\
\text { apoyan la pla- } \\
\text { nificación y las } \\
\text { estrategias de } \\
\text { desarrollo }\end{array}$ & $\begin{array}{l}\text { Con el programa Wink se integran entrenadores o tu- } \\
\text { tores que modelan el proceso de las actividades con el } \\
\text { Wii Mote. Dentro de las actividades propuestas en la } \\
\text { secuencia de aprendizaje, se propone una guía didácti- } \\
\text { ca para romper metas a largo plazo haciendo objetivos } \\
\text { a corto plazo, además de integrar las instrucciones para } \\
\text { reflexionar antes de realizar las actividades con el Wii } \\
\text { Mote. }\end{array}$ \\
\hline $\begin{array}{l}\text { Opciones que fa- } \\
\text { cilitan la gestión } \\
\text { de la información } \\
\text { y los recursos }\end{array}$ & $\begin{array}{l}\text { Los tutoriales de Wink vienen con instrucciones para } \\
\text { clasificar y sistematizar la información para el desarro- } \\
\text { llo de actividades. }\end{array}$ \\
\hline $\begin{array}{l}\text { Opciones que } \\
\text { mejoran la capa- } \\
\text { cidad de segui- } \\
\text { miento de los } \\
\text { progresos }\end{array}$ & $\begin{array}{l}\text { Dentro del tutorial desarrollado con Wink se pueden } \\
\text { incluir preguntas guiadas para la auto supervisión del } \\
\text { estudiante, y también para saber cómo debería ser el } \\
\text { logro del estudiante -por ejemplo imágenes del antes } \\
\text { y del después- para lograr la tarea de dicha actividad. }\end{array}$ \\
\hline
\end{tabular}

\section{c. Principio III. Proporcionar múltiples medios para la motivación e impli- cación en el aprendizaje}

Los estudiantes difieren notablemente en las formas en que se sienten comprometidos o motivados para aprender. Algunos estudiantes están muy interesados por la espontaneidad y la novedad, mientras que otros no, e incluso le tienen miedo y prefirieren una estricta rutina. En realidad, no hay un único medio de implicación que será óptimo para todos los estudiantes; ofrecer múltiples opciones para el compromiso y la motivación es esencial.

\section{Pauta 7. Ofrecer opciones para reclutar el interés}

La información a la que no se atiende, que no compromete la cognición del estudiante, es en realidad inaccesible, tanto en el momento (la información pertinente pasa desapercibida y sin procesamiento) y en el futuro (la información pertinente es poco probable que sea recordada).

Como resultado de ello, los profesores dedican un esfuerzo considerable para reforzar la atención y el compromiso de los estudiantes. Sin embargo, los estudiantes difieren significativamente en lo que atrae su atención y a lo 
que dedican su interés. Incluso el mismo estudiante variará a lo largo del tiempo y las circunstancias sus «intereses», los cuales cambian según se desarrollan y adquieren nuevos conocimientos y habilidades, al igual que sus entornos biológicos cambian en sintonía con las diferencias que existen en la autodeterminación entre adolescentes y adultos.

Por lo tanto, es importante contar con formas alternativas para conseguir captar este interés. Formas, por otra parte, que reflejen las diferencias intra e interindividuales entre los estudiantes.

\begin{tabular}{ll}
\hline Sugerencia & Descripción \\
\hline $\begin{array}{l}\text { Opciones que aumen- } \\
\text { tan la elección indivi- } \\
\text { dual y la autonomía }\end{array}$ & $\begin{array}{l}\text { Proporcionar a los estudiantes la mayor dis- } \\
\text { creción y autonomía como sea posible, ofre- } \\
\text { ciéndoles opciones para involucrarse, siempre } \\
\text { que sea posible, en el establecimiento de sus } \\
\text { propios objetivos personales, académicos y de } \\
\text { comportamiento. }\end{array}$ \\
\hline $\begin{array}{l}\text { Opciones que resaltan } \\
\text { la pertinencia, el valor }\end{array}$ & $\begin{array}{l}\text { Variar las actividades y fuentes de información. } \\
\text { y la autenticidad }\end{array}$ \\
das y lo más contextualizadas posible respecto \\
a la vida de estudiante. También son socialmen- \\
te pertinentes, adecuadas a las edades y capa- \\
cidades. Diseñar las actividades con el fin de \\
que los resultados sean auténticos y se puedan \\
comunicar a audiencias reales. \\
Las actividades con Wii Mote proporcionan \\
tareas que permiten la participación activa, la \\
exploración y la experimentación, además de \\
solicitarles respuestas personales, evaluación y \\
autoreflexión sobre los contenidos y las activi- \\
dades propuestas.
\end{tabular}

Opciones que reducen las amenazas y las distracciones
EL Wink ofrece opciones que pueden, en contraste con lo anterior, maximizar lo inesperado, sorprendente $u$ original cuando existen actividades muy rutinarias, por ejemplo, mostrar una reacción entre sustancias incoloras donde el producto formado es un precipitado de color amarillo. Las actividades con el Wii Mote permiten variar el nivel de estimulación sensorial en el aspecto kinestésico. 


\section{Pauta 8. Proporcionar opciones para mantener el esfuerzo y la persistencia}

Muchos tipos de aprendizajes, en particular el aprendizaje de habilidades y estrategias, requieren mantener la atención y el esfuerzo. Cuando están motivados para hacerlo, muchos estudiantes pueden regular su atención y sus afectos, a fin de mantener el esfuerzo y la concentración que exigirá este aprendizaje. Sin embargo, los estudiantes difieren considerablemente en su capacidad para auto-regularse de esta manera. Sus diferencias reflejan las disparidades en su motivación inicial, en su capacidad y sus habilidades para la autorregulación y en su susceptibilidad a la interferencia contextual, entre otros aspectos.

Una de las claves para el mejoramiento de la instrucción es construir las habilidades individuales en la autorregulación y la autodeterminación que iguala tales oportunidades de aprendizaje. Mientras tanto, sin embargo, el entorno externo debe proporcionar opciones que puedan igualar la accesibilidad, mediante el apoyo a los estudiantes que difieren en la motivación inicial, en las habilidades de la autorregulación, etc.

\begin{tabular}{|c|c|}
\hline Sugerencia & Descripción \\
\hline \multirow[t]{2}{*}{$\begin{array}{l}\text { Opciones que aumentan } \\
\text { la importancia de las me- } \\
\text { tas y objetivos }\end{array}$} & $\begin{array}{l}\text { El programa Wink ofrece una ayuda para formular } \\
\text { explícitamente o restablecer la meta perseguida, } \\
\text { además de recordarles la meta u objetivo a conse- } \\
\text { guir, visualizando el resultado deseado. }\end{array}$ \\
\hline & $\begin{array}{l}\text { También los programas Wink y Virtual Magnifying } \\
\text { Glass son herramientas informáticas que ayudan a } \\
\text { establecer esquemas temporales en el desarrollo de } \\
\text { las actividades o recordatorios de acciones a reali- } \\
\text { zar en una actividad determinada. }\end{array}$ \\
\hline \multirow[t]{2}{*}{$\begin{array}{l}\text { Opciones que varían los } \\
\text { niveles de desafío y de } \\
\text { apoyo }\end{array}$} & $\begin{array}{l}\text { El Wii Mote da permisividad en el uso de herramien- } \\
\text { tas y apoyos tecnológicos, como también oportuni- } \\
\text { dades de colaboración entre los estudiantes. }\end{array}$ \\
\hline & $\begin{array}{l}\text { Igualmente, las actividades poseen una variación de } \\
\text { los grados de libertad para un desempeño acepta- } \\
\text { ble dentro de las tareas del estudiante. Hacen hin- } \\
\text { capié en el proceso, el esfuerzo y la mejora en el } \\
\text { cumplimiento de los objetivos como alternativas a la } \\
\text { evaluación externa, los objetivos de rendimiento o la } \\
\text { mera competencia. La idea es siempre realizar eva- } \\
\text { luaciones formativas a los estudiantes para ir monito- } \\
\text { reando sus procesos y evolución en el aprendizaje. }\end{array}$ \\
\hline
\end{tabular}




\begin{tabular}{ll}
\hline Sugerencia & Descripción \\
\hline $\begin{array}{l}\text { Opciones que fomen- } \\
\text { tan la colaboración y la } \\
\text { comunicación }\end{array}$ & $\begin{array}{l}\text { Existen reglas de conducta para desarrollar las ac- } \\
\text { tividades con el Wii Mote; la participación de los } \\
\text { estudiantes condiciona a la mejora del comporta- } \\
\text { miento y a los objetivos actitudinales. }\end{array}$ \\
\hline $\begin{array}{l}\text { Opciones que aumen- } \\
\text { tan el dominio orien- } \\
\text { tado a la evaluación } \\
\text { formativa (retroali- } \\
\text { mentación formativa, } \\
\text { feedback) }\end{array}$ & $\begin{array}{l}\text { Cada actividad con el Wii Mote representa evalua- } \\
\text { ciones formativas en el estudiante que alientan la } \\
\text { cacia y la autoconciencia, la utilización de deter- } \\
\text { minados soportes y estrategias al enfrentarse a los } \\
\text { retos escolares del aprendizaje. Se pretende que } \\
\text { los estudiantes sean conscientes de estructurar el } \\
\text { conocimiento desde lo más simple hasta lo más } \\
\text { complejo, donde la eficacia en el desarrollo de } \\
\text { problemas involucre la unión de ideas y un razo- } \\
\text { namiento completo por parte de los estudiantes. } \\
\text { Este tipo de evaluaciones formativas hacen hin- } \\
\text { capié en el esfuerzo, la mejora y el logro de un } \\
\text { criterio, en lugar de señalar simplemente la conse- } \\
\text { cución de un rendimiento específico. Para lograr } \\
\text { la mejora y un aprendizaje significativo, las eva- } \\
\text { luaciones formativas son continuas y realizadas en } \\
\text { múltiples formatos como Wink y Wii Mote, con } \\
\text { el objetivo de informar el progreso de cada estu- } \\
\text { diante. } \\
\text { Evaluaciones que informen respecto a cómo in- } \\
\text { corporar la evaluación -en particular- y los erro- } \\
\text { res y respuestas erróneas, en estrategias positivas } \\
\text { para el futuro éxito. }\end{array}$ \\
\hline
\end{tabular}

\section{Pauta 9. Proporcionar opciones para la autorregulación}

Si bien es importante diseñar el entorno extrínseco a fin de que este pueda apoyar la motivación y el compromiso (véase las Pautas 7 y 8), también es importante desarrollar las habilidades intrínsecas del estudiante para regular sus propias emociones y motivaciones.

La capacidad de autorregularse para modular estratégicamente las reacciones emocionales o los estados personales a fin de ser más afectivo y hacer frente a las demandas del entorno, es un aspecto crítico del desarrollo 
humano. Si bien muchas personas desarrollan estas capacidades de autorregulación por sí mismas, ya sea por ensayo y error o mediante la observación de adultos con éxito, muchos otros tienen importantes dificultades en el desarrollo de estas habilidades.

Lamentablemente, la mayoría de las aulas no afrontan explícitamente la enseñanza de estas habilidades, lo que las deja como parte del currículo «oculto» que a menudo es inaccesible o invisible para muchos. Además, las aulas en las que, en ocasiones, se ocupan de la autorregulación en general, suelen asumir explícitamente un único modelo o método para hacerlo. Al igual que en otros tipos de aprendizaje, las diferencias individuales son mucho más probables que la uniformidad.

La perspectiva para tratar de mejorar el éxito escolar requiere proporcionar suficientes alternativas de apoyo a los estudiantes con aptitudes y experiencias previas muy diferentes al respecto, de forma que puedan aprender cómo autorregularse para mejorar su emociones, su compromiso y su motivación con las tareas de aprendizaje propuestas.

\begin{tabular}{ll}
\hline Sugerencia & Descripción \\
\hline $\begin{array}{l}\text { Opciones persona- } \\
\text { les que orientan el } \\
\text { establecimiento de } \\
\text { objetivos personales } \\
\text { y expectativas }\end{array}$ & $\begin{array}{l}\text { Los tutoriales de Wink y Virtual Magnifying Glass } \\
\text { enfatizan en preguntas, recordatorios, guías y listas } \\
\text { de controles, centrados en: } \\
\text { La autorregulación, como objetivo para la reduc- } \\
\text { ción en la frecuencia de rabietas o brotes agresivos } \\
\text { en respuesta a la frustración. } \\
\text { El aumento de la duración del «tiempo en la tarea» } \\
\text { frente a las distracciones. } \\
\text { Elevar la frecuencia de la autoreflexión y los auto- } \\
\text { refuerzos. } \\
\text { Entrenadores, tutores o agentes que modelan el } \\
\text { proceso de establecimiento de objetivos personales } \\
\text { adecuados que tienen en cuenta tanto los puntos } \\
\text { fuertes como los débiles de cada uno. }\end{array}$ \\
\hline
\end{tabular}




\section{Sugerencia}

Las opciones que desarrollar la autoevaluación y la reflexión

\section{Descripción}

El tutorial Wink representa una ayuda para los alumnos, ya que pueden aprender a visualizar los datos de su propio comportamiento con el fin de seguir y evaluar sus cambios. Estos dispositivos deberían proporcionar una gama de opciones que variarán en su nivel de inclusión y apoyo, con el objetivo de proporcionar un aprendizaje graduado de la capacidad para monitorizar el propio comportamiento, así como la adquisición de aptitudes en la capacidad de autoreflexión y de toma de conciencia emocional.

Las actividades deben incluir medios por los cuales los estudiantes obtienen información y acceso alternativo a las ayudas disponibles (gráficos, plantillas, pantallas de información) que los apoyan en el seguimiento de su progreso, de forma que les resulte comprensible y oportuno. 


\section{Orientaciones para el desarrollo de la gestión y la evaluación mediante el diseño de unidades didácticas en ciencias naturales}

Una vez planteadas las orientaciones para la elaboración de diseños didácticos, presentamos en primer lugar, y de manera concreta, cómo se puede realizar la gestión en el aula -entendida también como desarroIlo curricular- mediante el diseño y uso de Unidades Didácticas en los campos estructurantes de las ciencias naturales, teniendo en cuenta los contextos de diversidad, mediante el uso de tecnología. En segundo lugar, ofrecemos algunas orientaciones en torno a la evaluación didáctica teniendo en cuenta la diversidad en el aula.

\subsection{Orientaciones para el desarrollo de la gestión didáctica}

En este apartado se presenta un camino posible que pueden tomar los docentes formadores de profesores, los estudiantes que están ejerciendo su práctica docente y los docentes en ejercicio. El camino que se señala puede ser asumido como una posibilidad de análisis y reflexión sobre la importancia de integrar y articular los componentes didácticos en el diseño de las unidades didácticas con el uso de las TIC que serán desarrolladas con los estudiantes de las poblaciones objeto de estudio en el proyecto ALTERNATIVA. Para ello es necesario anotar que la categoría Unidad Didáctica, ha sido entendida como:

el sistema que interrelaciona los actores y los elementos centrales del proceso de enseñanza-aprendizaje: propósitos, contenidos, evaluación e interacciones, con una alta coherencia metodológica interna y que se emplea como instrumento de programación y orientación de la práctica docente y se sitúa en el marco del desarrollo del plan de área para un ciclo escolar (documento de las Áreas ALTER-NATIVA, 2012).

En ese sentido, es importante anotar que, como lo señala Hernández (2011):

El diseño de unidades didácticas ha dejado de ser un trabajo de personas ajenas al contexto escolar para ser una tarea fundamental del 
docente, quien como profesional de la educación tiene un papel activo y decisivo en la selección, organización y secuenciación de los contenidos; como también en la elección y diseño de los materiales, de las actividades, de las estrategias de desarrollo y de las formas de evaluación, entre otros (p. 82).

En el ejercicio práctico del diseño de una unidad didáctica pueden incidir varios factores. Uno de estos -y quizás de los más importantes- es el relacionado con las concepciones que los docentes tienen sobre los procesos de enseñanza y aprendizaje de las ciencias naturales, las cuales, de alguna u otra manera, se hacen presentes de manera implícita o explícita en el modelo didáctico que subyace a dichos conceptos (Sánchez \& Valcárcel, 1993). En ese orden de ideas, en el diseño de una unidad didáctica el docente les concederá mayor o menor importancia a unos aspectos que a otros. Los aspectos y criterios a considerar en el diseño de una unidad didáctica han ido cambiando y se han ido ajustando no solo a las nuevas visiones sobre educación, enseñanza y aprendizaje de las ciencias, sino también a las características y necesidades de la población y a los recursos disponibles, incluidas las TIC.

Los aspectos a considerar en una unidad didáctica, que se proponen en este apartado, deben ser interpretados y abordados a partir de las particularidades de las poblaciones objeto de estudio en el proyecto ALTER-NATIVA, y aunque se determinan desde el comienzo sus características, es importante dejar claro que cada uno de estos aspectos puede y debe ser reorientado -si es necesario- en el proceso y hacer los cambios pertinentes, siempre fundamentados en los objetivos de la unidad, ya que como lo anota Neus Sanmartí (2002), «un buen diseño didáctico es aquel que mejor responde a las necesidades diversas de los estudiantes». A continuación se señalan los aspectos y se describen las características que deben considerarse a la hora de planear, diseñar y evaluar una unidad didáctica. Estos aspectos son retomados desde la propuesta de Sanmartí (2002).

\section{A. Fase de planeación}

Los aspectos a considerar en esta fase giran básicamente alrededor de 7 asuntos que se explicitan a continuación:

a. Descripción y justificación de la unidad didáctica. Es necesario que este ejercicio reflexivo se haga en equipos de trabajo, que los docentes 
consideren aspectos como el contexto, la diversidad de la población a la que va dirigida, la edad de los estudiantes, su historia particular y de grupo. También es necesario considerar los recursos materiales, espaciales y económicos para la consecución de los objetivos.

b. Finalidades-objetivos. Se propone que sean pocos y explícitos. En su formulación, tener en cuenta los siguientes aspectos: i) enunciarlos para los estudiantes, teniendo en cuenta sus capacidades; ii) explicitar las acciones que el estudiante debe desarrollar; y iii) tener en cuenta el contexto (Allall, 1991).

c. Selección de contenidos. Aspectos a tener presentes: nivel escolar, condiciones socioculturales de los estudiantes, diversidad de ritmos y niveles de aprendizaje; los contenidos seleccionados deben permitir que todos estudiantes tengan las posibilidades de «progresar». Se espera que los contenidos sean significativos y aborden contenidos conceptuales, actitudinales y procedimentales.

d. Organización y selección de contenidos. Es importante anotar que los contenidos abordados en el marco de una unidad didáctica, además de ser objeto de reflexión por parte del docente, forman parte de los planes de estudio del área, los cuales previamente se han acordado al interior de quienes la conforman, además de ser aceptados por la comunidad educativa. Los contenidos se pueden organizar de varias maneras: por tópicos generativos, por problemas, por unidades globalizadoras, por conceptos estructurantes o por procesos investigativos, que pueden desarrollarse a manera de proyectos escolares. Para su estructuración y secuenciación, se recomiendan los mapas conceptuales.

e. Selección y secuenciación de actividades. Las actividades se organizan de acuerdo con los objetivos (figura 1), y son: i. Actividades de iniciación o de exploración inicial; ii. Actividades de introducción de nuevos puntos de vista o de promoción -que facilitan la introducción de nuevas variables-; iii. Actividades de síntesis; y iv. Actividades de aplicación o generalización, es decir, de evaluación, que deben ser continuas, estableciéndose los criterios y los instrumentos de acuerdo con las características de la población estudiantil. 


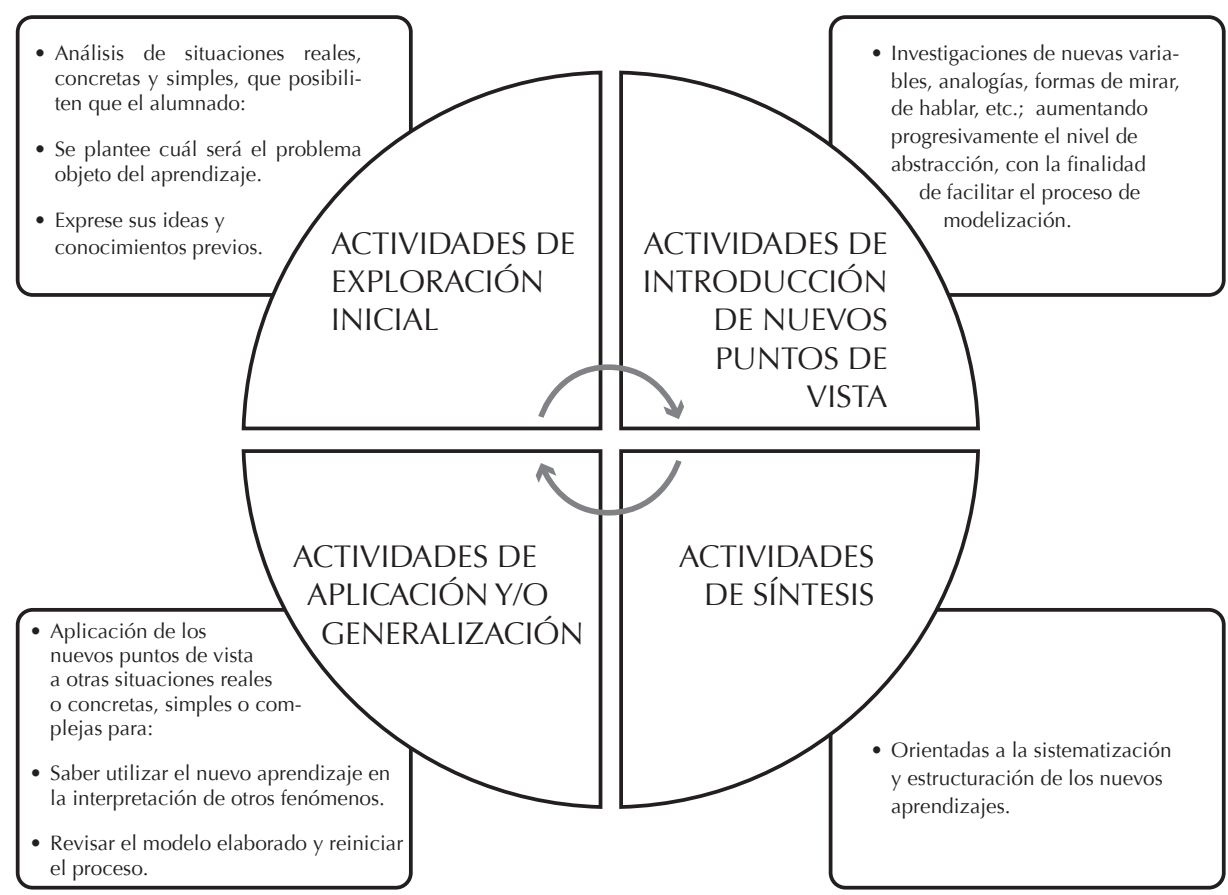

Figura 1: Propuesta de secuenciación de actividades con base en el planteamiento de Sanmartí (2002)

f. Organización y gestión del aula. Con el uso de las TIC, más que el espacio físico, debe ser estimado el espacio donde se establecen y convergen relaciones interpersonales, intereses y procesos de negociación de saberes, entre otros. Un aspecto fundamental y que guía el proyecto ALTER-NATIVA, es el relacionado con la diversidad. Una vez se han establecido y delimitado los aspectos mencionados anteriormente, se hace necesario concretar y organizar la información. Para ello se recomienda considerar, entre otros aspectos:

- Resumen de la unidad

- Objetivo general

- Objetivos específicos

1. Actitudinal

2. Procedimental

3. Conceptual

4. Comunicativo

- Justificación

- Población a quien está dirigida: mencionar el ciclo, grado, área de conocimiento y un diagnostico con respecto a la población, destacando los rasgos más relevantes 
- Tiempo

- Número de sesiones

- Número de horas

- Tema

1. General

2. Específicos

- Materiales

- Prácticas de laboratorio: presenciales y virtuales

Teniendo en cuenta que hay diferentes clases de actividades, las cuales tienen objetivos distintos y se plantean en diferentes momentos del desarrollo de la unidad didáctica, a continuación se mencionan aspectos que son fundamentales y se deben considerar a la hora del diseño de las actividades:

- Nombre y tipo de actividad

- Enunciado de la actividad

- ¿Por qué la clasifica como una actividad de este tipo?

- ¿Qué se pretende con la actividad?

- Debe hacerse evidente el componente comunicativo: ¿Qué hace el profesor y qué hace el estudiante? ¿Cómo se realizará el seguimiento y la retroalimentación a la actividad?

\section{B. Fase de diseño}

Una vez se ha planificado la unidad didáctica teniendo en cuenta los aspectos mencionados anteriormente, es necesario precisar las formas de proceder y las características de las mismas en el diseño metodológico. Para ello hay que retomar las particularidades en cuanto a los equipos de cómputo y la plataforma de acceso a la red ALTER-NATIVA. Las necesidades a considerar tienen que ver con el tema, con los objetivos y con las actividades, las cuales a su vez deben diseñarse pensando en la posibilidad que ofrecen los ambientes virtuales para el aprendizaje y, por lo tanto, en la consecución de los objetivos propuestos.

Es importante que quienes participen en la fase de diseño tengan presente que los Ava se definen como entornos informáticos digitales e inmateriales que brindan unas condiciones apropiadas para la realización de actividades de aprendizaje de forma sincrónica y asincrónica, y que estos pueden organizarse teniendo en cuenta un programa curricular o, como en este caso, una unidad didáctica mediante la cual se estructuran diferentes clases de actividades con el propósito de generar un sistema de aprendizaje en las áreas o campos temáticos. 
En ese sentido, no se puede olvidar que los AvA deben tener características de accesibilidad, condiciones de interactividad, que funcionen de manera independiente, que generen confianza y flexibilidad, entre otros. También deben ser motivantes para el estudiante, y para ello se deben incluir diferentes recursos digitales que tengan un objetivo educativo (fotos, diagramas, mapas, tablas, sonidos y fórmulas, entre otros).

Además de considerar el tema y subtemas y los contenidos en cada uno de ellos, así como las estrategias y el diseño de actividades, es fundamental pensar en el diseño de la interfaz, el nivel de interactividad, las simulaciones, la iconografía (imágenes, colores, tamaño y distribución en el espacio), la tipografía (tipo de letra y tamaño) y la estructura de la presentación y los mapas de navegación.

\section{Fase de evaluación}

Este aspecto se desarrolla a lo largo de las diferentes etapas de planeación y diseño, correspondientes a sus momentos y actividades. Los criterios a considerar tienen que estar directamente relacionados, por un lado, con los objetivos propuestos para la unidad, y por otro, con los aspectos considerados en el diseño de la unidad, que deben ser consecuentes con lo estipulado en la fase de planeación. Para ambos casos se hace necesaria una evaluación interna y externa.

\subsection{Orientaciones para el desarrollo de la evaluación didáctica}

Para ALTER-NATIVA es importante que el docente reflexione sobre los procesos evaluativos que ocurren tanto a nivel macro como a nivel de las microdinámicas del aula. También que tenga presente que la evaluación es un proceso dinámico y participativo, su objetivo debe estar relacionado con el objetivo mismo de la educación. La evaluación debe ser continua no solo con el fin de emitir un juicio específicamente sobre un estudiante, sino considerar también que es el proceso organizado a través del cual se observa, se recoge y se analiza información respecto del proceso de enseñanza-aprendizaje con la finalidad de reflexionar, emitir juicios de valor y tomar las decisiones más pertinentes, y que para ello hay que planificarla, atendiendo a cinco grandes preguntas: qué, para qué, quién, cómo y cuándo evaluar (Pérez, 1998). 
En esta medida el docente pasa de ser concebido como aplicador del currículo, que tiene la misión de reproducir un gran número de técnicas con gran eficacia (Perafán, 2005) a ser percibido como un profesional reflexivo (Shön, 1992) que toma decisiones, que emite juicios de valor, que reflexiona sobre su actuar y genera acciones propias de su desarrollo profesional. Por ello es importante tener presente lo que Fernández (1999) anota con respecto a la evaluación: es un proceso de reflexión sobre la práctica que orienta la toma de decisiones y proporciona al alumno y profesor información sobre cómo están los estudiantes, a dónde han llegado y qué pueden hacer.

De otro lado, la evaluación debe ser concebida de manera integral, es decir, debe cobijar todos los ámbitos del desarrollo de un individuo, que se valore el recorrido que cada estudiante hace en su proceso particular, destacando avances, logros y dificultades. También debe ser formativa, es decir, que fomente en los estudiantes el uso de procedimientos de auto y coevaluación.

La autoevaluación es entendida como una actividad individual, programada y sistemática de reflexión sobre las acciones desarrolladas por los estudiantes, es un ejercicio personal que debe ser guiado por el docente, debe ser entendido como un mecanismo permanente de autorregulación y seguimiento de los aprendizajes, que ayuda a interpretar y valorar los avances, logros y dificultades de los estudiantes, analizados estos aspectos a luz de los objetivos de la unidad didáctica y de las características particulares de los estudiantes.

A continuación, y teniendo en cuenta las características propias de las poblaciones objeto de estudio en el proyecto ALTER-NATIVA, se pone a consideración algunos aspectos que se establecen como capitales a la hora de desarrollar el proceso evaluativo.

Desde el campo específico de la evaluación para las personas con discapacidad (y de cualquiera en riesgo de exclusión social), Santos y De la Rosa (2009) proponen tener en cuenta los siguientes aspectos:

- Reconocer y valorar las diferencias.

- Identificar las desigualdades educativas que puedan estar provocando estas diferencias.

- Identificar, a través de la evaluación, las necesidades o espacios de mejora, especiales o no, tanto de los sujetos en particular como de los entornos con los que estos interaccionan, como la familia, la escuela y la comunidad, in- 
cluyendo cambios en la organización y en el currículum escolar ordinario para la inclusión, si es necesario.

- Detectar las potencialidades o recursos particulares de cada persona con discapacidad. La evaluación y la intervención deben centrarse más en las potencialidades personales que en las limitaciones, con lo que se reclama un cambio de enfoque en cuanto a la propia definición de discapacidad más que como limitación (diversidad funcional).

- Oír las voces de las personas con discapacidad.

Para el caso particular de los estudiantes ciegos o con limitación visual, en el proceso evaluativo se hace necesario considerar dos componentes:

- El técnico operativo: referido a la equiparación de oportunidades, es decir, se hace necesario facilitar al estudiante las ayudas tecnológicas, adaptación de material didáctico y todas aquellas herramientas que le permitan acceder en igualdad de oportunidades a la información.

- El pedagógico: donde usted como maestro debe recurrir a su capacidad inventiva para confrontar lo que enseña, interrogar con respecto a un tema con el fin de indagar en qué punto de elaboración se encuentra el estudiante y de esta manera provocar la construcción o transformación de sus conceptos.

En cuanto a la población sorda, es necesario considerar que para la evaluación, es preciso que el estudiante pueda observar la cara del evaluador; de hecho, se recomienda la ubicación de los escritorios en forma de semicírculo para que el estudiante sordo pueda observar la cara de sus compañeros. En cuanto a la población indígena, se hace necesario considerar, entre otros, los siguientes aspectos para mejorar los procesos evaluativos en el aula:

- Lo importante de la evaluación para poblaciones indígenas radica en el acercamiento del individuo a las normas y pautas culturales que permitan salvaguardar la identidad del pueblo.

- Una de las características de la evaluación para poblaciones indígenas es que se da en una relación estrecha de padre-hijo, madre-hija y otros parientes en el momento mismo en el que el hijo(a) realiza una determinada actividad. Se evalúa diariamente.

- La evaluación para poblaciones indígenas también se caracteriza por su carácter cualitativo, y es integral porque considera todos los ámbitos de la vida del niño/a: afectivo, cognoscitivo y psicomotor.

- El aspecto valorativo en la evaluación para poblaciones indígenas es una responsabilidad colectiva, pues participan todos los miembros de la comunidad, tanto personas mayores como grupos de igual edad. 
- Es así como los niños se enfrentan a dos paradigmas: la escuela que sanciona y la educación indígena, que pretende hacer personas mejores, capaces de dar solución a problemas y desenvolverse en su medio, entre otros aspectos.

Teniendo en cuenta que el propósito de la educación es responder a las necesidades de potenciar el desarrollo integral de cada niño, y a la necesidad de producir y reproducir la parte cultural de la comunidad, se debe plantear en la escuela un enfoque cualitativo de la evaluación donde el evaluador debe tratar de interpretar el significado de las conductas de los individuos y no simplemente establecer cantidad y tipo de conducta (Arévalo, Pardo \& Vigil, 2006).

En el contexto de poblaciones diversas, la evaluación ha de considerar las diferencias individuales y socioculturales, y partir del reconocimiento de la diversidad en sí misma. Estos aspectos posibilitarían la emergencia de la singularidad del estudiante, quien conlleva un andamiaje y un equipamiento cultural, afectivo, social, intelectual, particular y único. Si bien existe dentro de las aulas de clase diversidad cultural, física, social y lingüística entre otras-, también existen grupos completos de clase que se caracterizan por poseer algún rasgo de diversidad; sin embargo, en cualquiera de los dos casos, la evaluación debe centrarse en el seguimiento de las habilidades, conocimientos, destrezas y valores construidos y desarrollados por los estudiantes en virtud de su contexto, más que en la medida cuantitativa de saberes universales.

Es por eso que la evaluación en la integración de las tecnologías de la información y comunicación tendría como propósito los seguimientos elementos:

- Desarrollar competencias. Los estudiantes pueden realizar un proyecto que conlleve a aumentar su conocimiento y habilidad en una disciplina o en un área de contenido interdisciplinario. Con frecuencia, cuando el estudiante realiza un proyecto, alcanza un nivel de habilidad elevado en el área específica que está estudiando y hasta puede convertirse en la persona que más sabe sobre un tema específico. Algunas veces, su nivel de conocimiento puede exceder al del profesor.

- Mejorar las habilidades de investigación. El proyecto requiere de aptitudes para investigar y ayuda a que estas se desarrollen.

- Incrementar las capacidades mentales de orden superior. Capacidad de análisis y síntesis. Esto se logra cuando el proyecto es retador y va enfocado a que los estudiantes desarrollen tales habilidades. 
- Aprender a usar las TIC. Los estudiantes incrementan el conocimiento y habilidad que tienen en las TIC a medida que trabajan en el proyecto. Un proyecto puede diseñarse con el objetivo específico de alentar en los estudiantes la adquisición de nuevas habilidades y conocimientos en las tecnologías.

- Aprender a autoevaluarse y evaluar a los demás. Los estudiantes aumentan su habilidad de autoevaluación, con lo que se responsabilizan de su trabajo y desempeño. También aprenden a evaluar el trabajo y desempeño de sus compañeros y a darles retroalimentación.

- Desarrollar un portafolio. Requiere que los estudiantes hagan un proyecto, una presentación o una función de alta calidad que debe estar acorde con el grado escolar que cursen.

- Comprometerse en un proyecto. Los alumnos se comprometen activa y adecuadamente a realizar el trabajo del proyecto, de ahí que se encuentren motivados de manera interna: tal es una meta del proceso. El profesor puede efectuar observaciones diarias que permitan establecer si el estudiante tiene un compromiso con la tarea o si muestra una colaboración ejemplar.

- Ser parte de una comunidad académica. Todos los estudiantes, profesores o grupo social se convierten en una comunidad académica donde se trabaja de manera cooperativa y se aprende del otro. Esta comunidad se expande para incluir a padres, alumnos de otras aulas y otras personas, para trabajar en ideas que son importantes y de su interés. El proyecto debe enfocarse a temas que tengan continuidad y sean relevantes para el profesor, el colegio y demás miembros de la comunidad. Por ejemplo, el trabajo interdisciplinario tiene que perfilarse como una de las metas que conformen los proyectos. 


\section{Ejemplo de Unidades Didácticas para la ciencia escolar}

A manera de cierre, ofrecemos tres (3) ejemplos del diseño de una unidad didáctica (UD) que puede ser útil al profesorado -en ejercicio y en formación- y quienes podrán posteriormente acceder a los AVA y OVA que se han elaborado en el marco del proyecto ALTER-NATIVA y se encuentran en la plataforma del mismo ${ }^{1}$. Las UD corresponden a los campos estructurantes de ser vivo y cambio químico; dos de las unidades, "Seres vivos» y "Materia», están diseñadas para el ciclo de educación primaria, y la de «Cambio químico», para la educación primaria y secundaria. Pero las actividades que se presentan en este ejemplo, están dirigidas a la población infantil -de ahí la nomenclatura de I, al inicio de cada actividad-.

Al inicio de cada UD se presenta el mapa de diseño, que permite visualizar la estructuración y secuenciación de los conceptos a abordar en cada caso.

\subsection{Unidad didáctica «Seres vivos», para estudiantes de primaria en contextos de diversidad cultural: medio indígena}

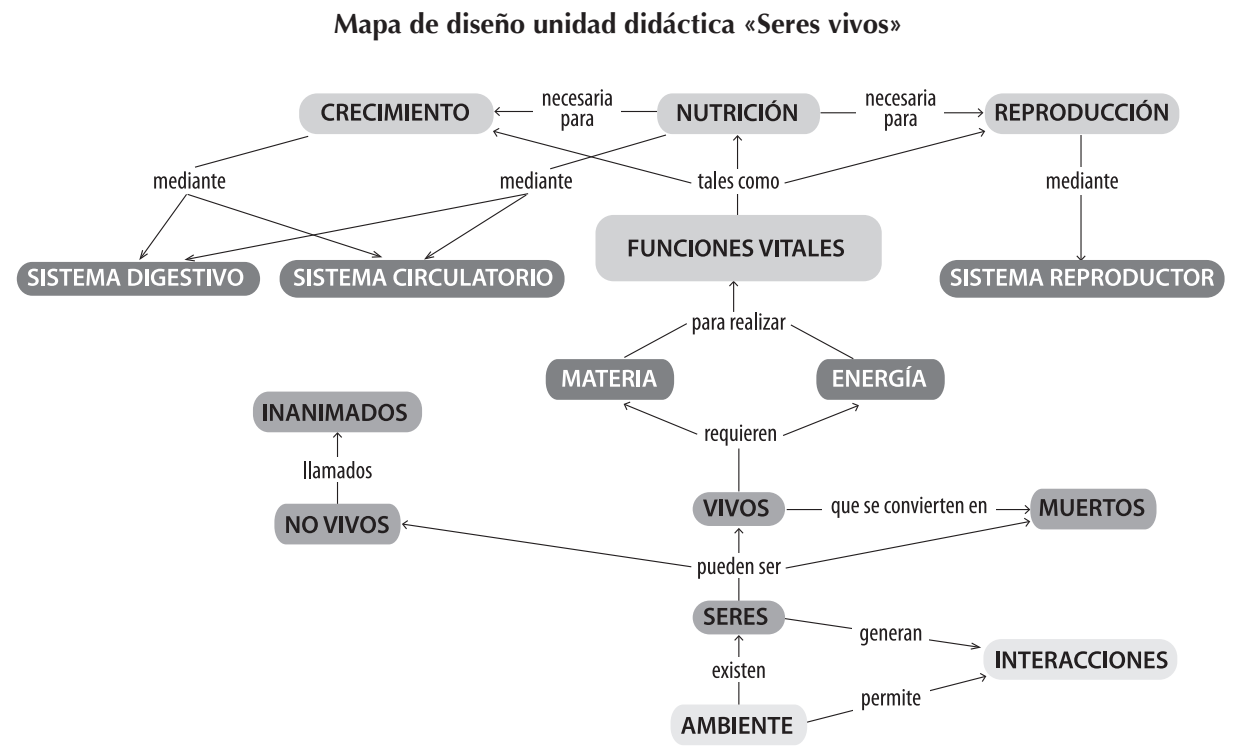

1 http://boppo.udg.edu:8000/ATutor/login.php 


\section{ESTRUCTURA UNIDAD DIDÁCTICA²}

UNIDAD DIDÁCTICA «SERES VIVOS» PARA ESTUDIANTES DE PRIMARIA EN CONTEXTOS DE

DIVERSIDAD CULTURAL: MEDIO INDÍGENA

\section{RESUMEN}

Se desarrolla una propuesta de enseñanza para la construcción del modelo de ser vivo en estudiantes de educación primaria -hablantes de alguna lengua indígena-, mediante la realización de actividades apoyadas en el uso de tecnologías de la información y comunicación, en la cuales se reconoce la importancia de pensar, discutir y comunicar el conocimiento escolar de manera concreta y en un ambiente virtual. Para el diseño de esta unidad didáctica se tienen en cuenta el referente teórico de la modelización (Izquierdo \& AdúrizBravo, 2003) y el modelo de secuenciación de actividades -de exploración inicial, de introducción de nuevos puntos de vista, de síntesis y de aplicación y generalización- (Sanmartí, 2002).

Por lo tanto, preliminarmente se identificó el Modelo cognitivo inicial de ser vivo de los estudiantes de primaria, con base en lo reportado en la literatura sobre ideas previas (figura 1), el cual se evidenciará en el grupo de clase mediante las actividades de exploración inicial.

Posteriormente se elaboró el modelo final sobre seres vivos (figura 2) que se espera sea construido por los estudiantes de primaria a partir, específicamente, de las actividades de la Fase de Introducción de Nuevos puntos de vista; fase en la cual se espera poder introducir nuevos elementos, relaciones y condiciones en el modelo, tales como:

- Nuevos elementos: materia, energía, sistema circulatorio.

- Nuevas relaciones: entre reproducción y nacimiento, entre materia y energía con los otros elementos.

- Condiciones: - Medio ambiente $\quad$ - Físico (temperatura) - Interacciones $\quad\{$ - Otros seres vivos

2 Estructura de unidad didáctica tomado de García-Martínez, Hernández \& Abella (en prensa). 


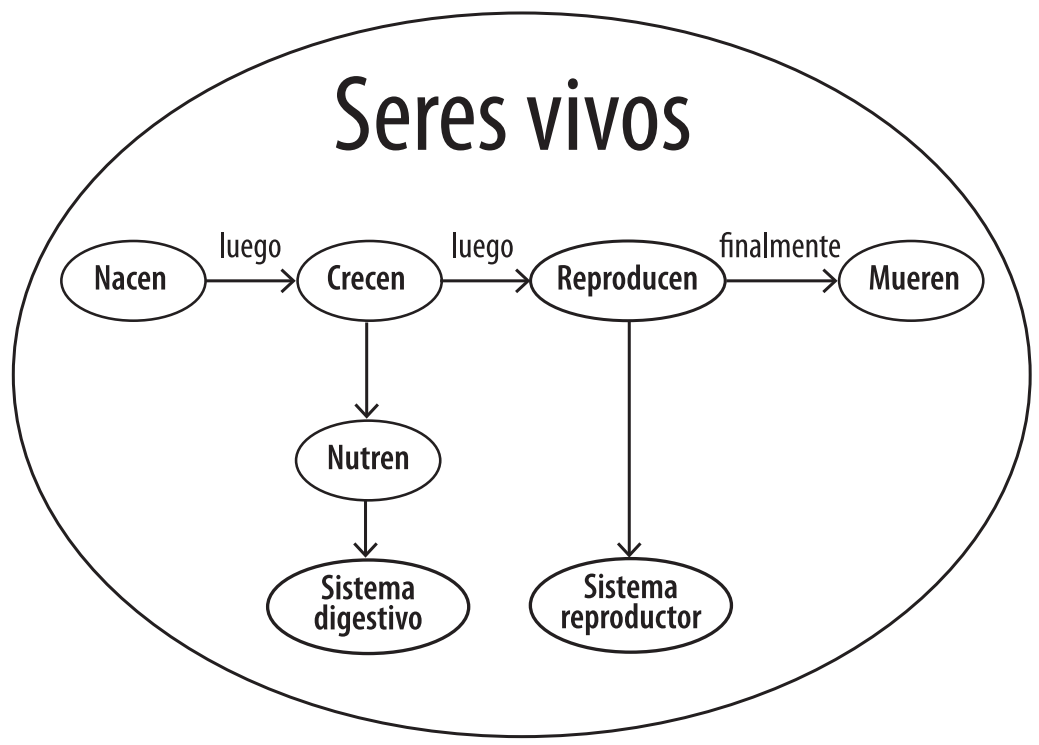

Figura 1. Modelo cognitivo inicial de seres vivos.

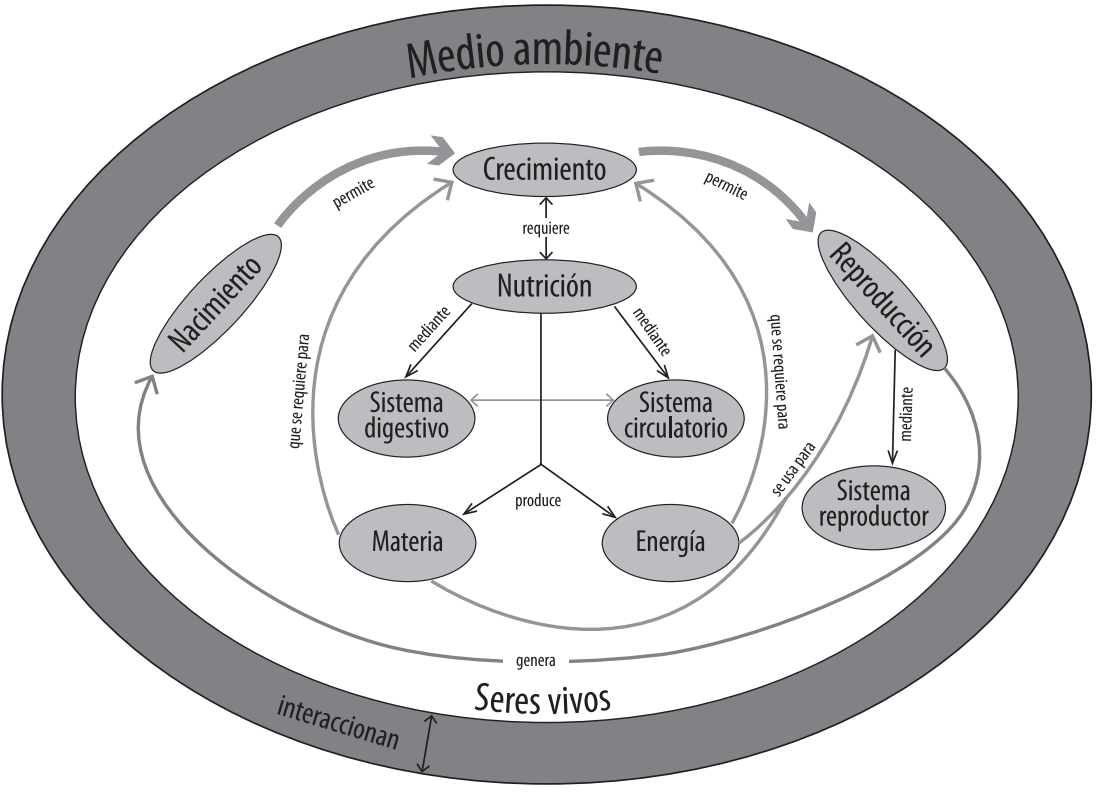

Figura 2. Modelo final de seres vivos. 


\begin{tabular}{|c|c|}
\hline $\begin{array}{l}\text { OBJETIVO } \\
\text { GENERAL }\end{array}$ & $\begin{array}{l}\text { Como producto de las actividades propuestas, los estu- } \\
\text { diantes de tercero de primaria que se encuentran en un } \\
\text { contexto de diversidad -medio indígena-, modelizarán } \\
\text { el fenómeno «ser vivo» a partir del uso de herramientas } \\
\text { tecnológicas, a fin de propiciar el acercamiento al mo- } \\
\text { delo científico escolar. }\end{array}$ \\
\hline \multicolumn{2}{|c|}{ OBJETIVOS ESPECÍFICOS } \\
\hline \multicolumn{2}{|c|}{$\begin{array}{l}\text { (Redactar cada uno de los objetivos teniendo en cuenta los aspectos que } \\
\text { aparecen en el lado izquierdo) }\end{array}$} \\
\hline ACTITUDINAL & $\begin{array}{l}\text { El estudiante representa cómo los seres humanos trans- } \\
\text { forman la naturaleza, sin dañarla, al obtener recursos } \\
\text { para su nutrición y protección, a través de la elabora- } \\
\text { ción de esquemas de sucesos cercanos a ellos. }\end{array}$ \\
\hline PROCEDIMENTAL & $\begin{array}{l}\text { El estudiante relaciona los cambios que experimentan } \\
\text { plantas y animales (e.g. los humanos) como consecuen- } \\
\text { cia de la carencia de nutrientes mediante la resolución } \\
\text { de casos, problemas o situaciones experimentales. }\end{array}$ \\
\hline CONCEPTUAL & $\begin{array}{l}\text { El estudiante distingue los seres vivos a partir de las } \\
\text { actividades que realizan -particularmente la de la nu- } \\
\text { trición- en un ambiente natural próximo o dentro de } \\
\text { su comunidad, tomando en cuenta los alimentos de la } \\
\text { región, mediante la comparación de las estructuras de } \\
\text { plantas y animales. }\end{array}$ \\
\hline \multicolumn{2}{|r|}{ JUSTIFICACIÓN } \\
\hline \multicolumn{2}{|c|}{$\begin{array}{l}\text { Dentro del marco del proyecto ALTER-NATIVA surge la necesidad de ofrecer a los } \\
\text { docentes en formación ejemplos Concretos de la aplicación de las TIC a pobla- } \\
\text { ciones en contextos de diversidad. Como parte de los compromisos adquiridos } \\
\text { por la Universidad Pedagógica Nacional de México, la presente UD responde } \\
\text { a la necesidad de que los niños reconozcan que existe diversidad natural, } \\
\text { dado que existen diversos tipos de seres: vivos, muertos e inanimados. Y que } \\
\text { al interior de cada grupo, particularmente de los seres vivos, existen una serie } \\
\text { de características comunes, conocidas como funciones vitales (nutrición, re- } \\
\text { producción y crecimiento, entre otras) que les dan unidad, es decir, les permite } \\
\text { pertenecer al grupo de los seres vivos. De tal manera que conocer el conjunto } \\
\text { de dichas características, permite identificar a los seres vivos. Inicialmente da- } \\
\text { remos cuenta en esta uD de la nutrición. }\end{array}$} \\
\hline
\end{tabular}




\begin{tabular}{|c|c|c|}
\hline $\begin{array}{l}\text { POBLACIÓN A QUIEN } \\
\text { ESTÁ DIRIGIDA } \\
\text { (Mencionar el ciclo, grado, } \\
\text { área de conocimiento y un }\end{array}$ & \multicolumn{2}{|c|}{$\begin{array}{l}\text { Población de estudiantes de tercero de primaria } \\
\text { en condiciones de diversidad -indígenas-. }\end{array}$} \\
\hline \multirow{2}{*}{ TIEMPO } & $\begin{array}{l}\text { NÚMERO DE } \\
\text { SESIONES }\end{array}$ & NÚMERO DE HORAS \\
\hline & 8 & 6 \\
\hline \multirow[b]{2}{*}{ TEMA } & GENERAL & ESPECÍFICOS \\
\hline & Seres vivos & $\begin{array}{l}\text { Tipos de seres, funciones } \\
\text { vitales (crecimiento, nutri- } \\
\text { ción y reproducción); pa- } \\
\text { pel del ambiente (materia y } \\
\text { energía). }\end{array}$ \\
\hline MATERIALES & \multicolumn{2}{|c|}{$\begin{array}{l}\text { Equipos de cómputo, plataforma de acceso a } \\
\text { la red ALTER-NATIVA. }\end{array}$} \\
\hline
\end{tabular}

\section{DESCRIPCIÓN DE ACTIVIDADES}

\section{Actividades de exploración inicial}

Son actividades que tienen como objetivo dos asuntos: por un lado, facilitar que los estudiantes se planteen el problema que se va a estudiar, y por otro, que estos sean capaces de expresar sus ideas o conocimientos previos. Producto de esta fase, se podrá evidenciar la cercanía del modelo cognitivo inicial de los estudiantes, con el modelo presentado en la figura 1. 


\begin{tabular}{|c|c|c|c|c|}
\hline \multirow{6}{*}{ 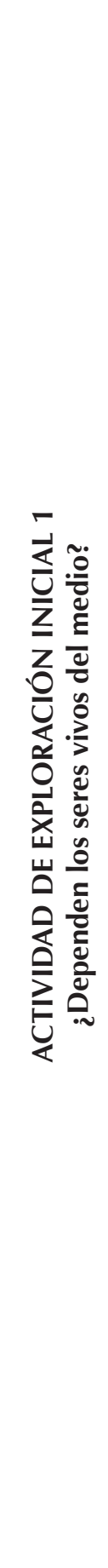 } & \multirow{6}{*}{ 岁 } & \multirow{6}{*}{ 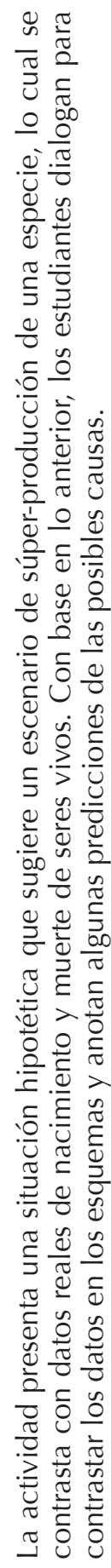 } & 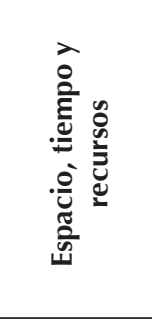 & 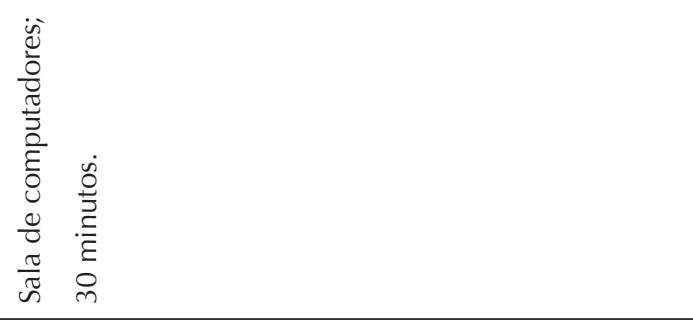 \\
\hline & & & 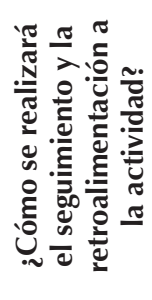 & 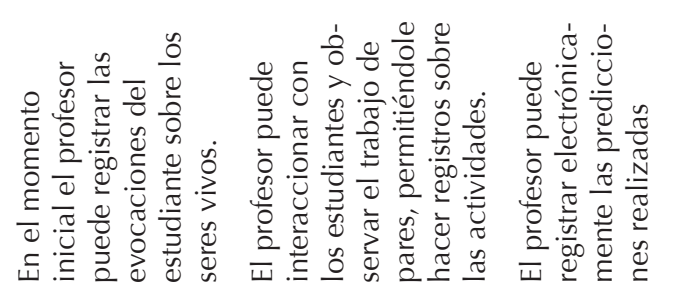 \\
\hline & & & 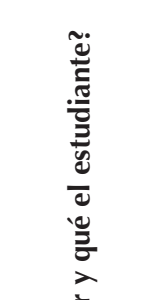 & 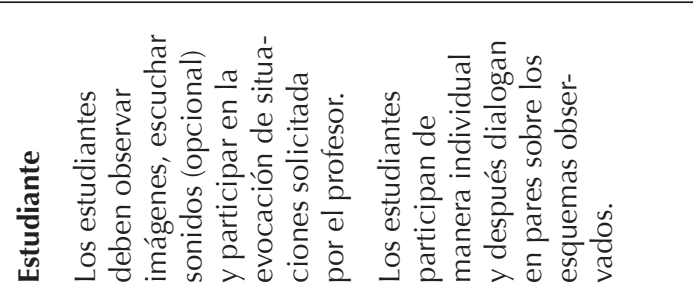 \\
\hline & & & 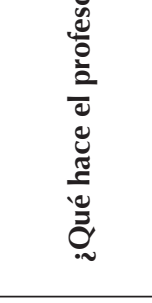 & 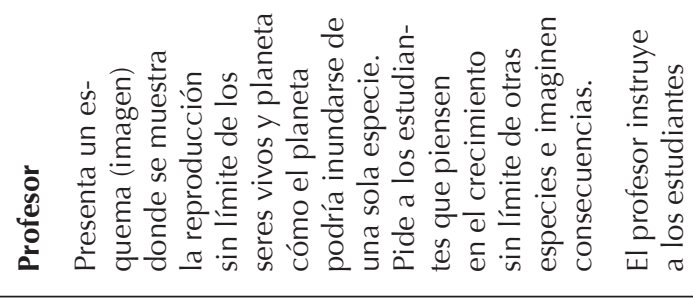 \\
\hline & & & 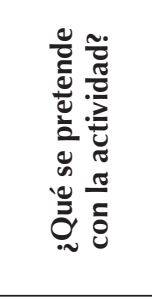 & 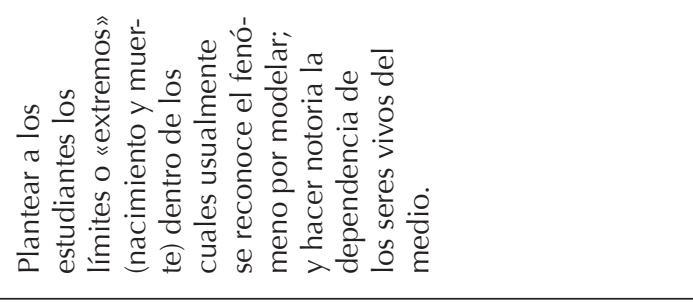 \\
\hline & & & 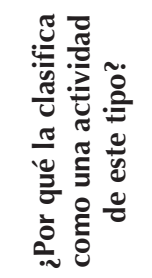 & 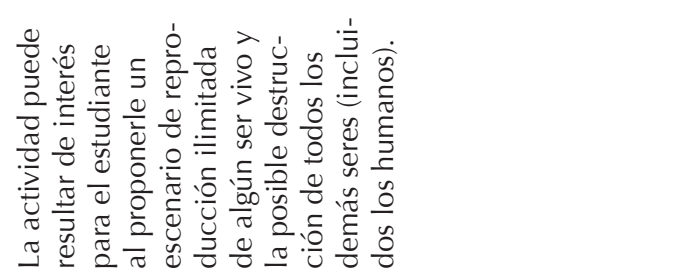 \\
\hline
\end{tabular}




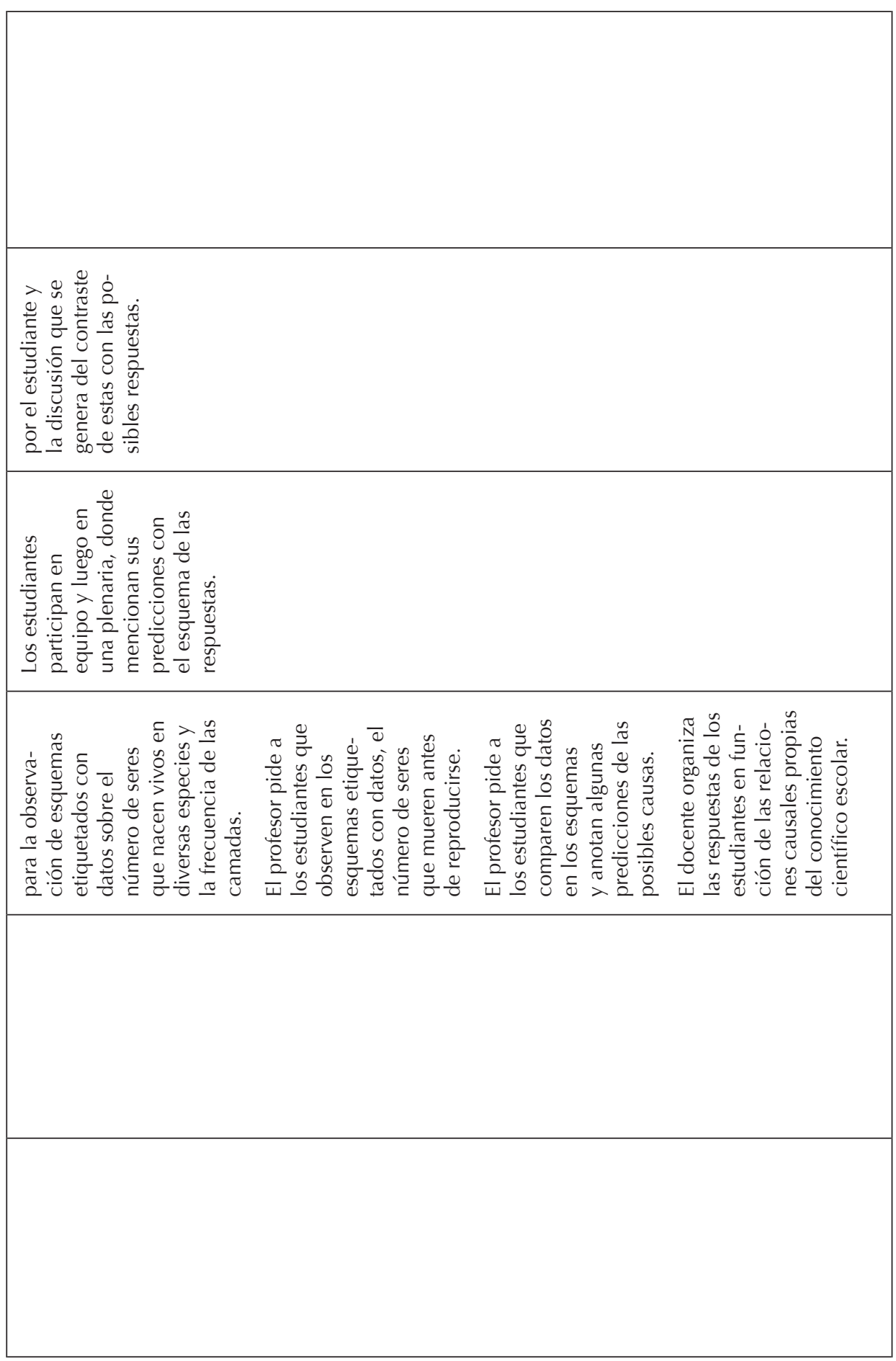




\begin{tabular}{|c|c|c|c|}
\hline \multirow{6}{*}{ 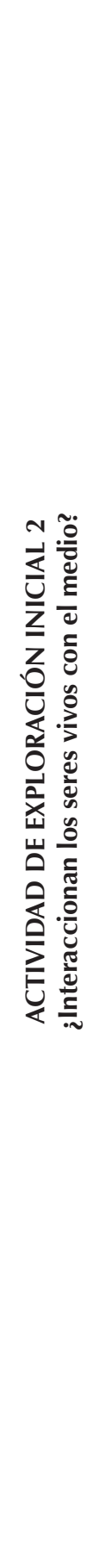 } & \multirow{6}{*}{ 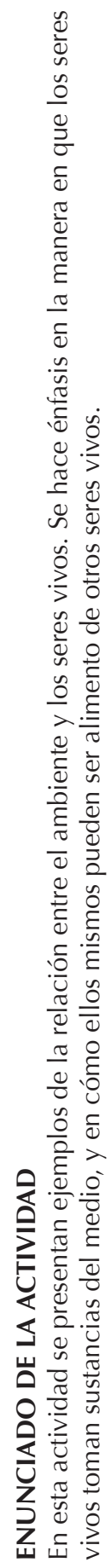 } & 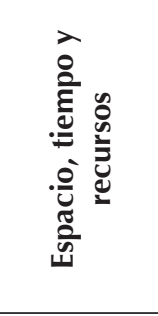 & 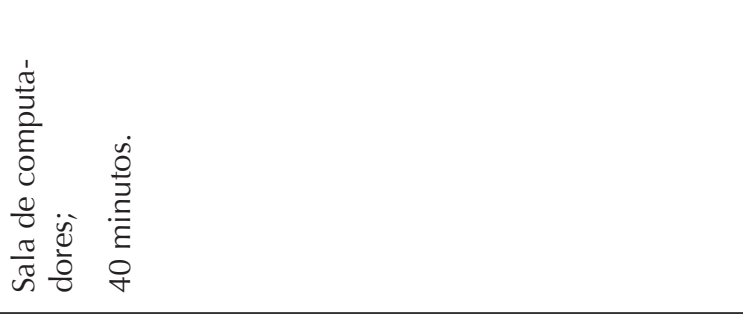 \\
\hline & & 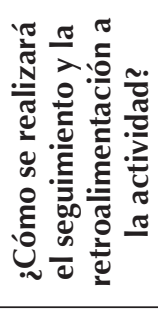 & 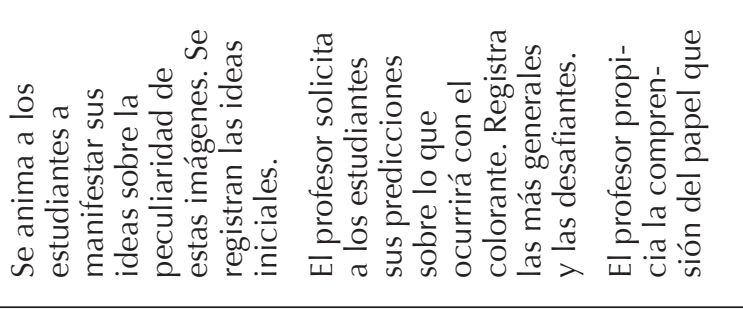 \\
\hline & & 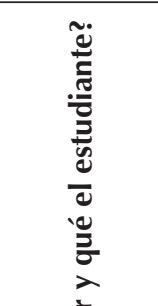 & 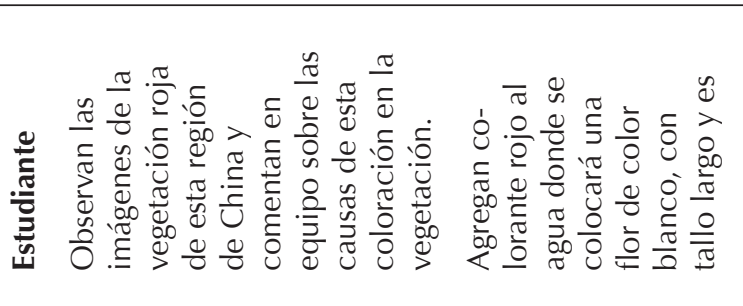 \\
\hline & & 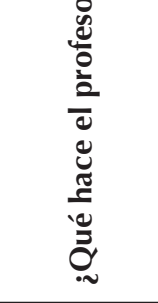 & 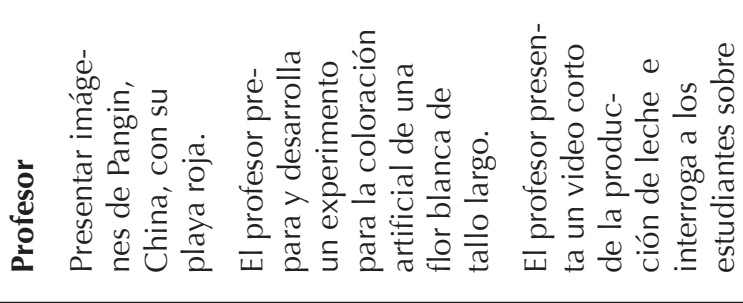 \\
\hline & & 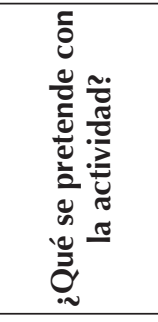 & 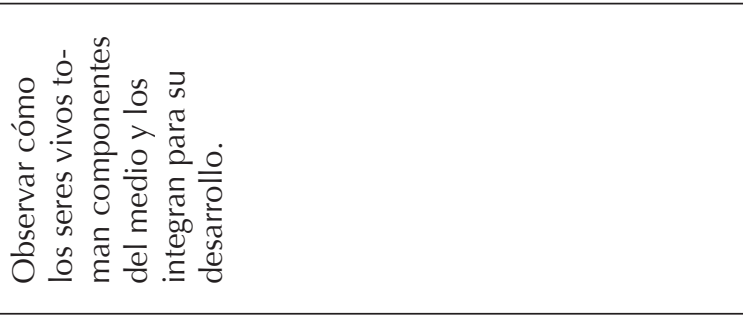 \\
\hline & & 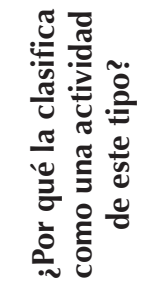 & 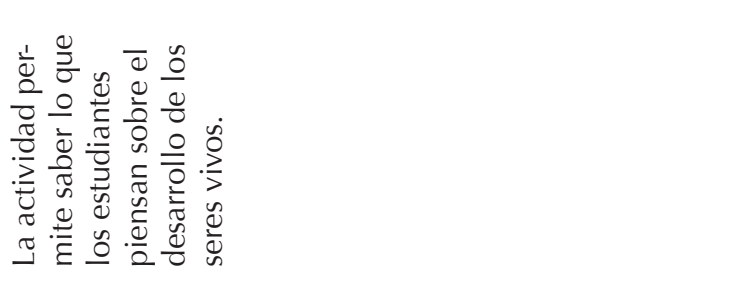 \\
\hline
\end{tabular}




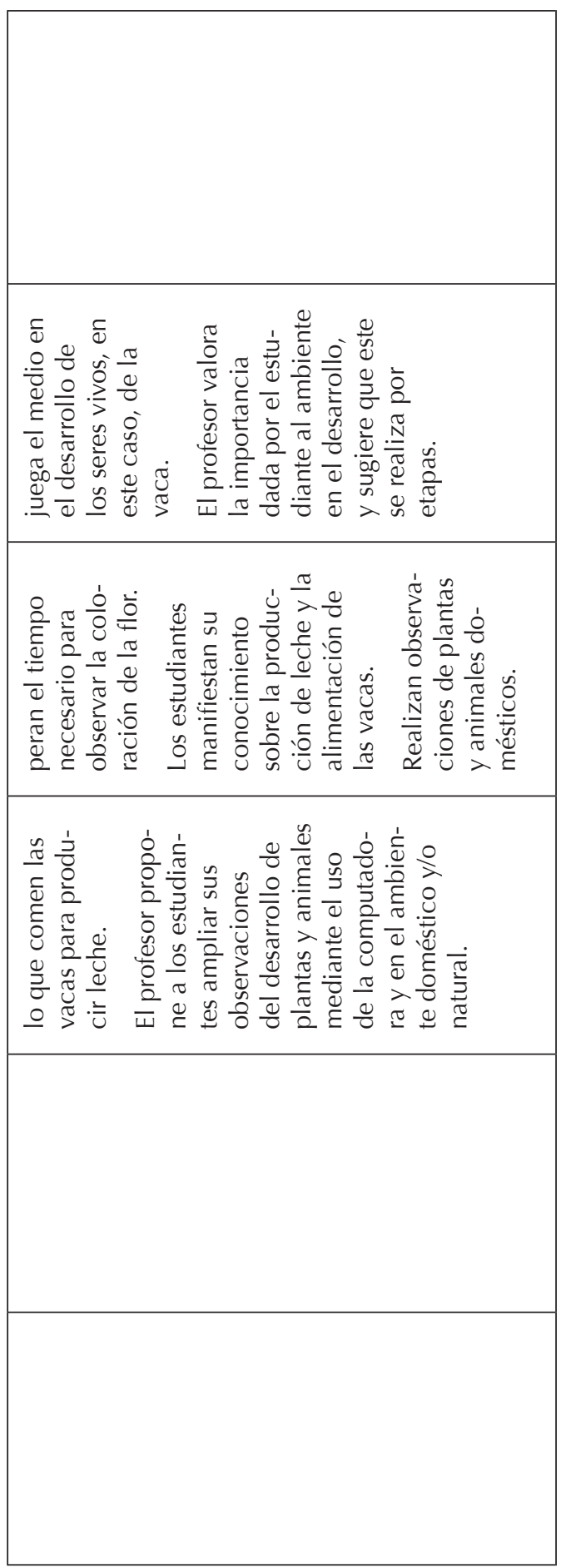




\begin{tabular}{|c|c|c|c|c|}
\hline \multirow{6}{*}{ 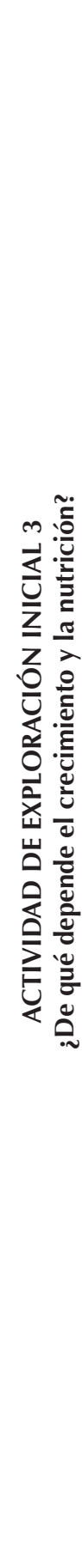 } & \multirow{6}{*}{\multicolumn{2}{|c|}{ 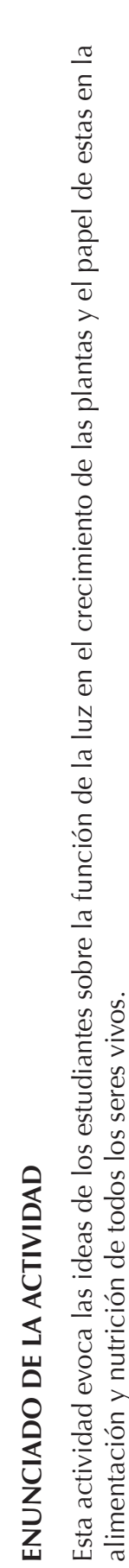 }} & 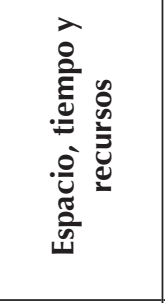 & 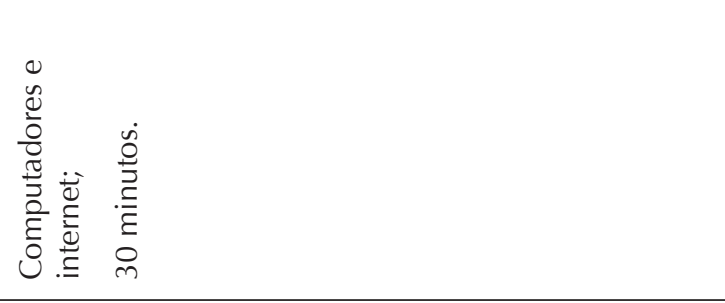 \\
\hline & & & 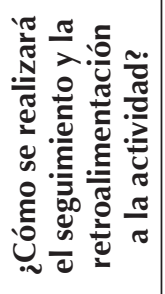 & 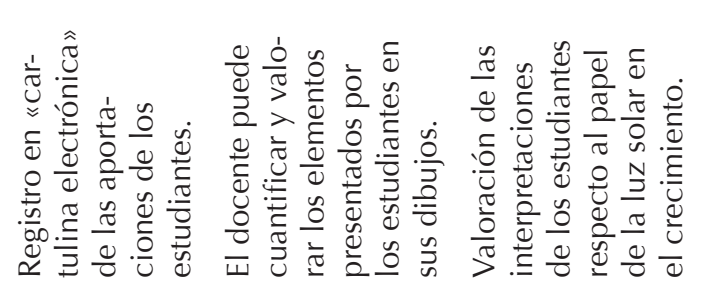 \\
\hline & & & 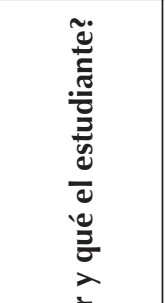 & 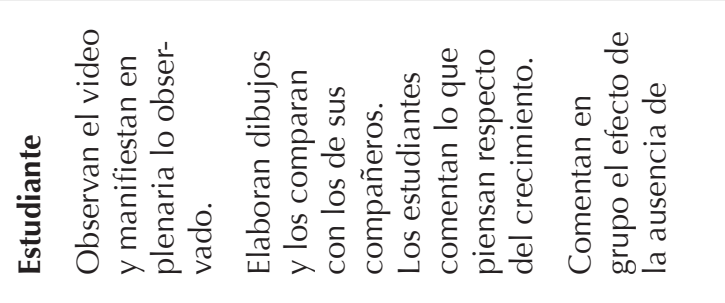 \\
\hline & & & 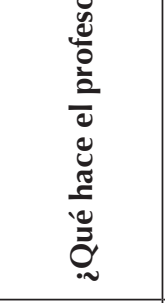 & 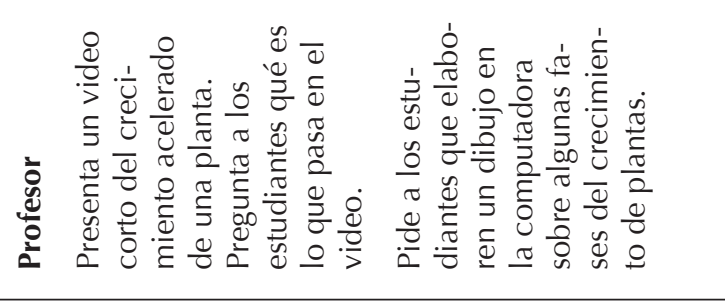 \\
\hline & & & 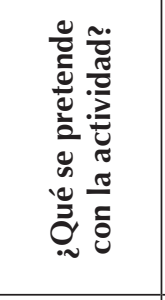 & 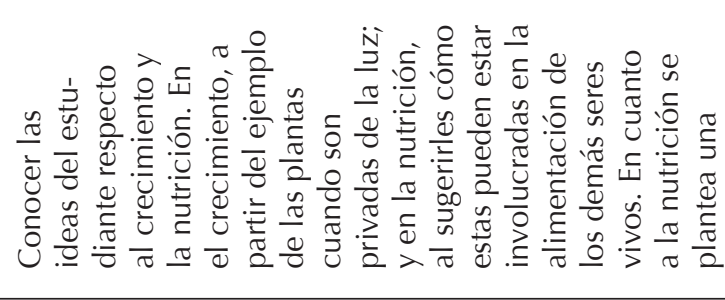 \\
\hline & & & 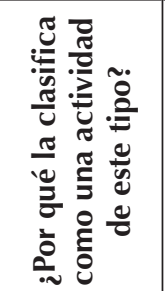 & 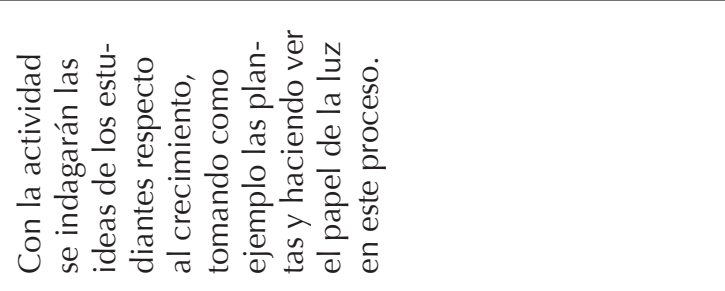 \\
\hline
\end{tabular}




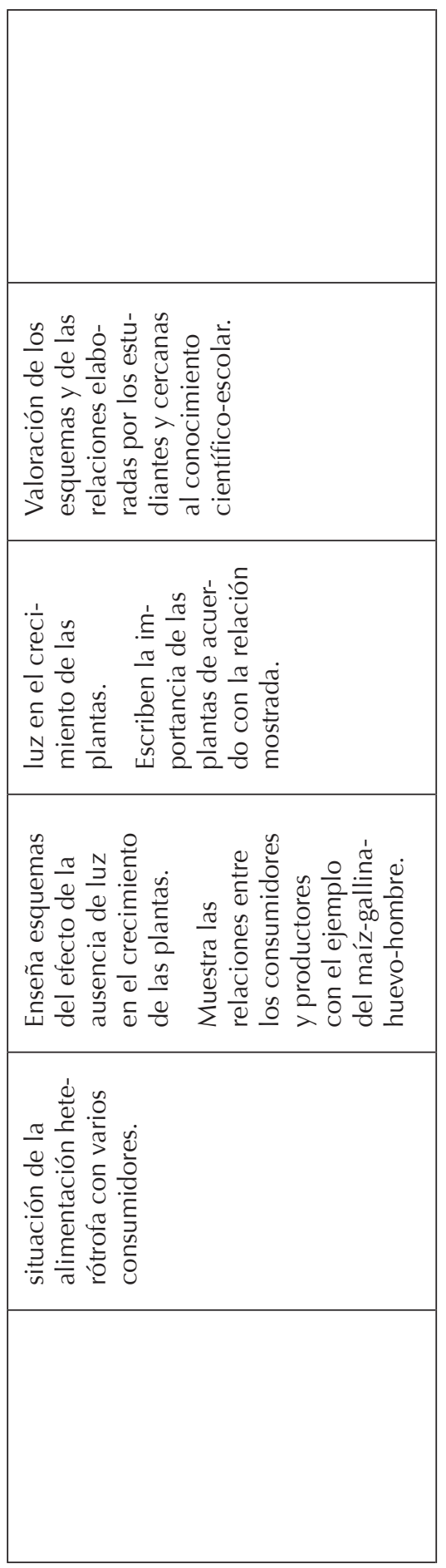


○ं

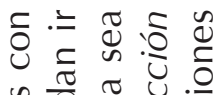

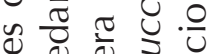

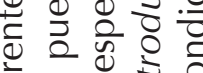

¿

广⿺辶

ปิ

(1) 유

$\because>>\frac{0}{0} \frac{0}{0}$

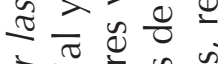

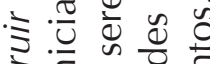

离.

ปิ

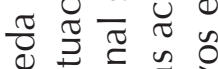

光

는은 응

䒕 苂

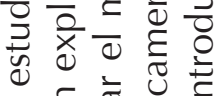

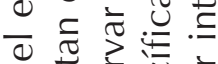

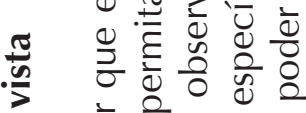

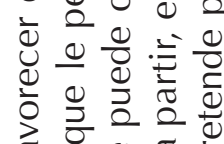

‡)

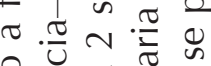

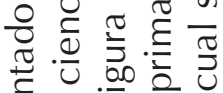

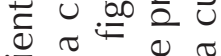

- 등 음

드뤄

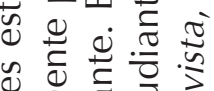

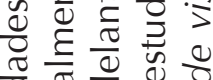

응 웡

.

ช

응 응 응

용 ᅯ

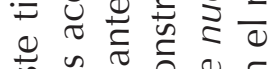

岕

\begin{tabular}{|c|c|c|c|c|}
\hline \multirow{6}{*}{ 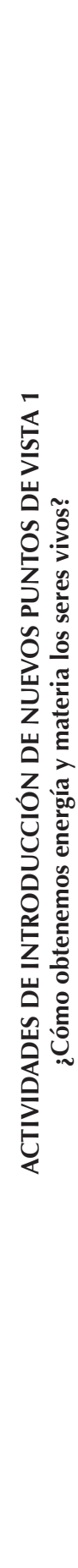 } & \multirow{6}{*}{\multicolumn{2}{|c|}{ 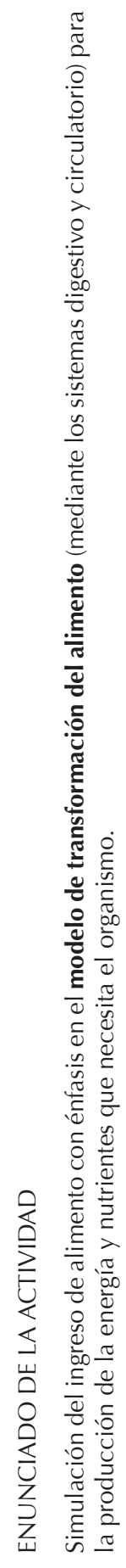 }} & 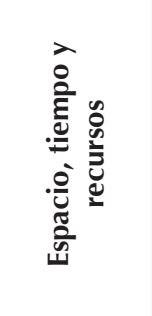 & 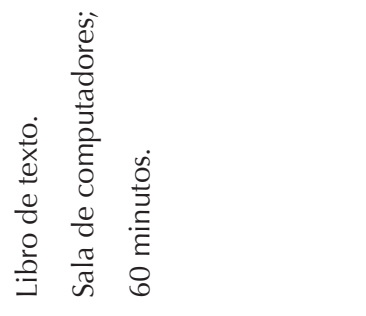 \\
\hline & & & 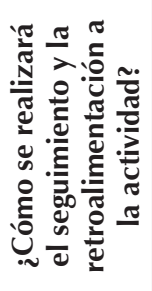 & 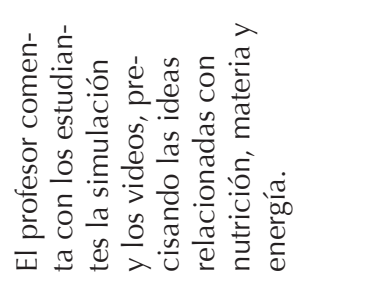 \\
\hline & & & 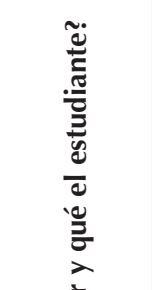 & 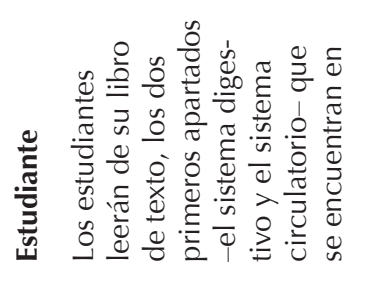 \\
\hline & & & 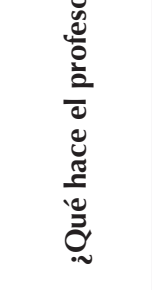 & 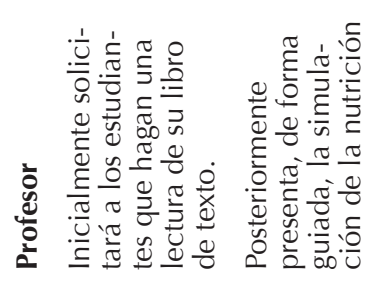 \\
\hline & & & 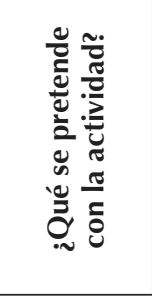 & 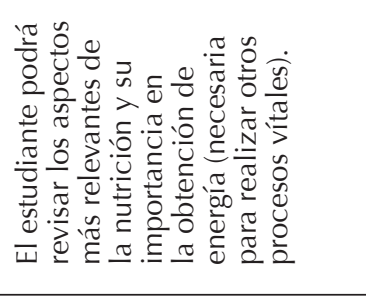 \\
\hline & & & 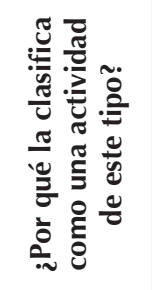 & 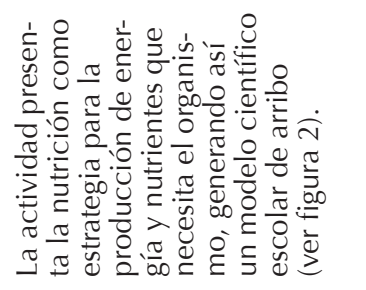 \\
\hline
\end{tabular}




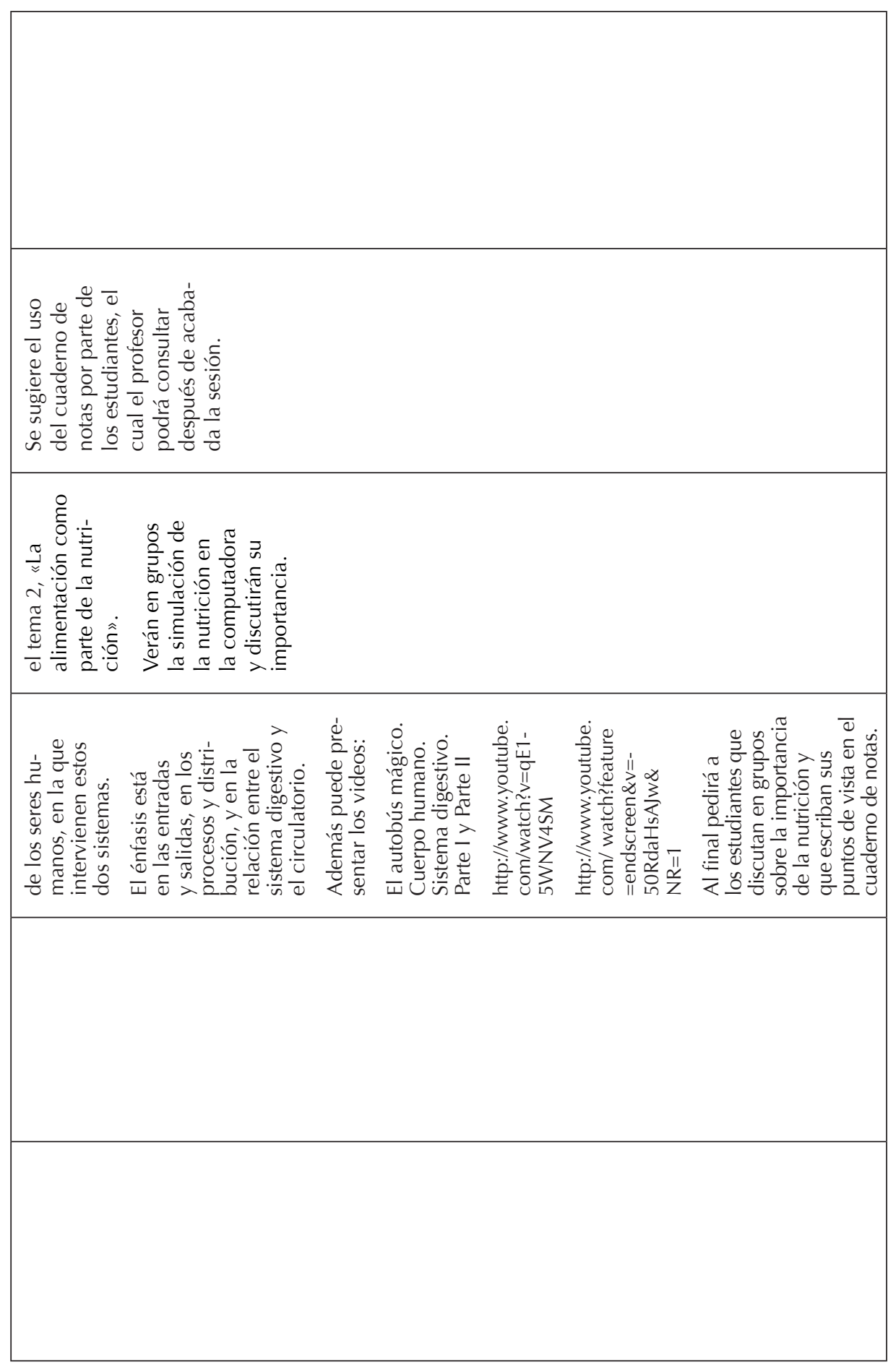




\begin{tabular}{|c|c|c|c|c|c|}
\hline \multirow{6}{*}{ 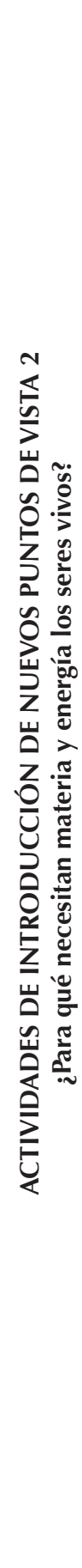 } & \multirow{6}{*}{\multicolumn{2}{|c|}{ 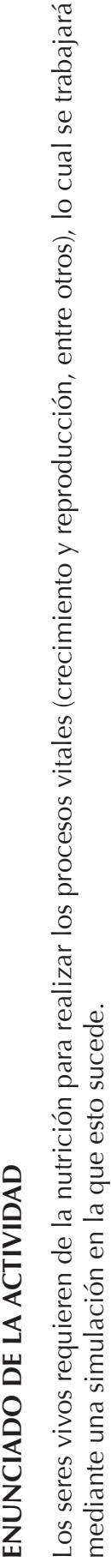 }} & \multirow{6}{*}{ 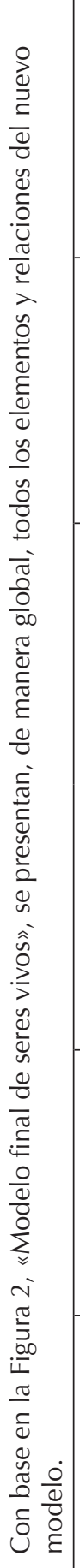 } & 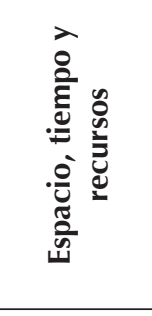 & 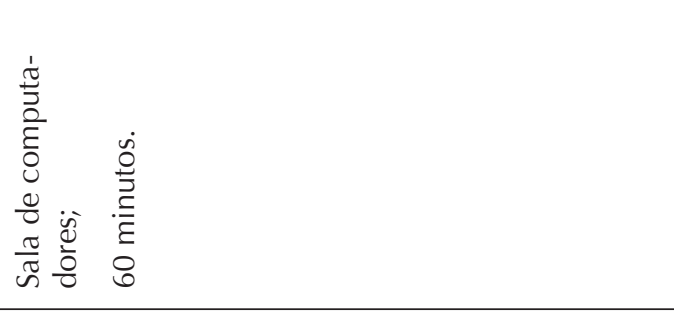 \\
\hline & & & & 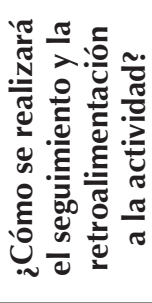 & 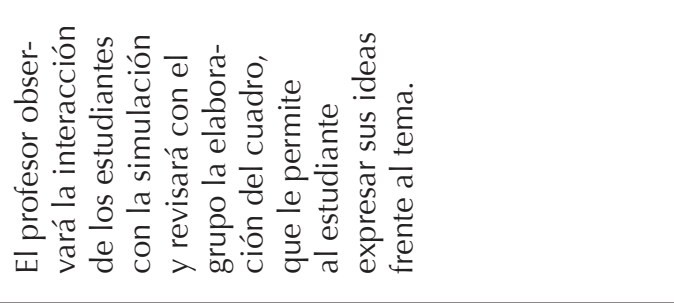 \\
\hline & & & & 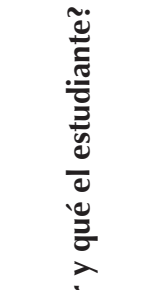 & 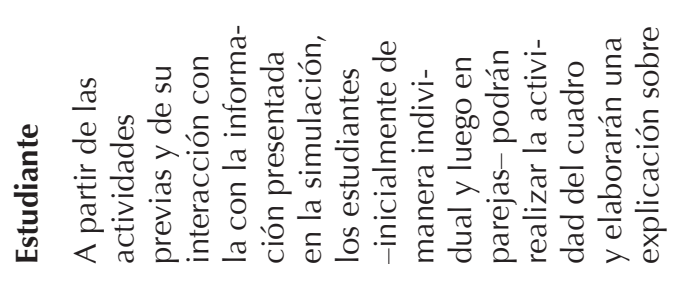 \\
\hline & & & & 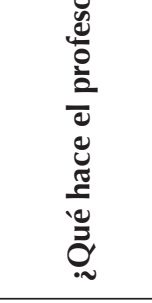 & 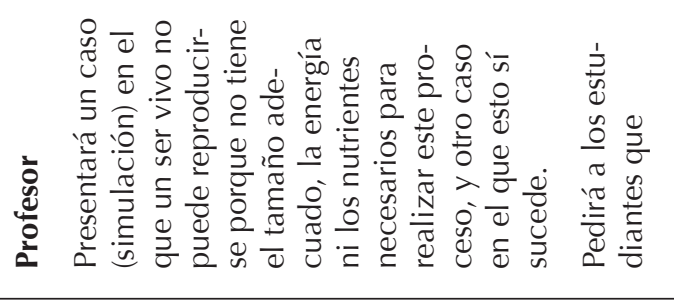 \\
\hline & & & & 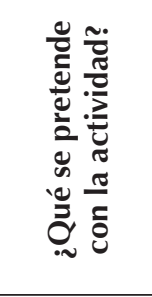 & 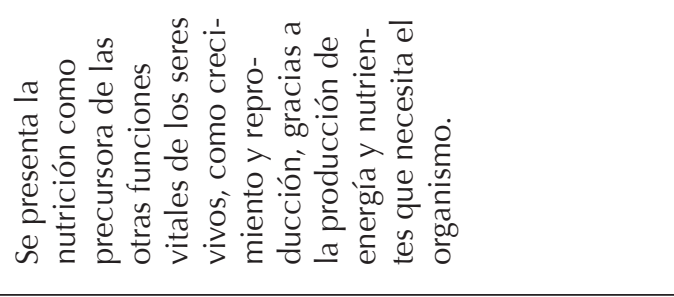 \\
\hline & & & & 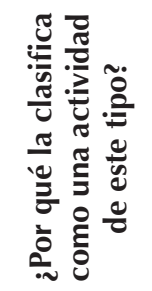 & 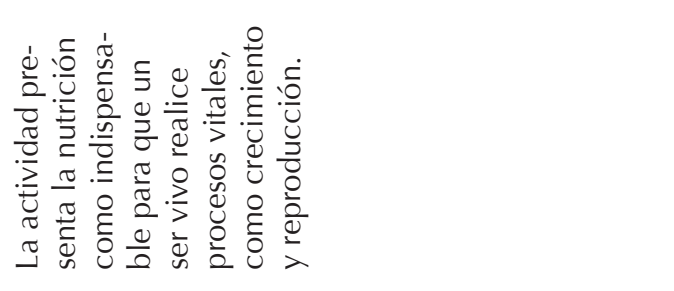 \\
\hline
\end{tabular}




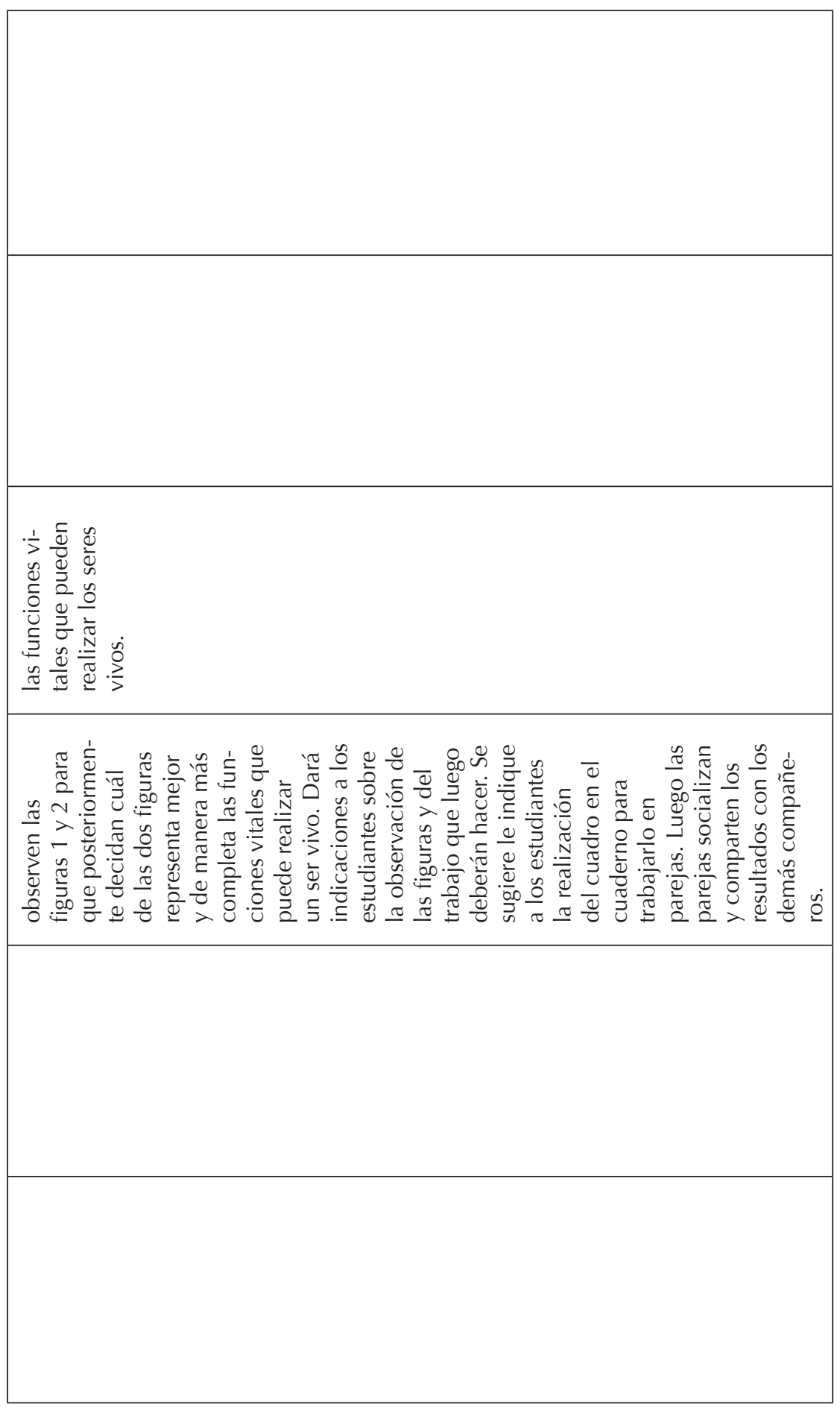




\section{EN LA SIGUIENTE ACTIVIDAD DEBES ESCRIBIR EN LAS CELDAS LA INFORMACIÓN}

SOLICITADA EN RELACIÓN A LAS FIGURAS OBSERVADAS SOBRE EL SER VIVO

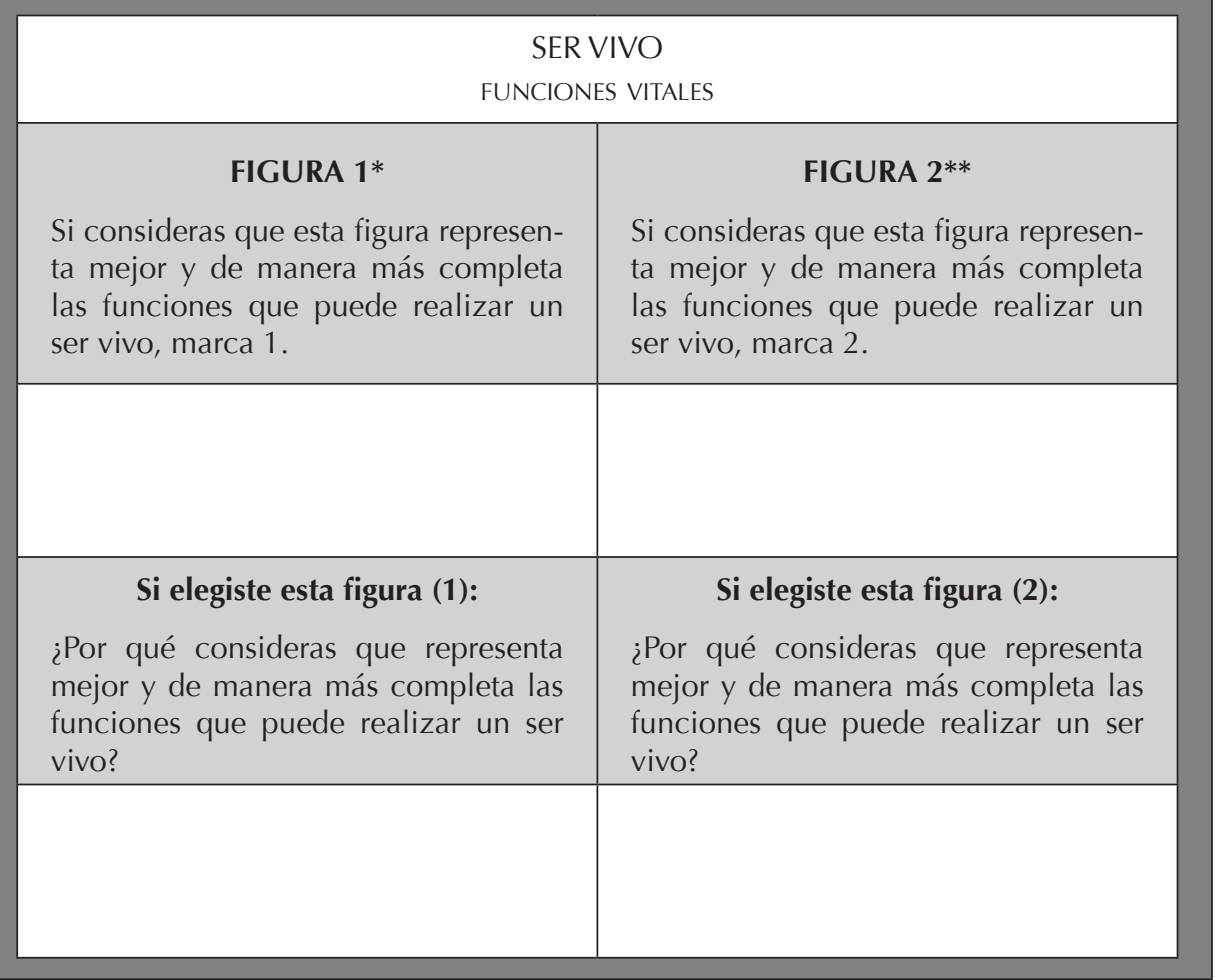

\section{Actividades de síntesis}

Mediante esta actividad se pretende que los estudiantes tomen conciencia del modelo construido hasta este momento y de cómo expresarlo o comunicarlo; la actividad no se relaciona con la explicación del fenómeno de nutrición, sino con la manera en que el modelo es utilizado para explicarlo.

* Se mostrará a los niños la Figura 1 «Modelo cognitivo inicial de seres vivos», que está al principio de esta Unidad Didáctica (ver Figura 1, página 79).

** Se mostrará a los niños la Figura 2 «Modelo final de seres vivos», que está al principio de esta Unidad Didáctica (ver Figura 2, página 79). 


\begin{tabular}{|c|c|c|c|c|}
\hline \multirow{6}{*}{ 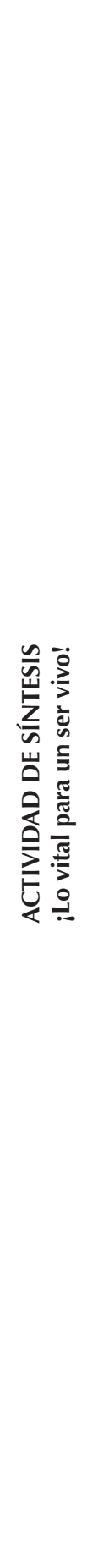 } & \multirow{6}{*}{\multicolumn{2}{|c|}{ 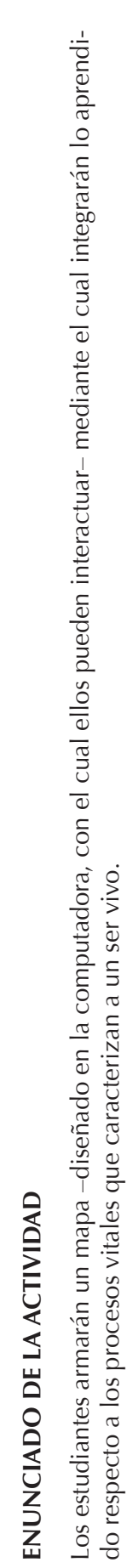 }} & 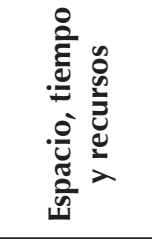 & 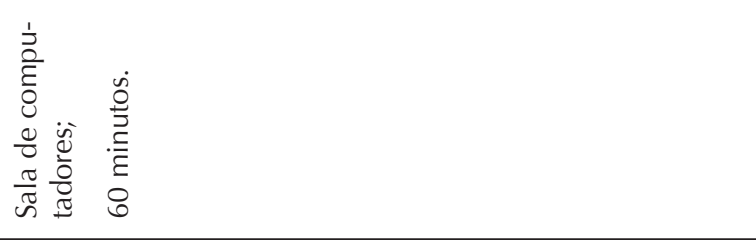 \\
\hline & & & 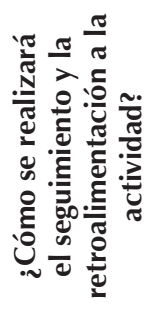 & 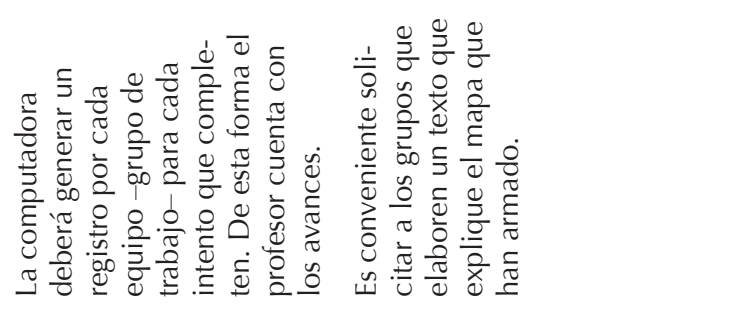 \\
\hline & & & 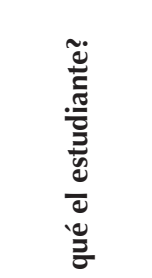 & 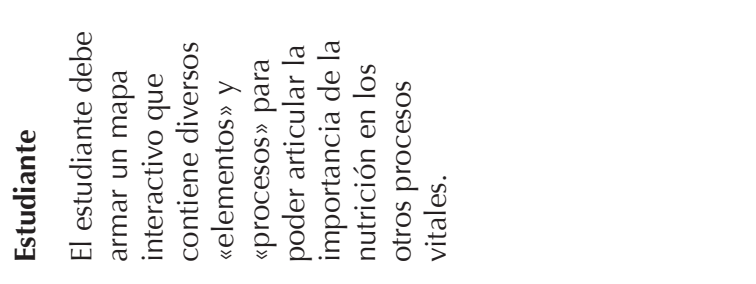 \\
\hline & & & 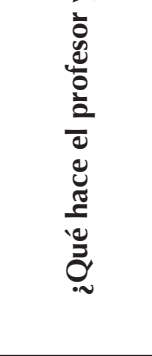 & 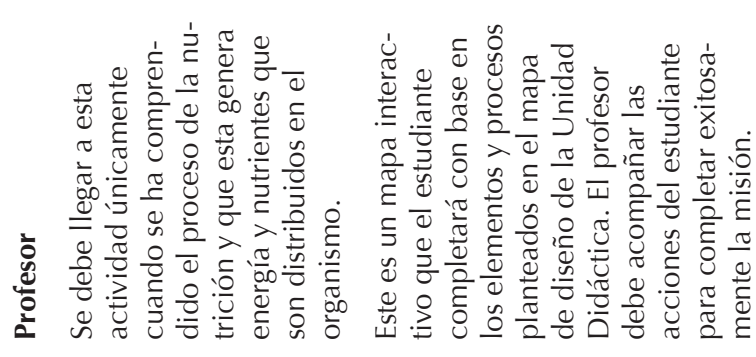 \\
\hline & & & 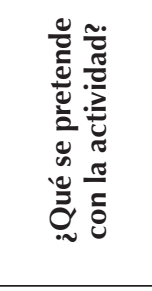 & 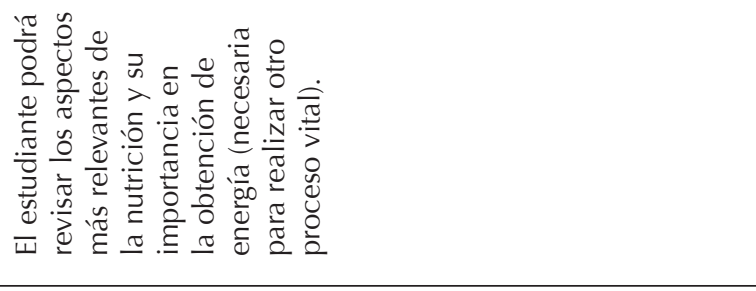 \\
\hline & & & 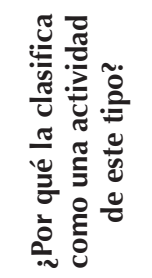 & 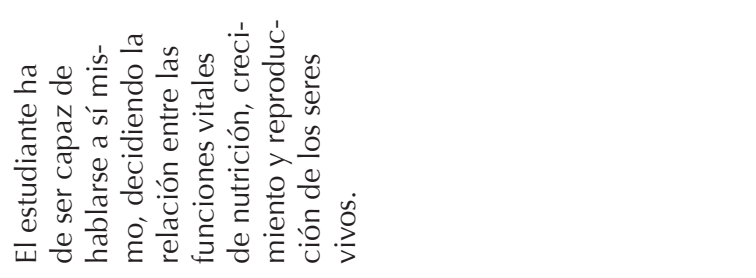 \\
\hline
\end{tabular}




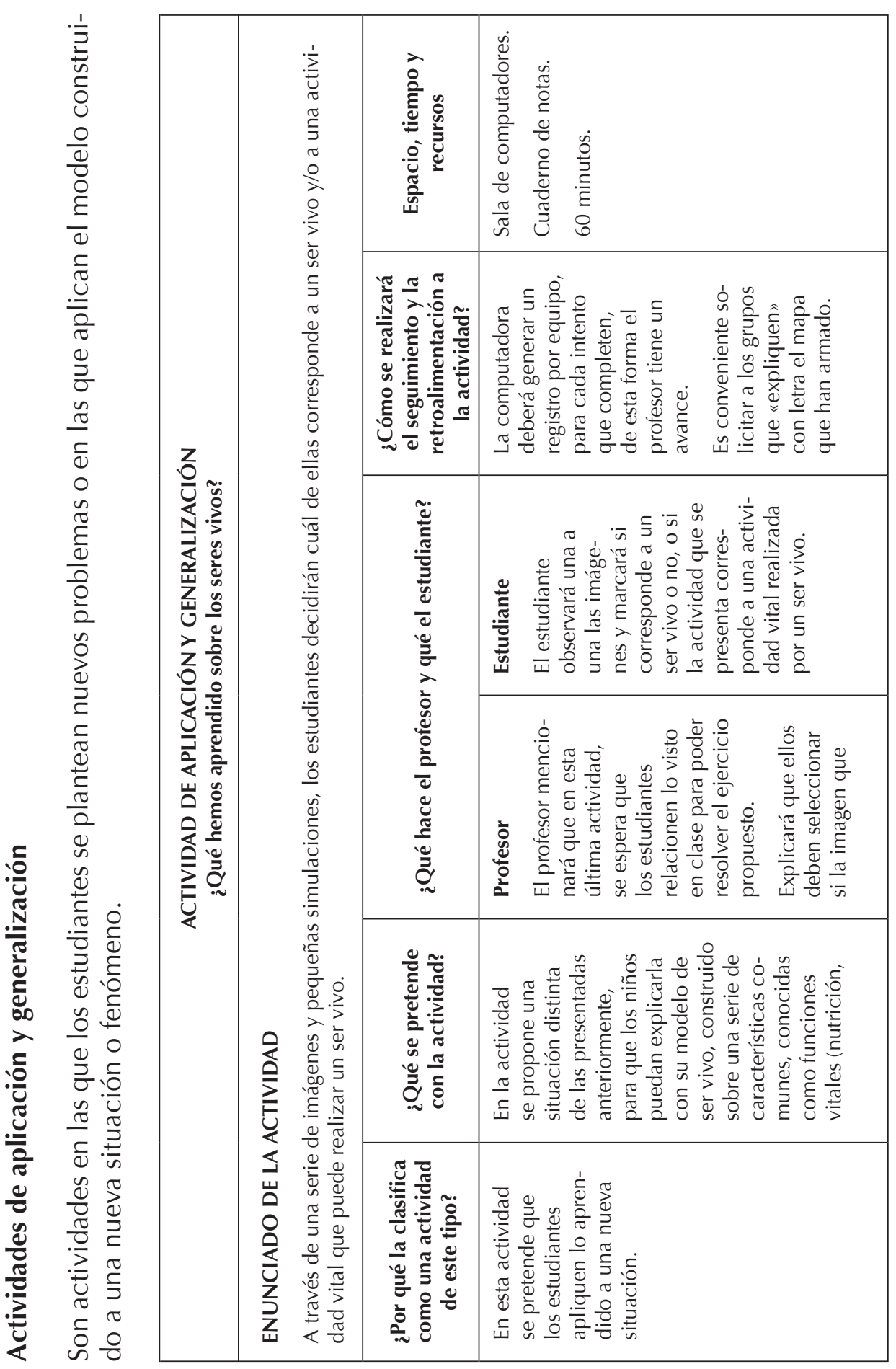




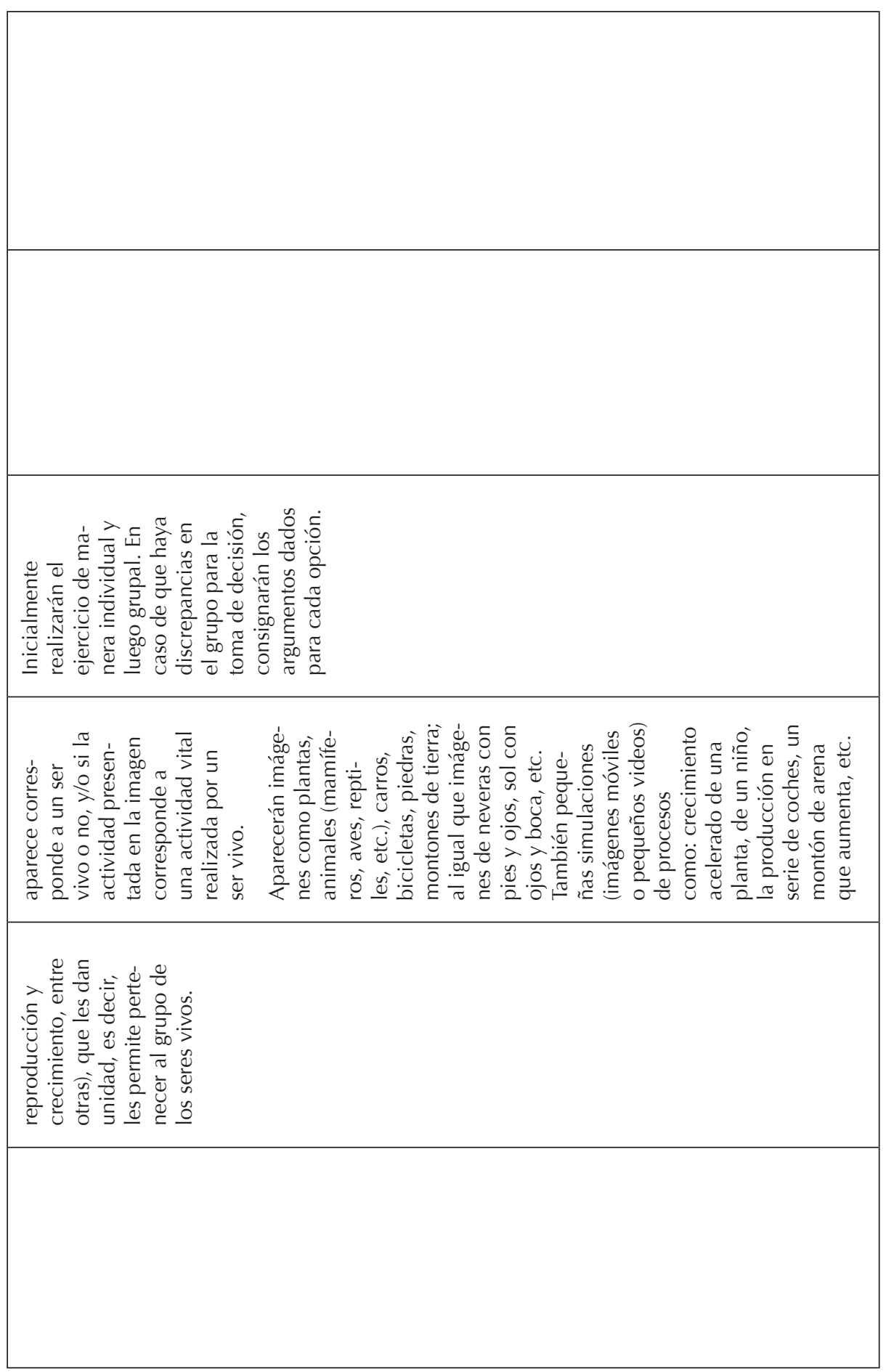




\subsection{Unidad didáctica «Cambio químico» en contextos de diversidad}

Mapa de diseño curricular unidad didáctica «Cambio químico»

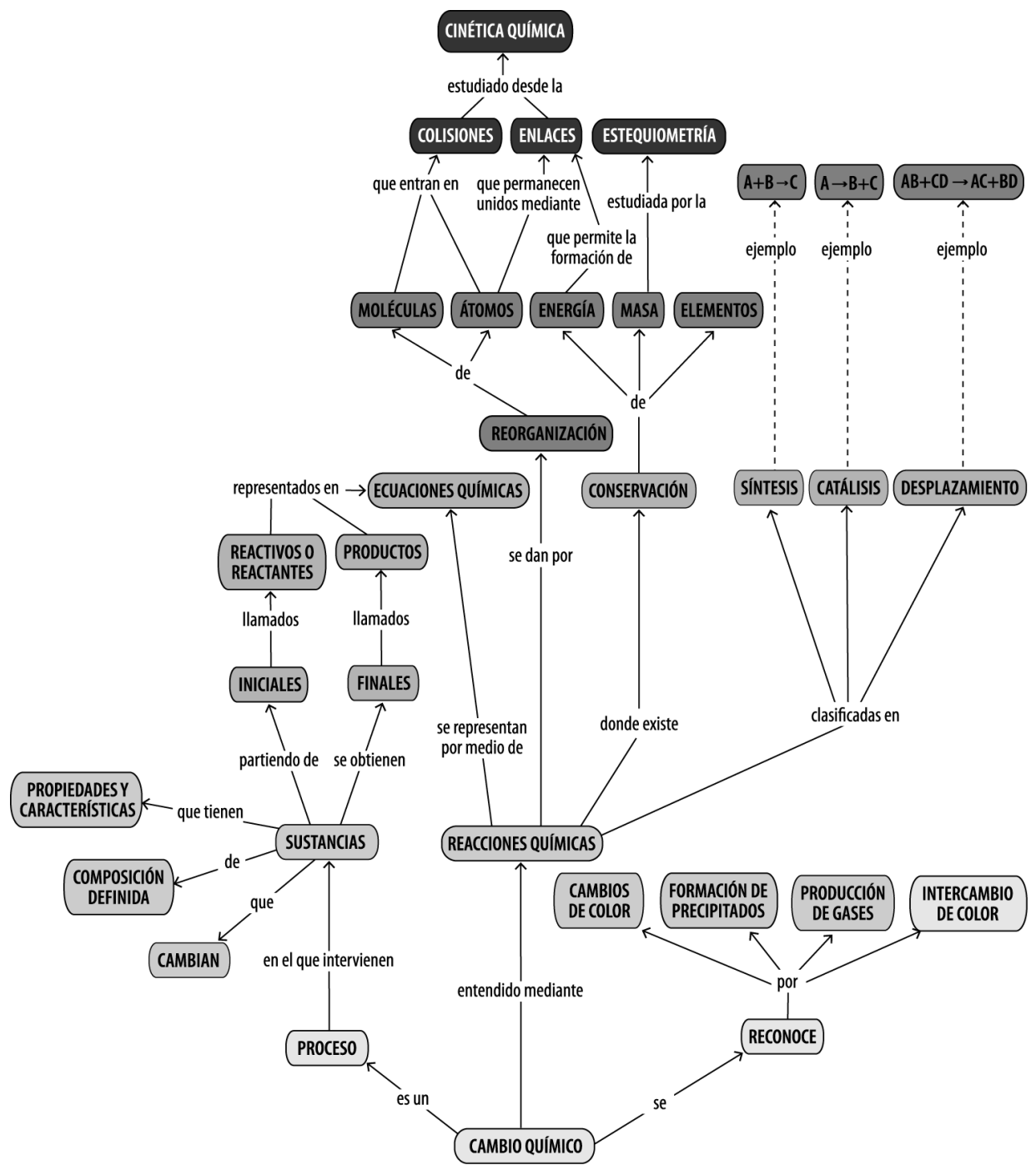




\section{ESTRUCTURA UNIDAD DIDÁCTICA}

UNIDAD DIDÁCTICA «CAMBIO QUÍMICO»EN CONTEXTOS DE DIVERSIDAD

\section{RESUMEN}

La presente unidad didáctica intentará desarrollar una mejor comprensión sobre el cambio químico en las poblaciones diversas en las cuales se pretende aplicar, teniendo como soporte el uso de las TIC (software con propósitos educativos). La unidad presenta varias actividades, entre las cuales se pueden reconocer actividades prácticas experimentales, actividades de construcción de textos, actividades asistidas y mediadas por computador.

\section{OBJETIVO GENERAL}

(con respecto al trabajo a desarrollar en el proceso de aplicación de la unidad didáctica)
Mediante la aplicación de actividades de aula, actividades asistidas por computador y prácticas de laboratorio, propiciar la comprensión del concepto de cambio químico en los estudiantes que se encuentran en contextos de diversidad.

\section{OBJETIVOS ESPECÍFICOS}

(Redactar cada uno de los objetivos teniendo en cuenta los aspectos que aparecen en el lado izquierdo)

\begin{tabular}{|l|l|}
\hline ACTITUDINAL & $\begin{array}{l}\text { Desarrollar habilidades para el trabajo autónomo } \\
\text { y cooperativo a partir del uso apropiado de las TIC, } \\
\text { que le permita mejorar su comprensión sobre los } \\
\text { fenómenos del cambio químico. } \\
\text { Suscitar el interés e importancia del uso adecua- } \\
\text { do del AVA, generando condiciones que permitan } \\
\text { el trabajo individual y en equipo, donde se resalte } \\
\text { la importancia de escuchar y compartir las expe- } \\
\text { riencias. }\end{array}$ \\
\hline PROCEDIMENTAL & $\begin{array}{l}\text { Generar habilidades para la organización, secuen- } \\
\text { ciación y seguimiento de actividades mediadas por } \\
\text { computador en Ava, actividades de aula y prácticas } \\
\text { de laboratorio. }\end{array}$ \\
\hline CONCEPTUAL & $\begin{array}{l}\text { Desarrollar habilidades para la comprensión e } \\
\text { identificación del cambio químico y diferenciarlo } \\
\text { de otro tipo de cambios o transformaciones que le } \\
\text { suceden a la materia. }\end{array}$ \\
\hline
\end{tabular}




\begin{tabular}{|c|c|c|}
\hline COMUNICATIVO & \multicolumn{2}{|c|}{$\begin{array}{l}\text { Promover el desarrollo de habilidades comunicati- } \\
\text { vas en el estudiante para que comparta y justifique } \\
\text { sus aprendizajes. }\end{array}$} \\
\hline \multicolumn{3}{|c|}{ JUSTIFICACIÓN } \\
\hline \multicolumn{3}{|c|}{$\begin{array}{l}\text { Dentro del marco del Proyecto ALTER-NATIVA surge la necesidad de ofrecer a los } \\
\text { docentes en formación ejemplos Concretos de la aplicación de las TIC a pobla- } \\
\text { ciones en contextos de diversidad. Como parte de los compromisos adquiridos } \\
\text { por la Universidad Distrital Francisco José de Caldas, la presente Unidad Di- } \\
\text { dáctica responde a las necesidades de las poblaciones en contexto de diver- } \\
\text { sidad para abordar temáticas específicas de química, en el caso del cambio } \\
\text { químico. }\end{array}$} \\
\hline \multirow{2}{*}{$\begin{array}{l}\text { POBLACIÓN A QUIEN } \\
\text { ESTÁ DIRIGIDA } \\
\text { (Mencionar el ciclo, gra- } \\
\text { do, área de conocimien- } \\
\text { to y un diagnostico con } \\
\text { respecto a la población, } \\
\text { destacando los rasgos } \\
\text { más relevantes) }\end{array}$} & \multirow{2}{*}{\multicolumn{2}{|c|}{$\begin{array}{l}\text { Población de estudiantes de primaria y primeros } \\
\text { grados de bachillerato en condiciones de diversi- } \\
\text { dad, denominada de manera general población } \\
\text { infantil (I). } \\
\text { Población adolescente en condiciones de diver- } \\
\text { sidad (sordos, en condición de desplazamiento e } \\
\text { indígenas). }\end{array}$}} \\
\hline & & \\
\hline \multirow[b]{2}{*}{ TIEMPO } & $\begin{array}{c}\text { NÚMERO DE } \\
\text { SESIONES }\end{array}$ & NÚMERO DE HORAS \\
\hline & 5 & $\begin{array}{l}\text { Cada sesión contará con una } \\
\text { hora en promedio para su de- } \\
\text { sarrollo completo. }\end{array}$ \\
\hline \multirow[b]{2}{*}{ TEMA } & GENERAL & ESPECÍFICOS \\
\hline & $\begin{array}{l}\text { Cambio } \\
\text { químico }\end{array}$ & $\begin{array}{l}\text { Cambio químico } \\
\text { Mezclas } \\
\text { Materia } \\
\text { Ecuación química }\end{array}$ \\
\hline MATERIALES & \multicolumn{2}{|c|}{$\begin{array}{l}\text { Equipos de cómputo, plataforma de acceso a la red } \\
\text { ALTER-NATIVA, laboratorio, materiales y reactivos de } \\
\text { química. }\end{array}$} \\
\hline
\end{tabular}

\section{DESCRIPCIÓN DE ACTIVIDADES}

\section{Población infantil}




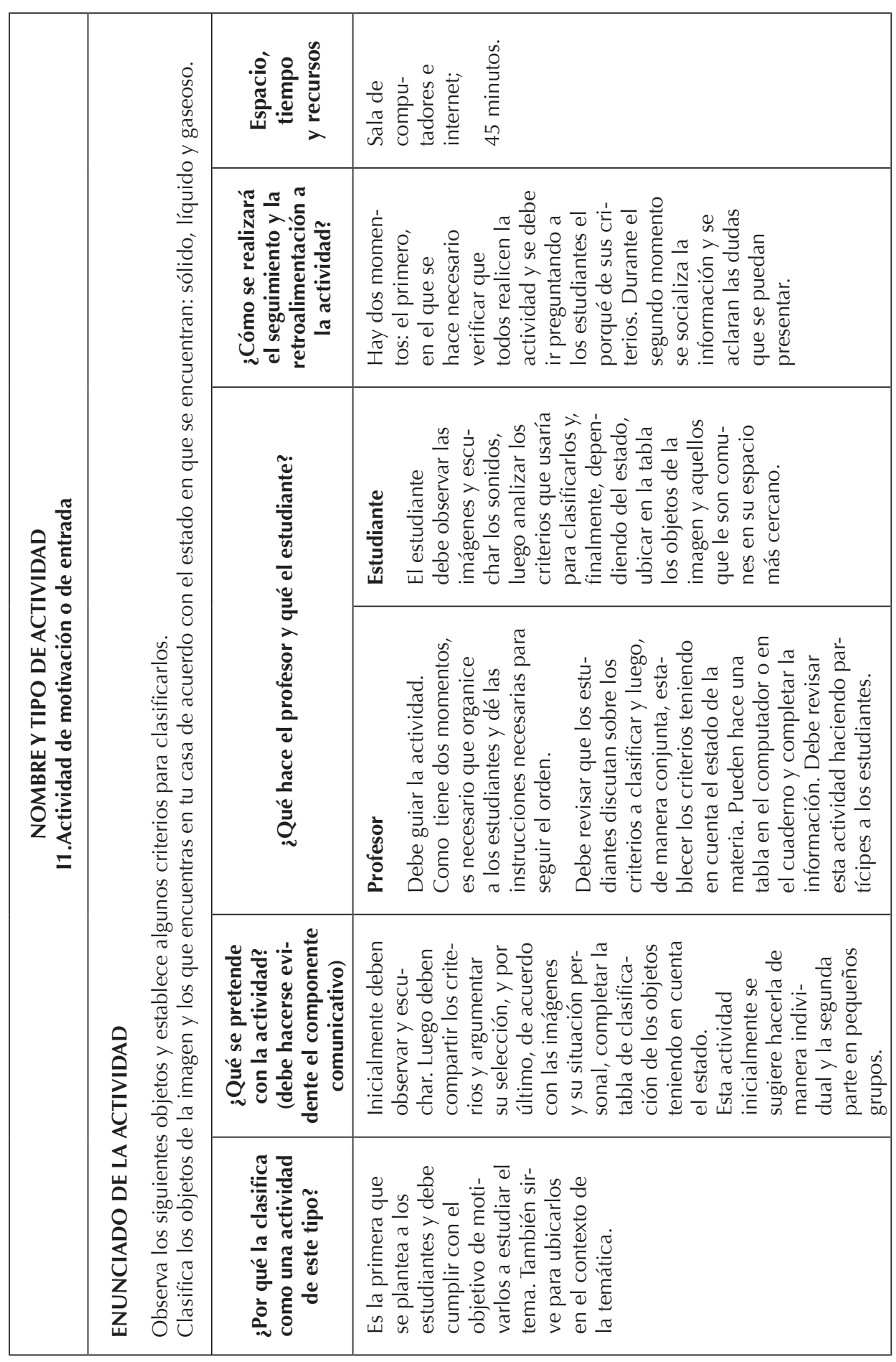




\begin{tabular}{|c|c|c|c|c|}
\hline \multirow{6}{*}{ 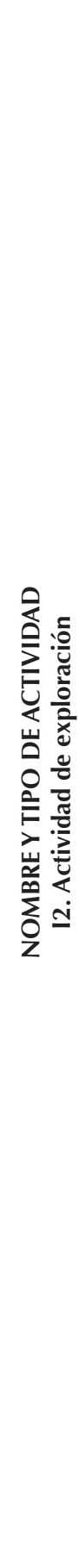 } & \multirow{6}{*}{\multicolumn{2}{|c|}{ 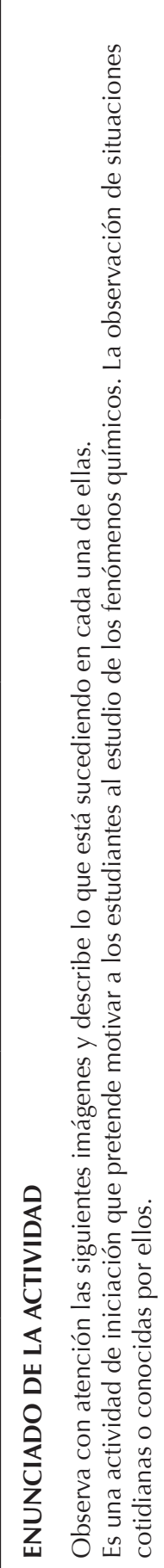 }} & 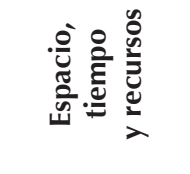 & 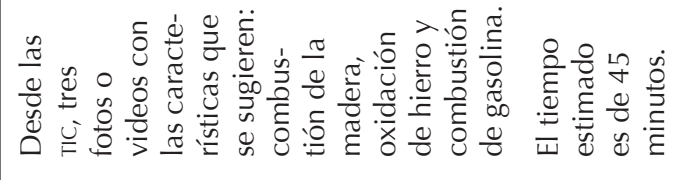 \\
\hline & & & 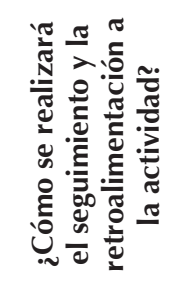 & 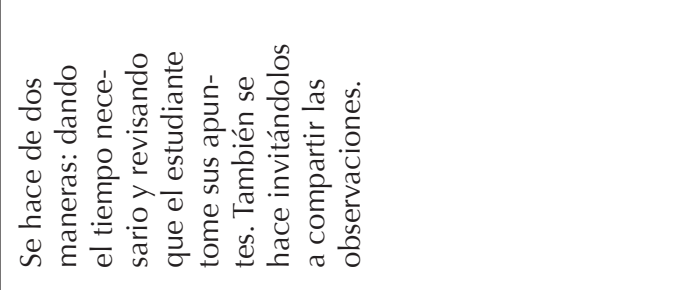 \\
\hline & & & 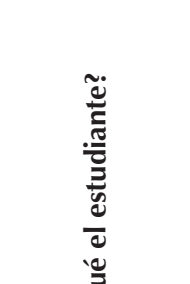 & 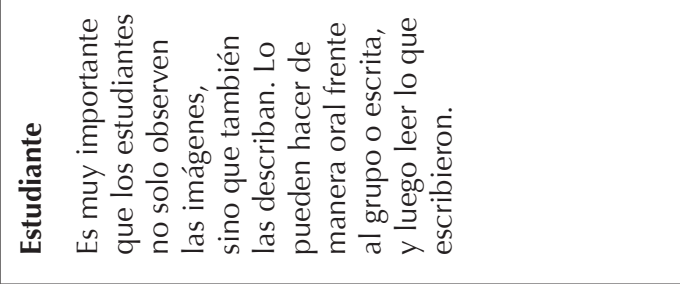 \\
\hline & & & 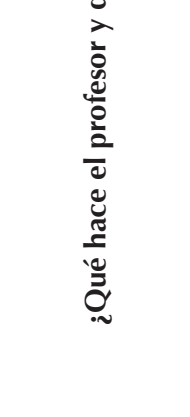 & 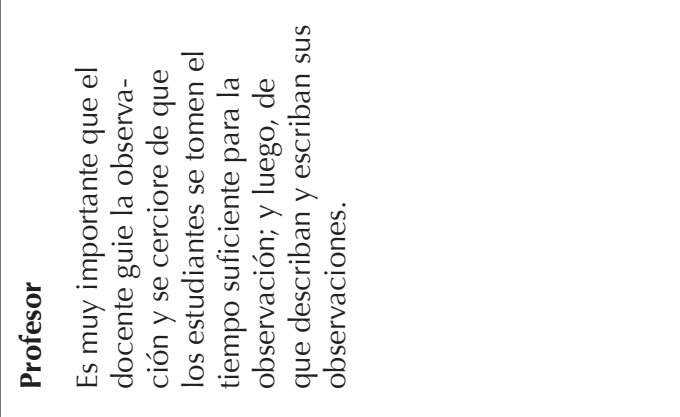 \\
\hline & & & 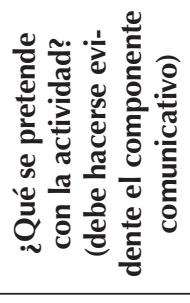 & 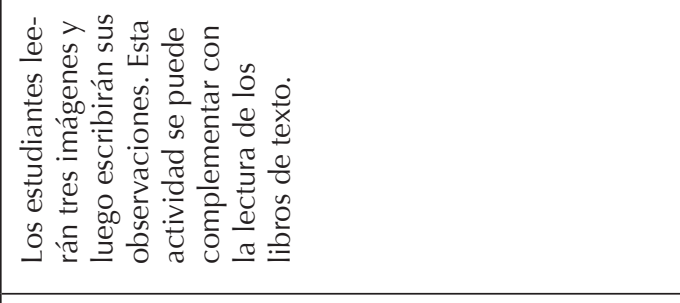 \\
\hline & & & 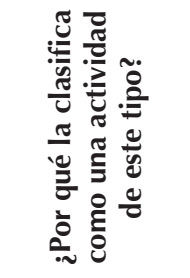 & 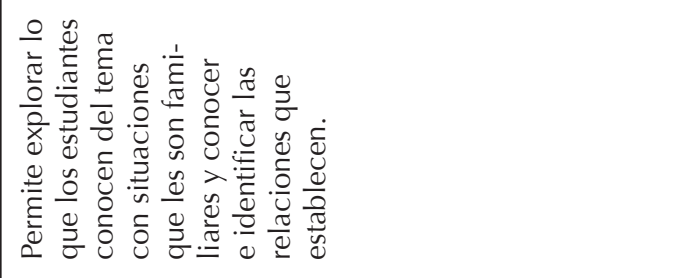 \\
\hline
\end{tabular}




\begin{tabular}{|c|c|c|c|c|}
\hline \multirow{6}{*}{ 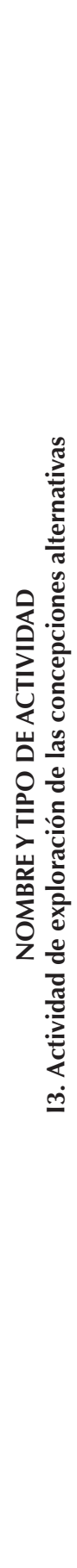 } & \multirow{6}{*}{\multicolumn{2}{|c|}{ 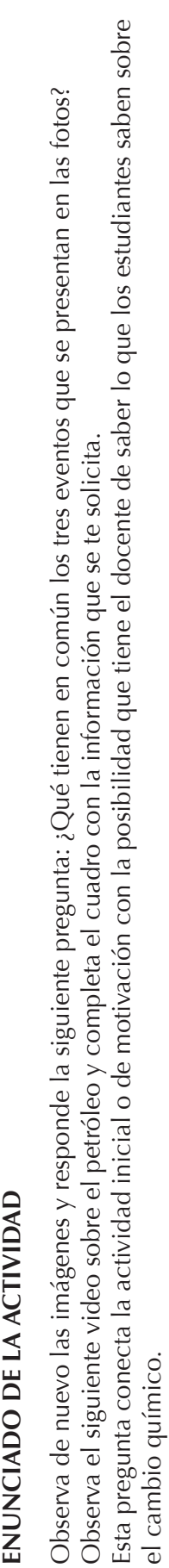 }} & 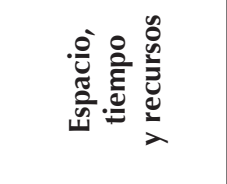 & 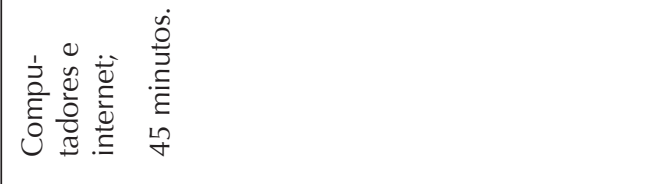 \\
\hline & & & 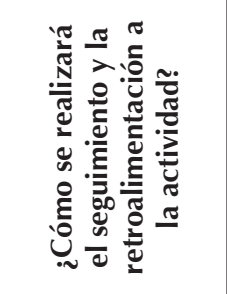 & 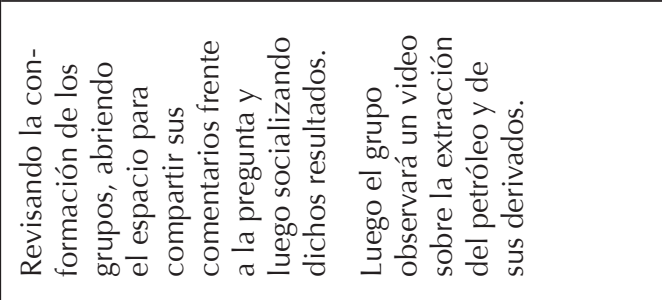 \\
\hline & & & 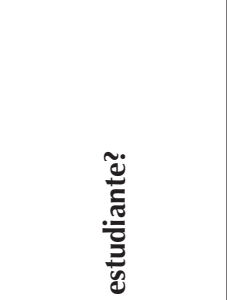 & 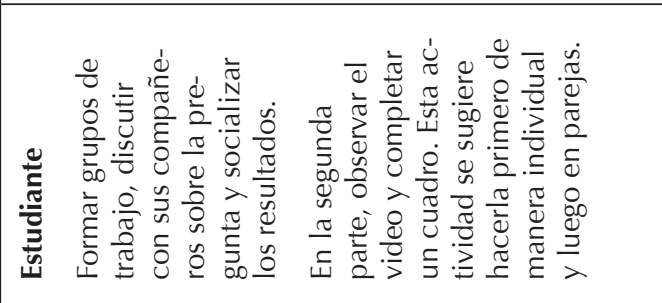 \\
\hline & & & 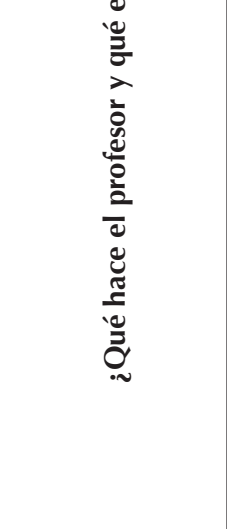 & 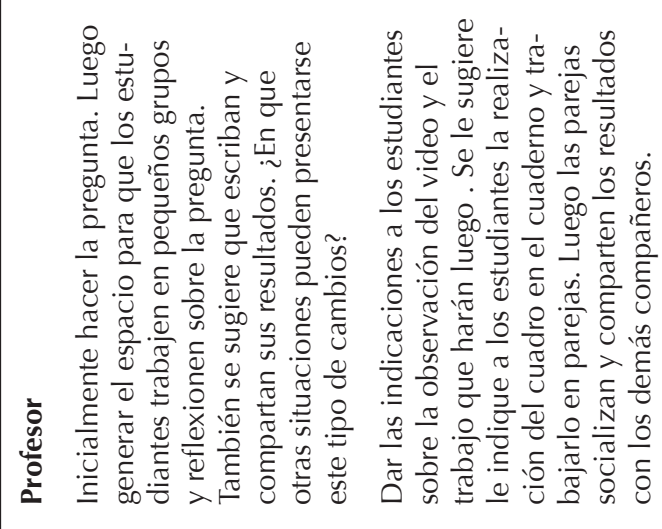 \\
\hline & & & 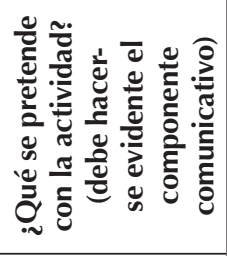 & 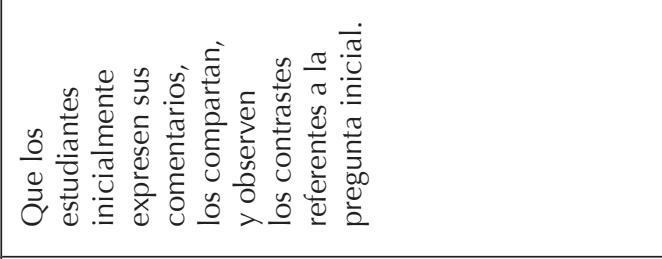 \\
\hline & & & 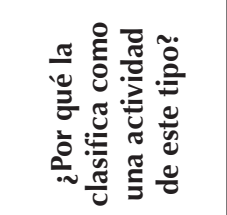 & 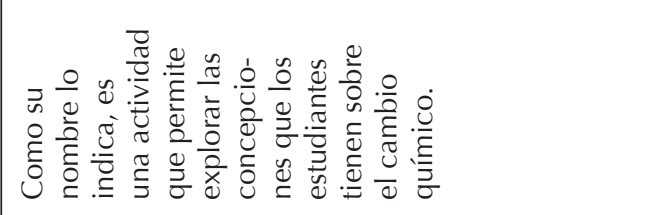 \\
\hline
\end{tabular}




\begin{tabular}{|c|c|c|c|c|c|}
\hline \multirow{6}{*}{ 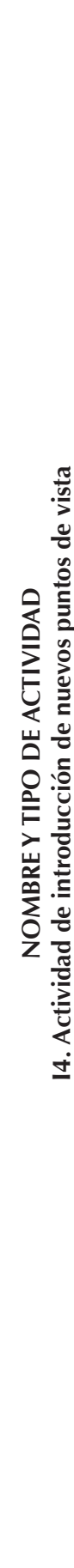 } & \multirow{6}{*}{\multicolumn{3}{|c|}{ 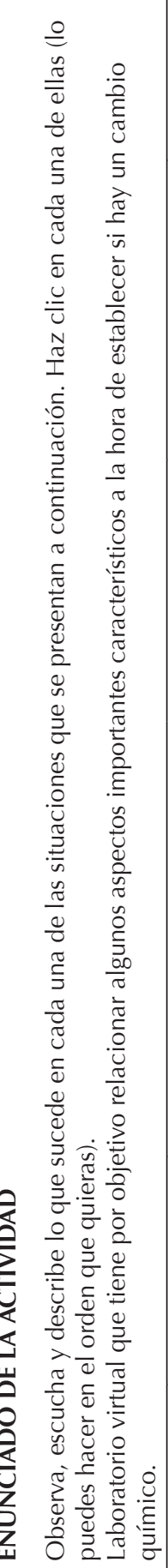 }} & 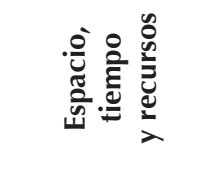 & 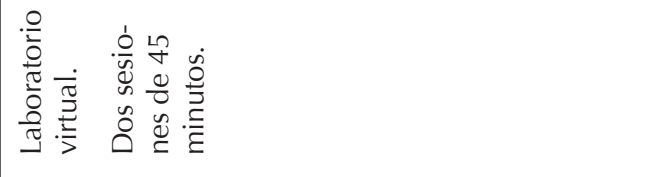 \\
\hline & & & & 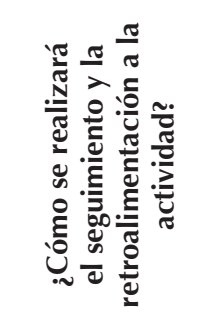 & 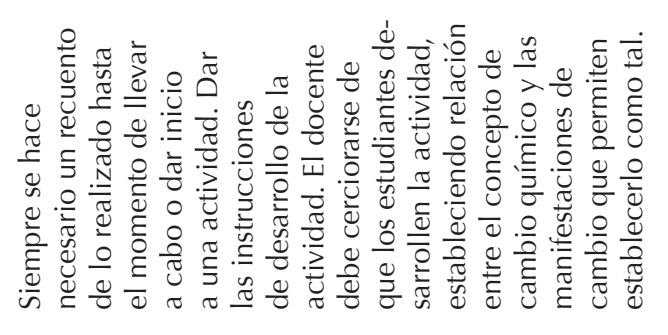 \\
\hline & & & & 苞 & 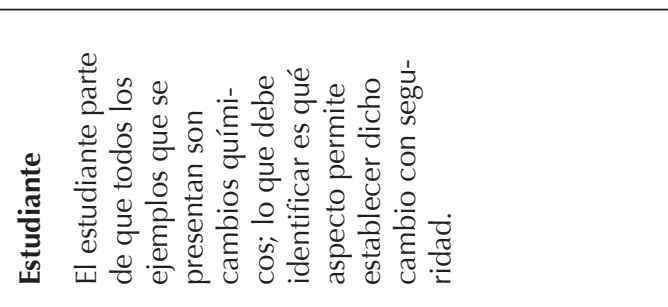 \\
\hline & & & & 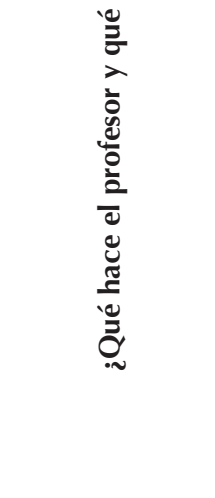 & 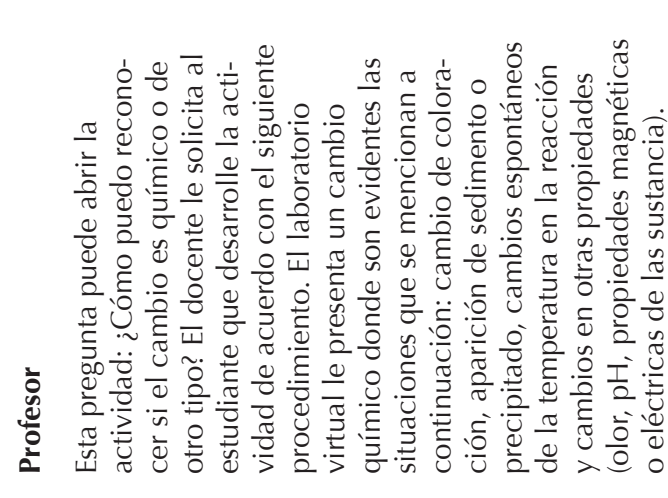 \\
\hline & & & & 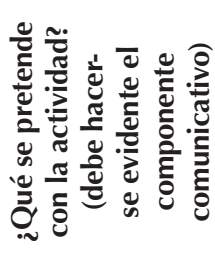 & 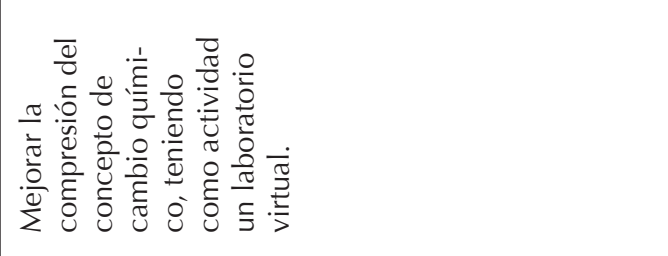 \\
\hline & & & & 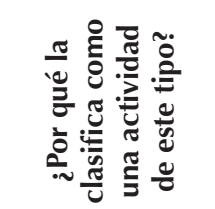 & 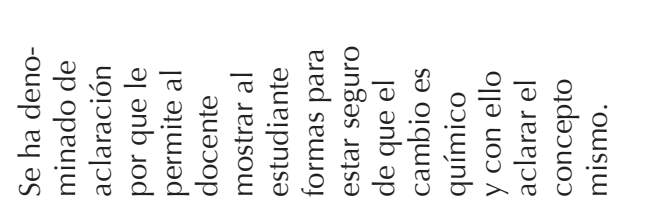 \\
\hline
\end{tabular}




\begin{tabular}{|c|c|c|c|c|c|}
\hline \multirow{6}{*}{ 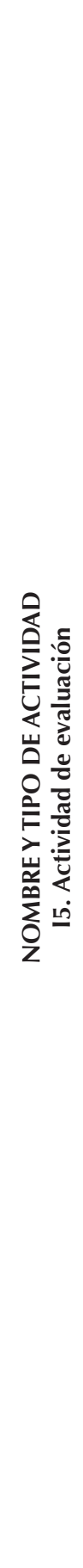 } & \multirow{6}{*}{. } & \multirow{6}{*}{\multicolumn{2}{|c|}{ 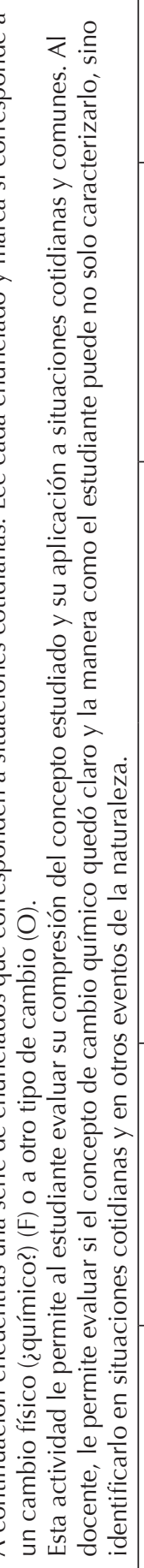 }} & 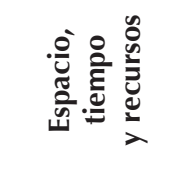 & 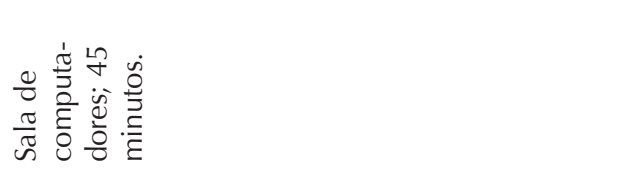 \\
\hline & & & & 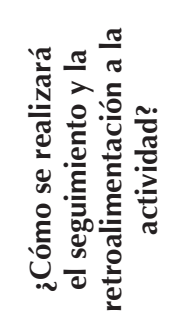 & 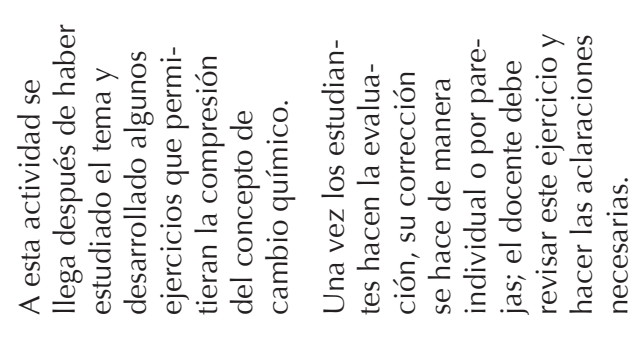 \\
\hline & & & & 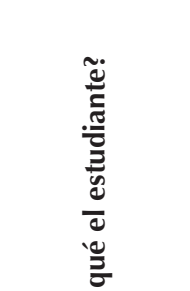 & 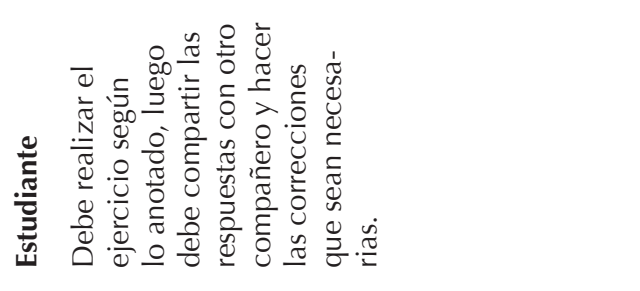 \\
\hline & & & & 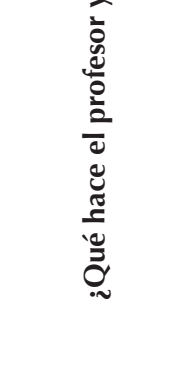 & 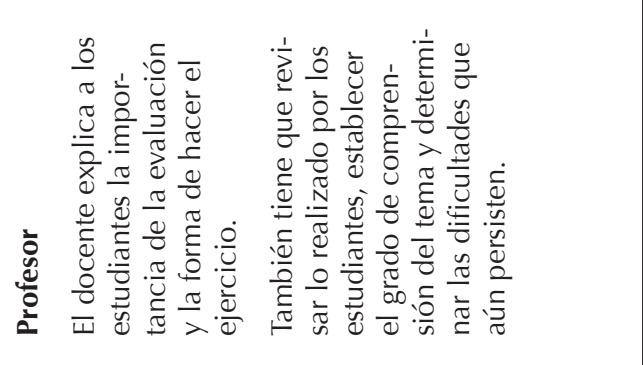 \\
\hline & & & & 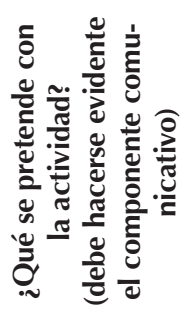 & 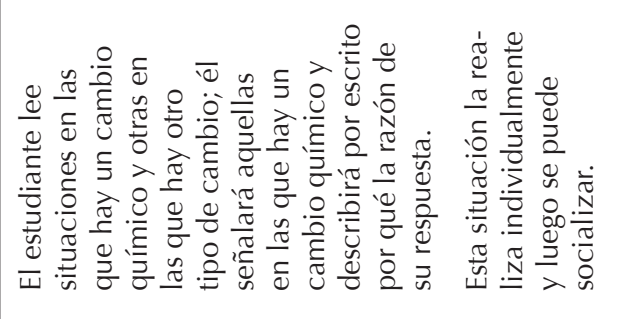 \\
\hline & & & & 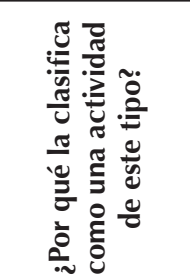 & 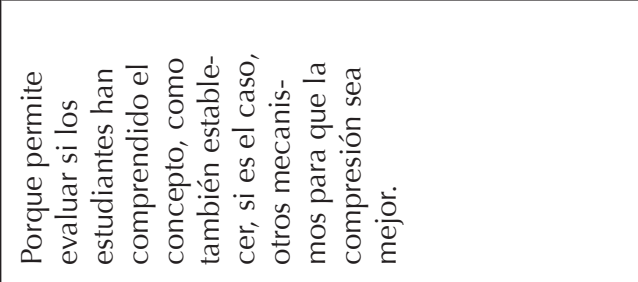 \\
\hline
\end{tabular}




\subsection{Unidad didáctica «La materia» para estudiantes de primaria en contextos de diversidad (sordos)}

Mapa de diseño unidad didáctica «La materia»

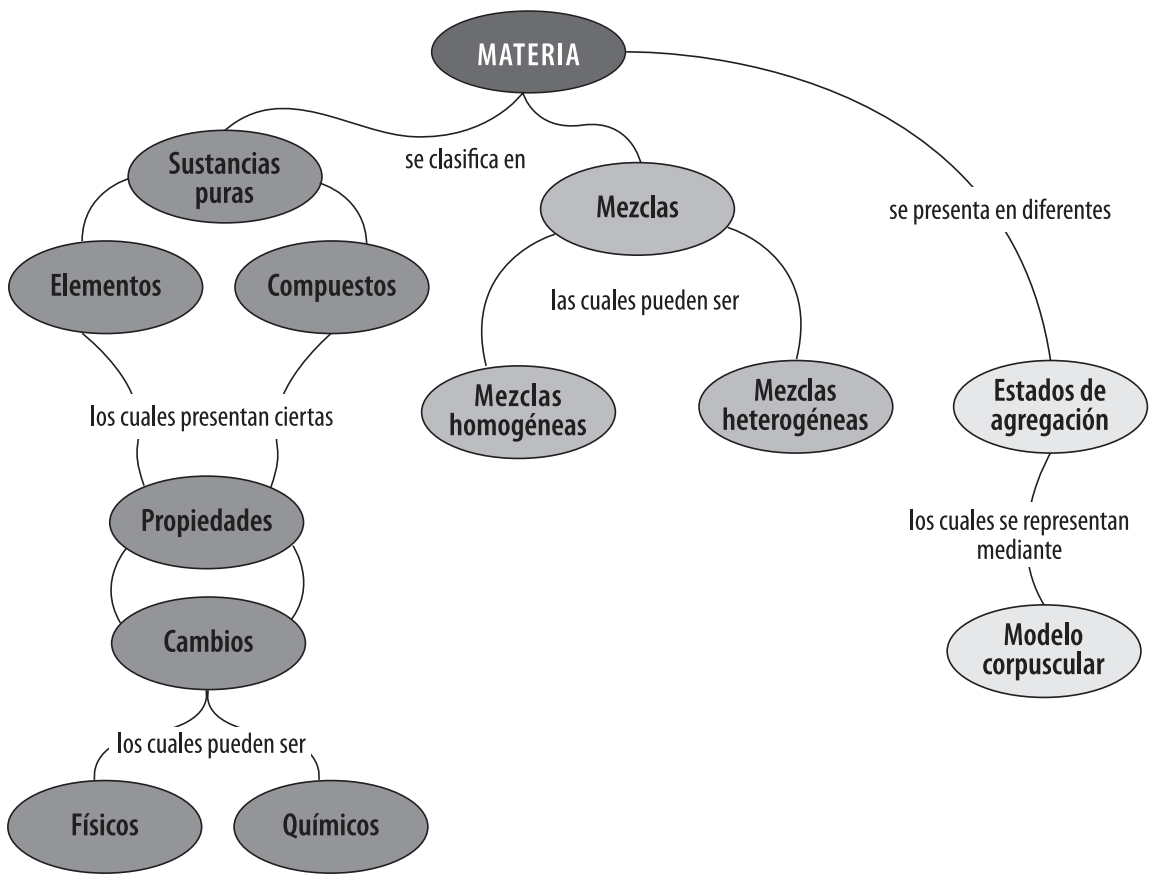

\section{ESTRUCTURA UNIDAD DIDÁCTICA}

UNIDAD DIDÁCTICA «LA MATERIA» PARA ESTUDIANTES DE PRIMARIA EN CONTEXTOS DE DIVERSIDAD (SORDOS)

\section{RESUMEN}

La presente unidad didáctica pretende desarrollar la comprensión del contenido la materia en poblaciones con problemas auditivos, teniendo como soporte el uso de las TIC (software con propósitos educativos).

OBJETIVO GENERAL
Comprender las propiedades de la materia, la clasificación, las transformaciones que experimenta y los principios de conservación, para estudiantes que se encuentran en contextos de diversidad. 


\section{OBJETIVOS ESPECÍFICOS}

(Redactar cada uno de los objetivos teniendo en cuenta los aspectos que aparecen en el lado izquierdo)

\begin{tabular}{|l|l|}
\hline ACTITUDINAL & $\begin{array}{l}\text { Desarrollar habilidades para el trabajo autónomo y cooperativo a } \\
\text { partir del uso apropiado de las TIC. }\end{array}$ \\
\hline PROCEDIMENTAL & $\begin{array}{l}\text { Desarrollar habilidades para la organización, secuenciación y se- } \\
\text { guimiento de actividades mediadas por computador en AVA. }\end{array}$ \\
\hline CONCEPTUAL & $\begin{array}{l}\text { Desarrollar habilidades para describir y clasificar las propiedades } \\
\text { de la materia, clasificar la materia, identificar los métodos de sepa- } \\
\text { ración de mezclas, reconocer los tipos de cambios de la materia, } \\
\text { identificar los componentes de la disolución, explicar el proceso de } \\
\text { solubilidad y aplicar las unidades de concentración a situaciones } \\
\text { problemáticas simples. }\end{array}$ \\
\hline
\end{tabular}

\section{JUSTIFICACIÓN}

Dentro del marco del proyecto ALTER-NATIVA surge la necesidad de ofrecer a los estudiantes ejemplos concretos de la aplicación de las tIC a poblaciones en contextos de diversidad. Como parte de los compromisos adquiridos por la Pontificia Universidad Católica de Valparaíso, Chile, la presente Unidad Didáctica responde a las necesidades de las poblaciones en contexto de diversidad para abordar temáticas específicas de química, en el caso del estudio de la materia.

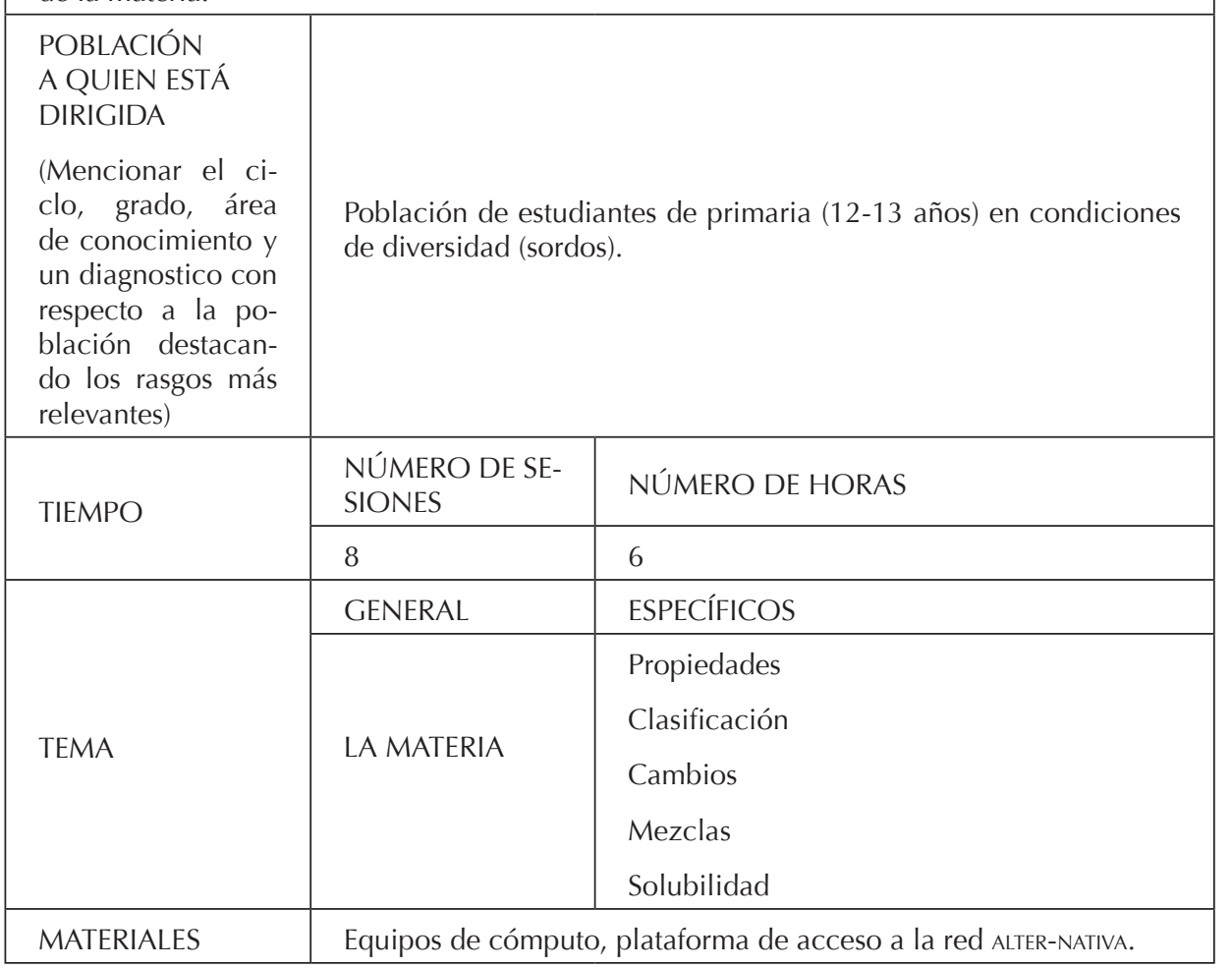




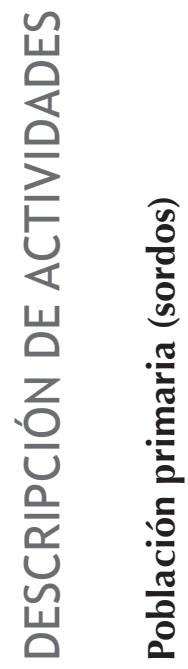

\begin{tabular}{|c|c|c|c|c|}
\hline \multirow{6}{*}{ 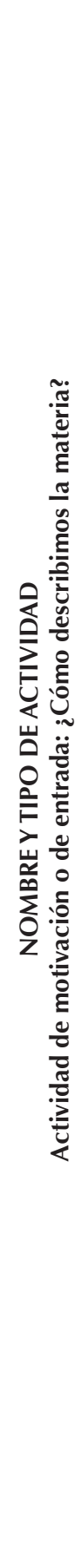 } & \multirow{6}{*}{\multicolumn{2}{|c|}{ 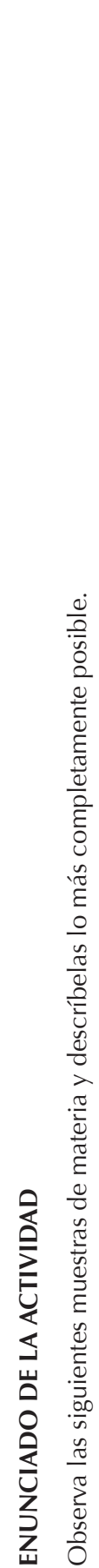 }} & 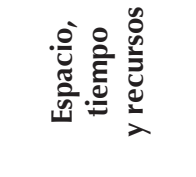 & 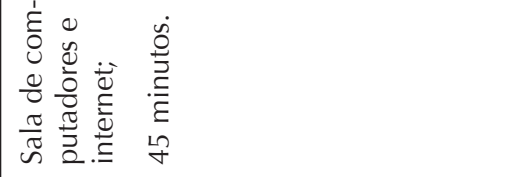 \\
\hline & & & 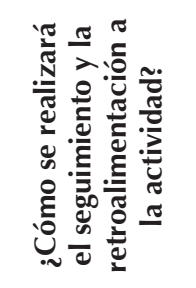 & 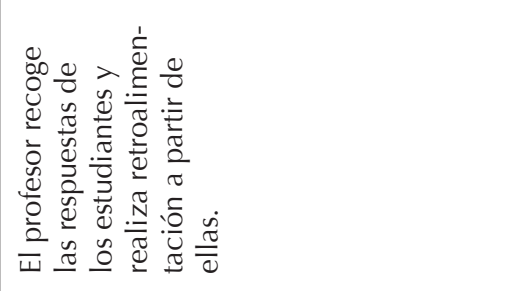 \\
\hline & & & 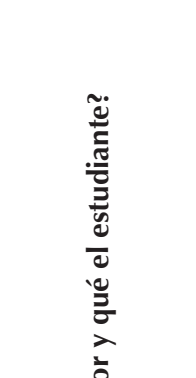 & 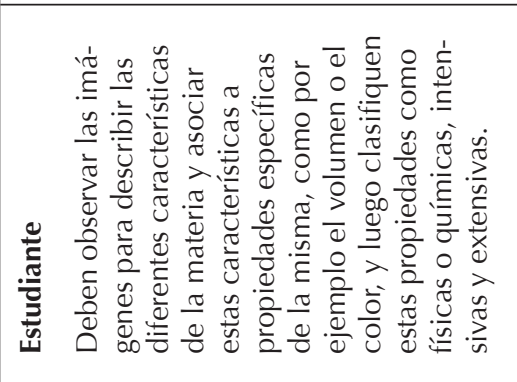 \\
\hline & & & 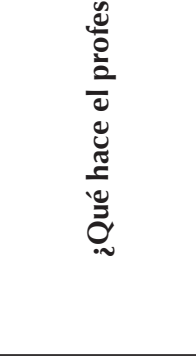 & 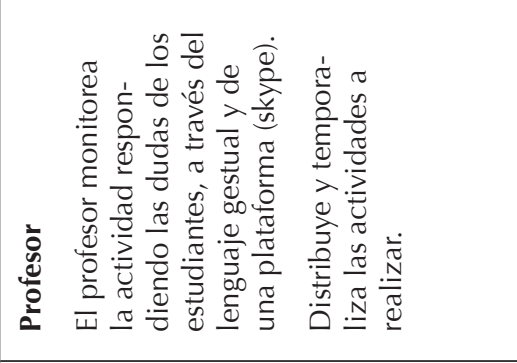 \\
\hline & & & 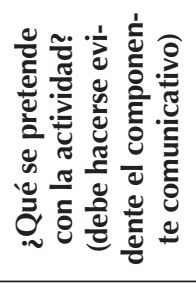 & 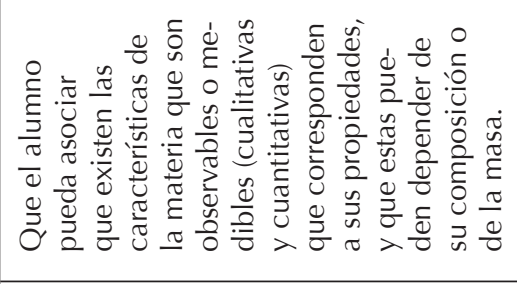 \\
\hline & & & 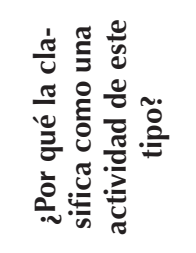 & 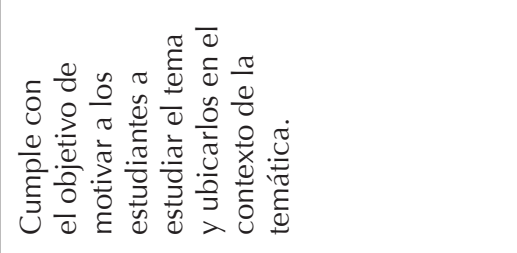 \\
\hline
\end{tabular}




\begin{tabular}{|c|c|c|c|c|}
\hline \multirow{6}{*}{ 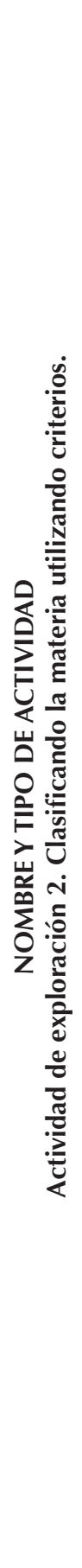 } & \multirow{6}{*}{\multicolumn{2}{|c|}{ 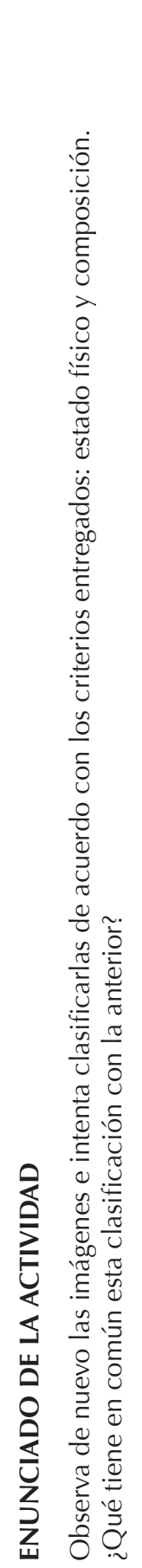 }} & 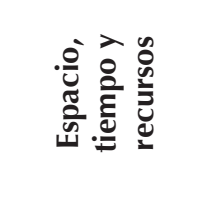 & 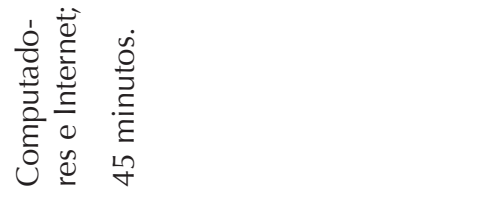 \\
\hline & & & 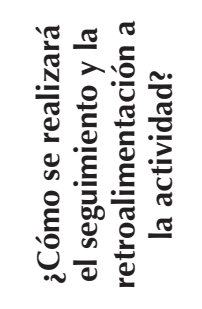 & 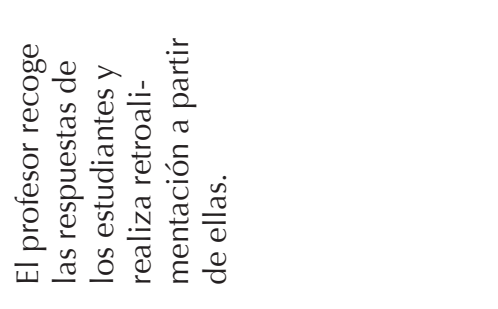 \\
\hline & & & 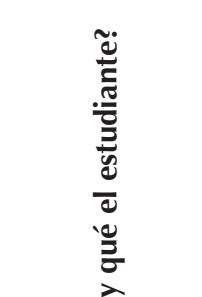 & 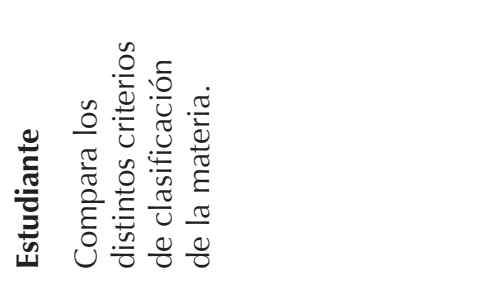 \\
\hline & & & 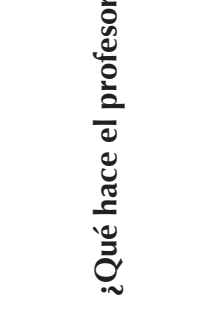 & 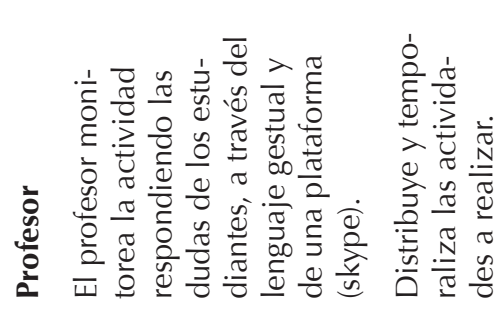 \\
\hline & & & 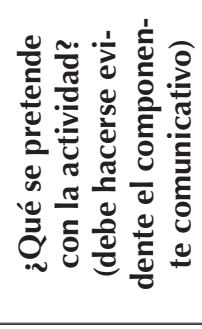 & 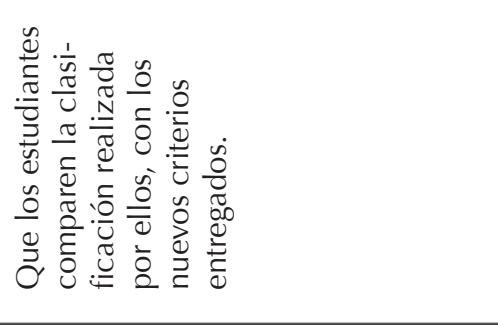 \\
\hline & & & 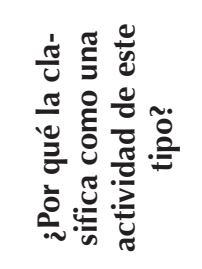 & 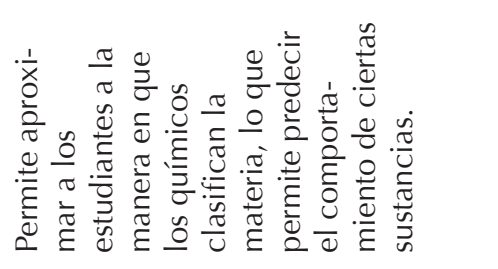 \\
\hline
\end{tabular}




\begin{tabular}{|c|c|c|c|c|}
\hline \multirow{6}{*}{ 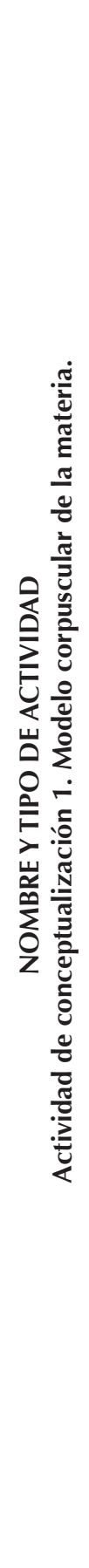 } & \multirow{6}{*}{\multicolumn{2}{|c|}{ 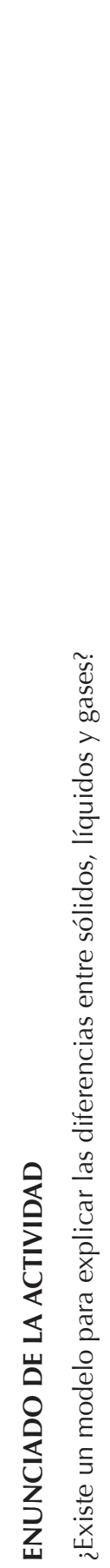 }} & 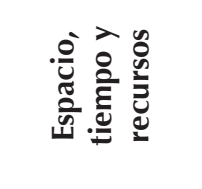 & 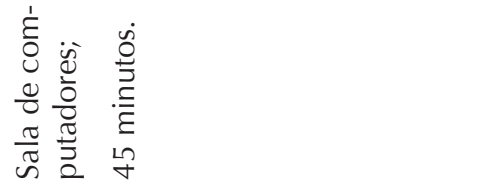 \\
\hline & & & 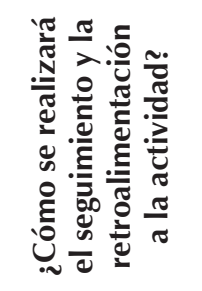 & 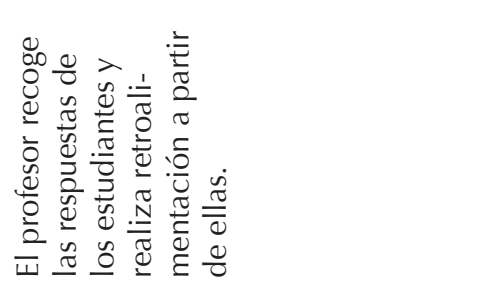 \\
\hline & & & 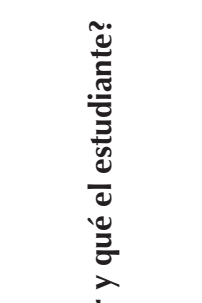 & 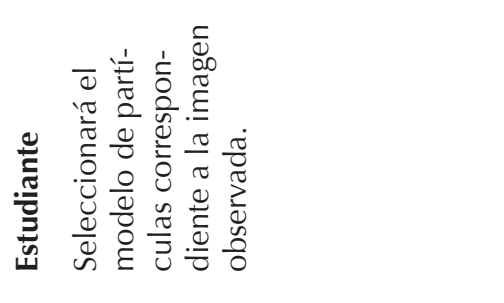 \\
\hline & & & 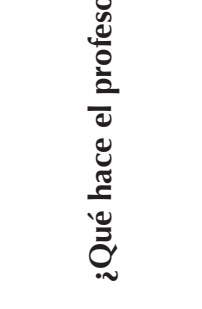 & 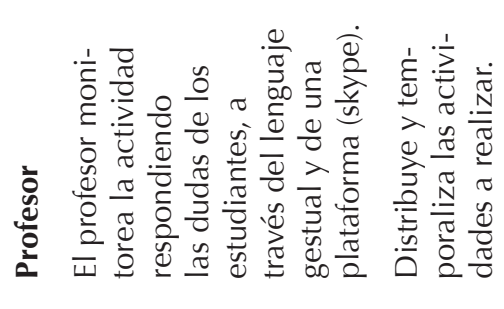 \\
\hline & & & 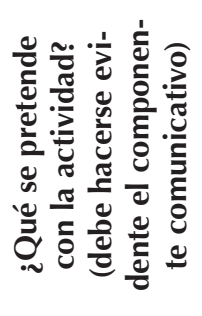 & 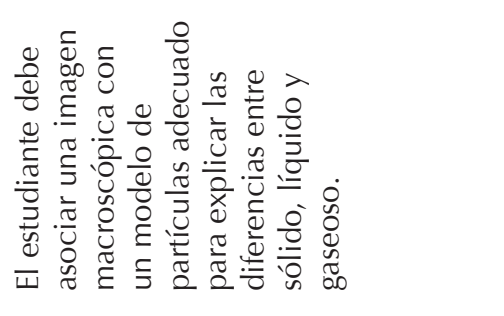 \\
\hline & & & 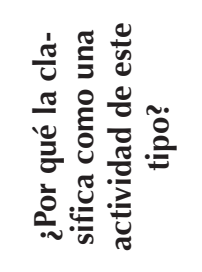 & 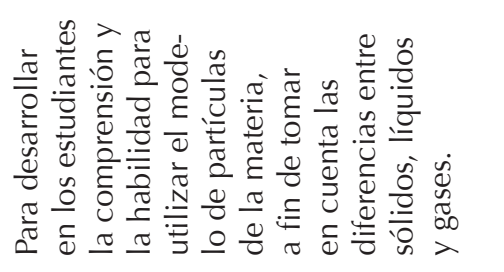 \\
\hline
\end{tabular}




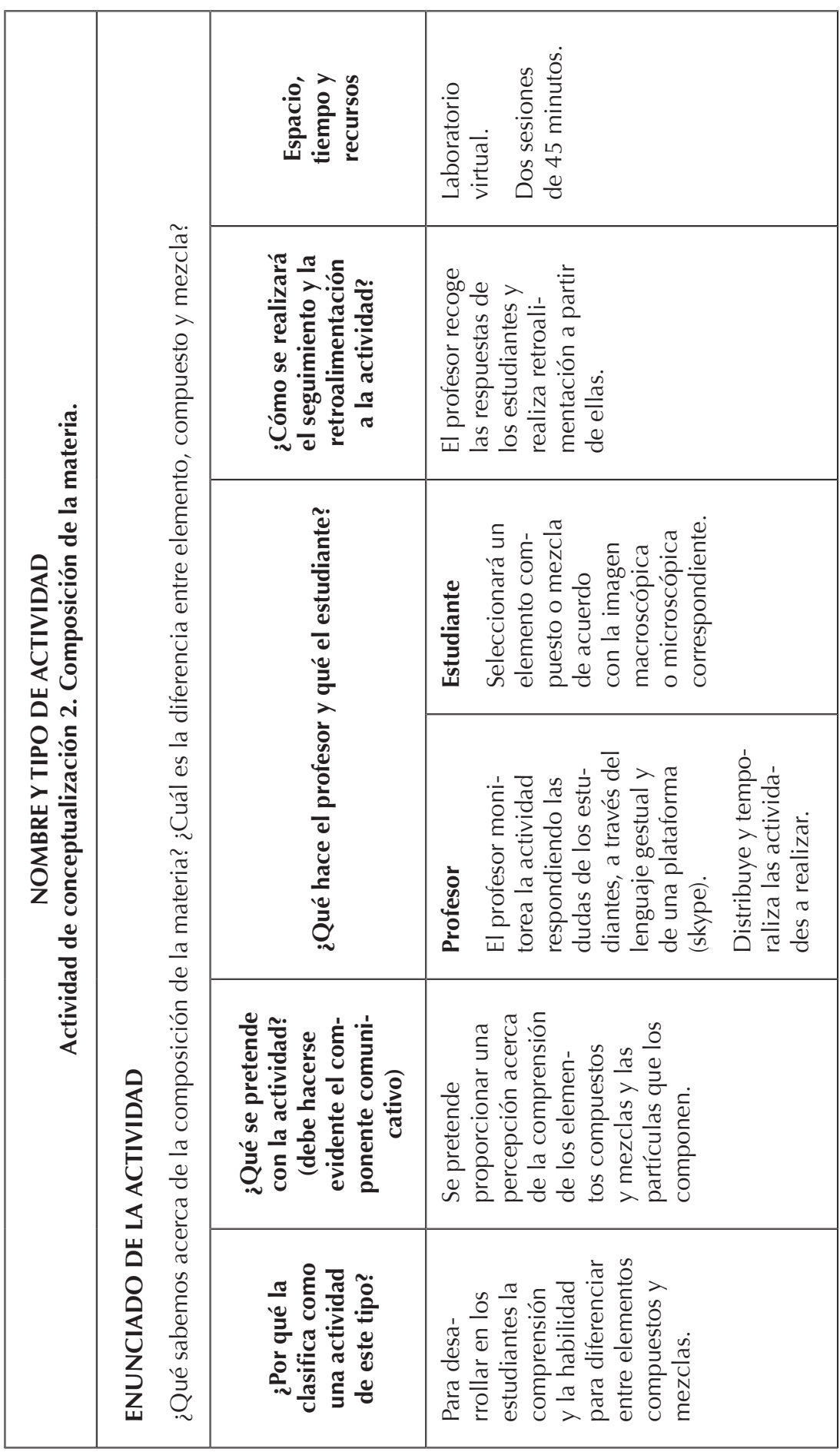




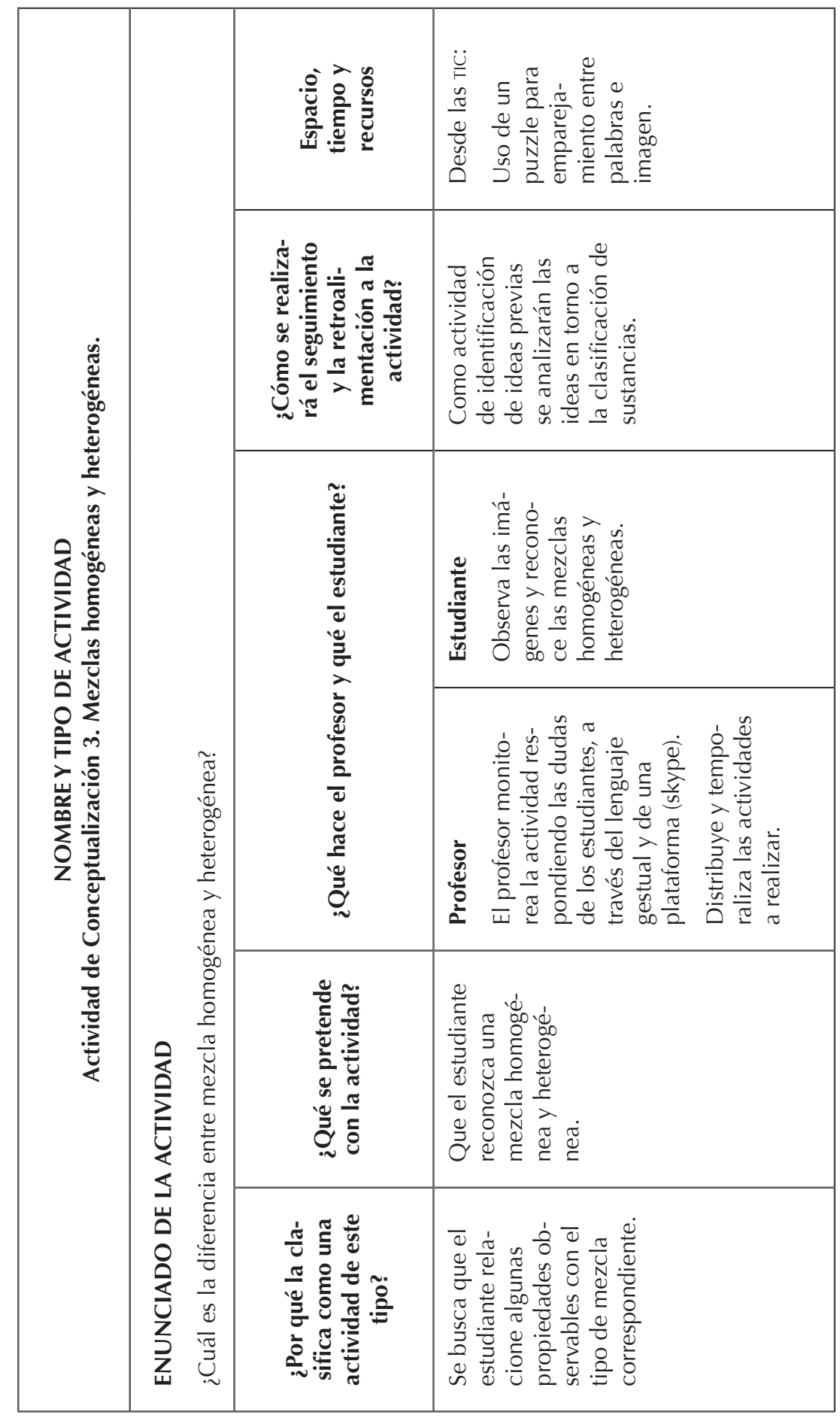




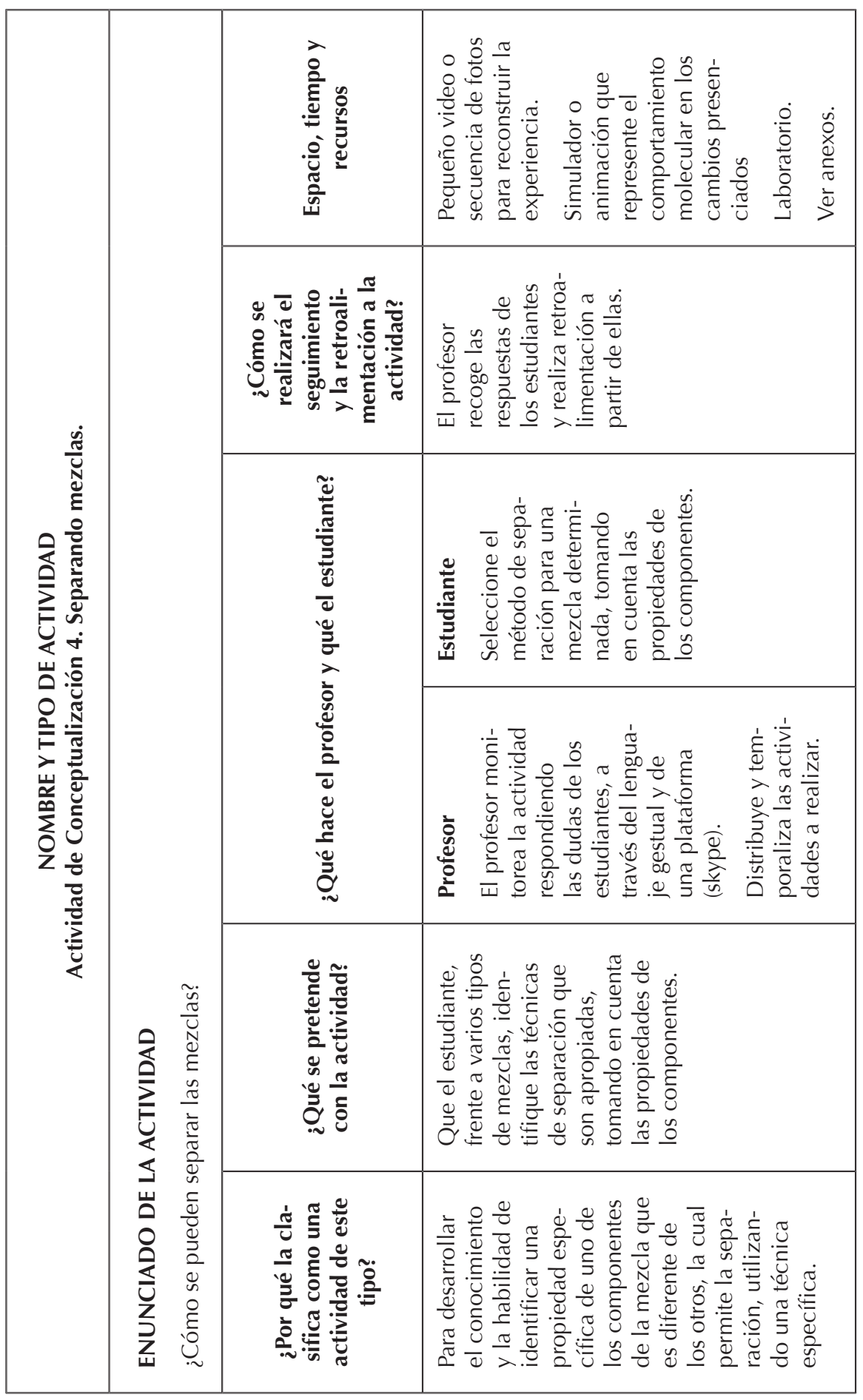




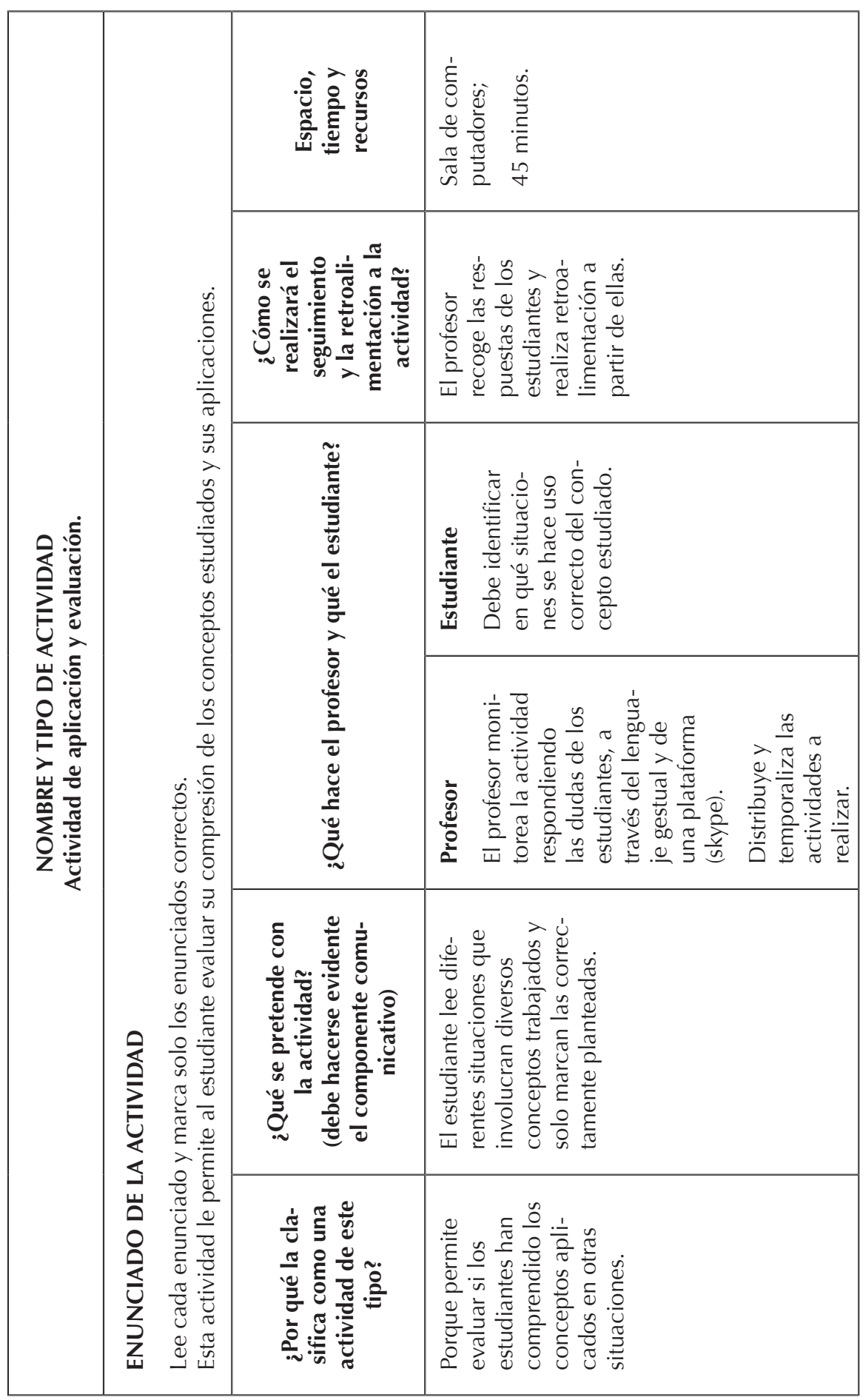




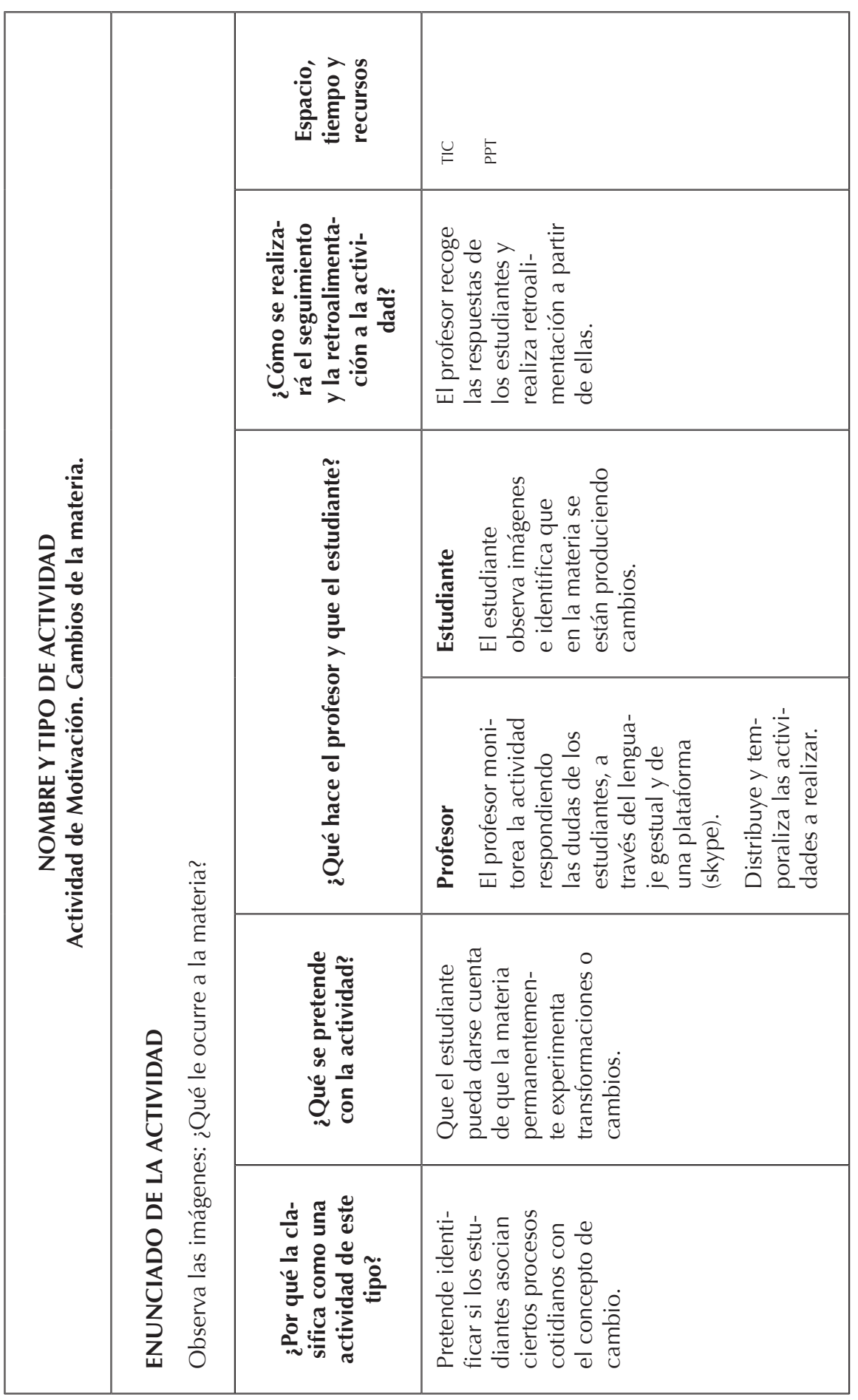




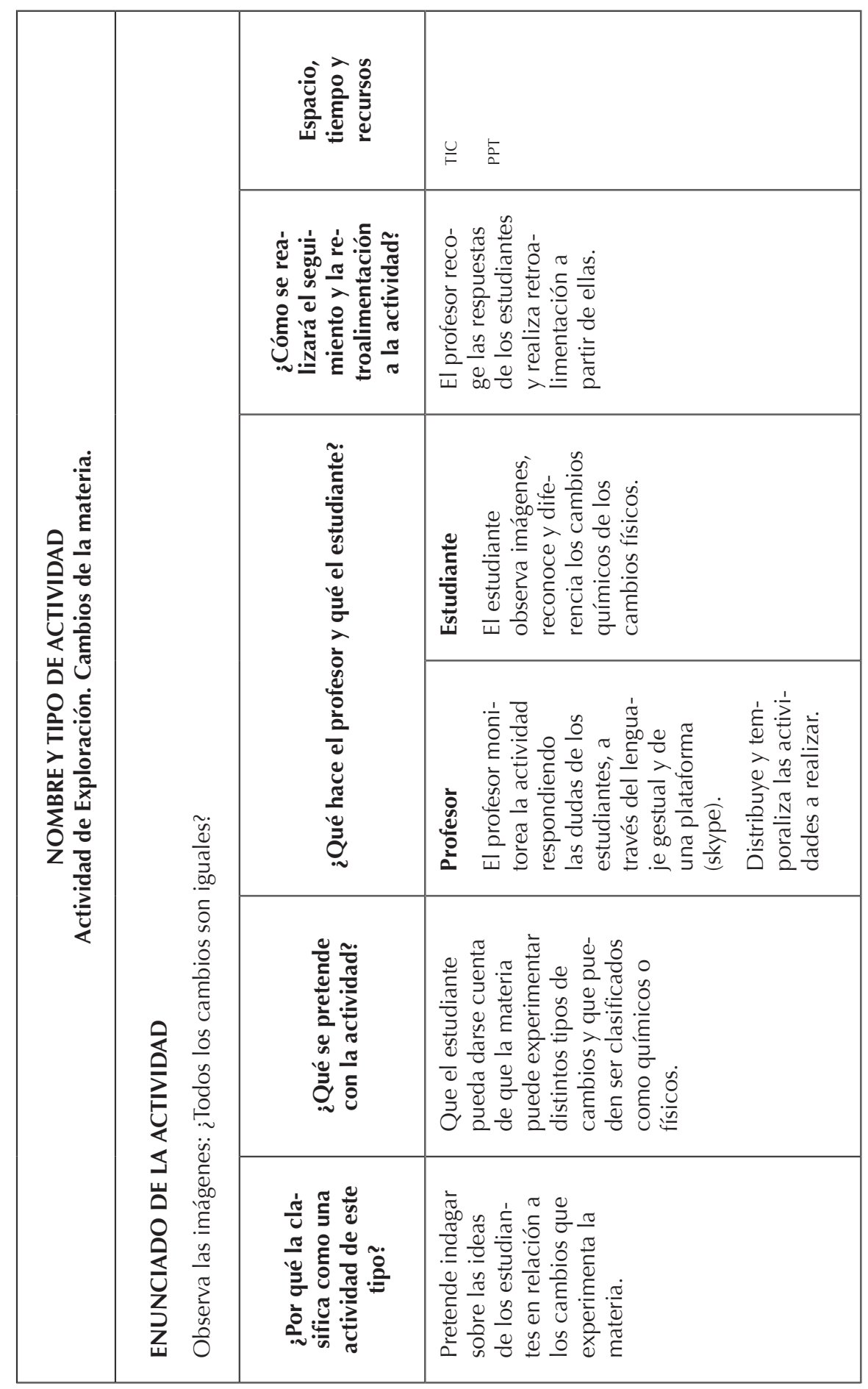




\begin{tabular}{|c|c|c|c|c|}
\hline \multirow{6}{*}{ 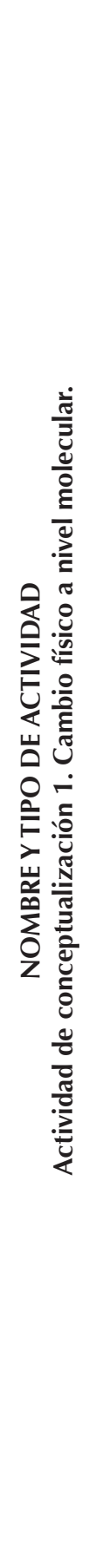 } & \multirow{6}{*}{\multicolumn{2}{|c|}{ 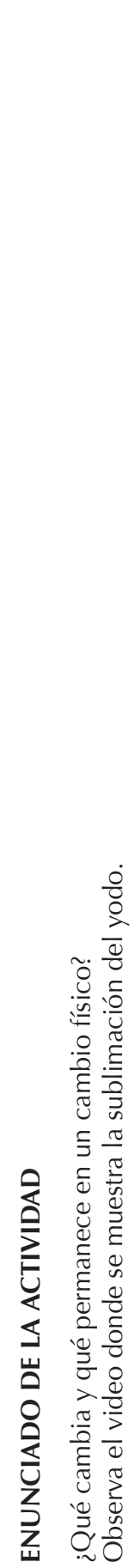 }} & 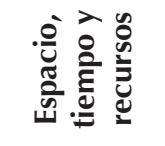 & $\frac{8}{\frac{d}{0}}$ \\
\hline & & & 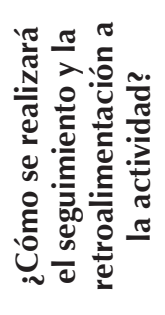 & 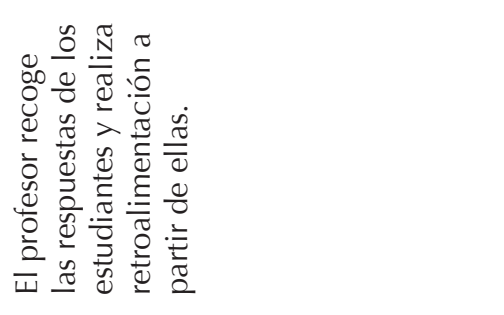 \\
\hline & & & 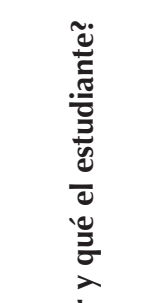 & 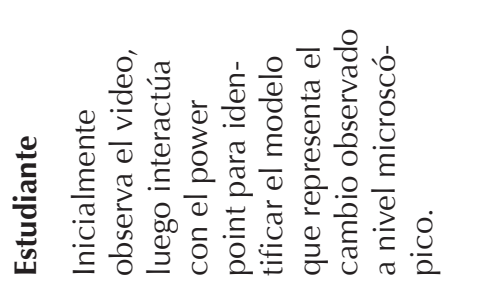 \\
\hline & & & 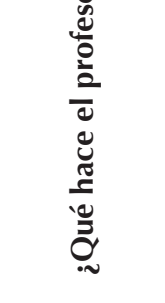 & 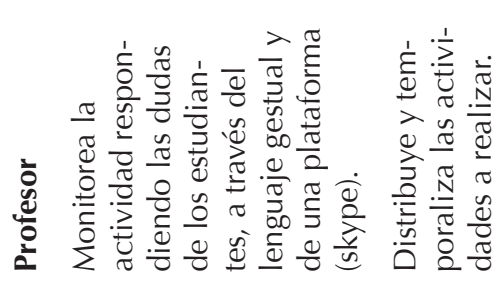 \\
\hline & & & 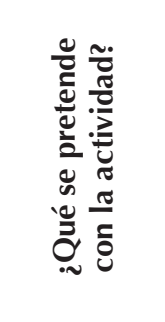 & 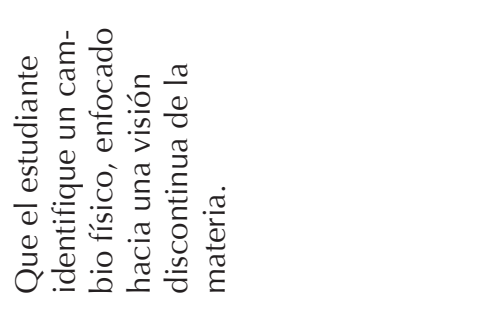 \\
\hline & & & 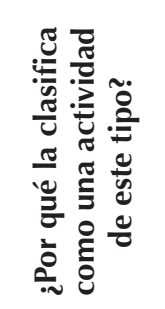 & 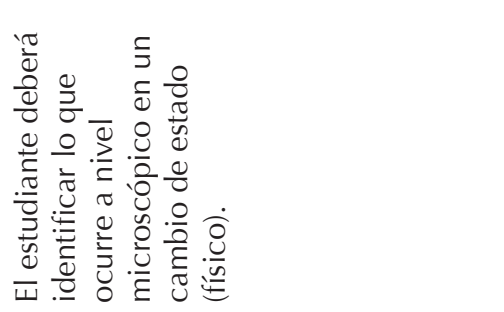 \\
\hline
\end{tabular}




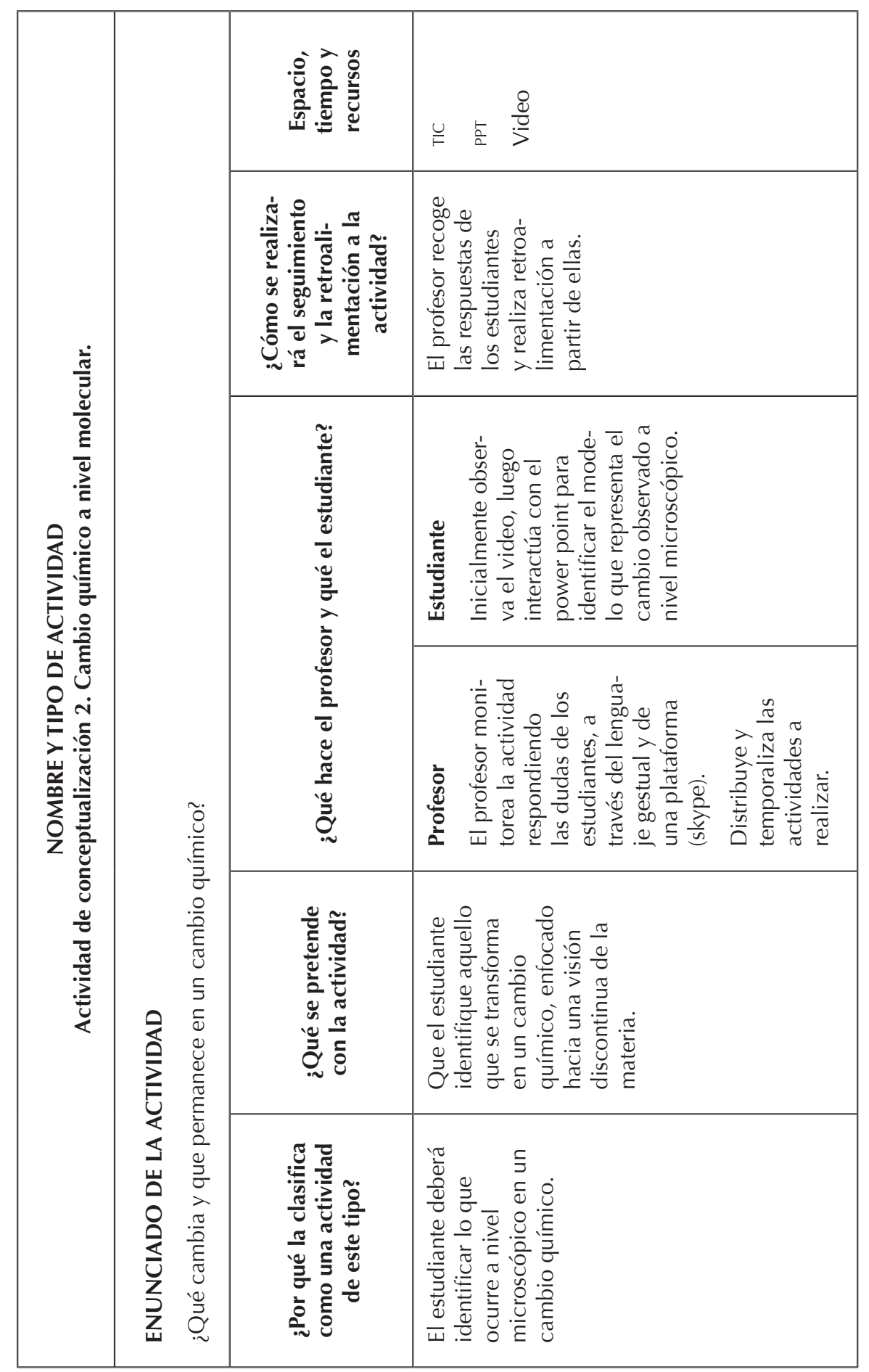




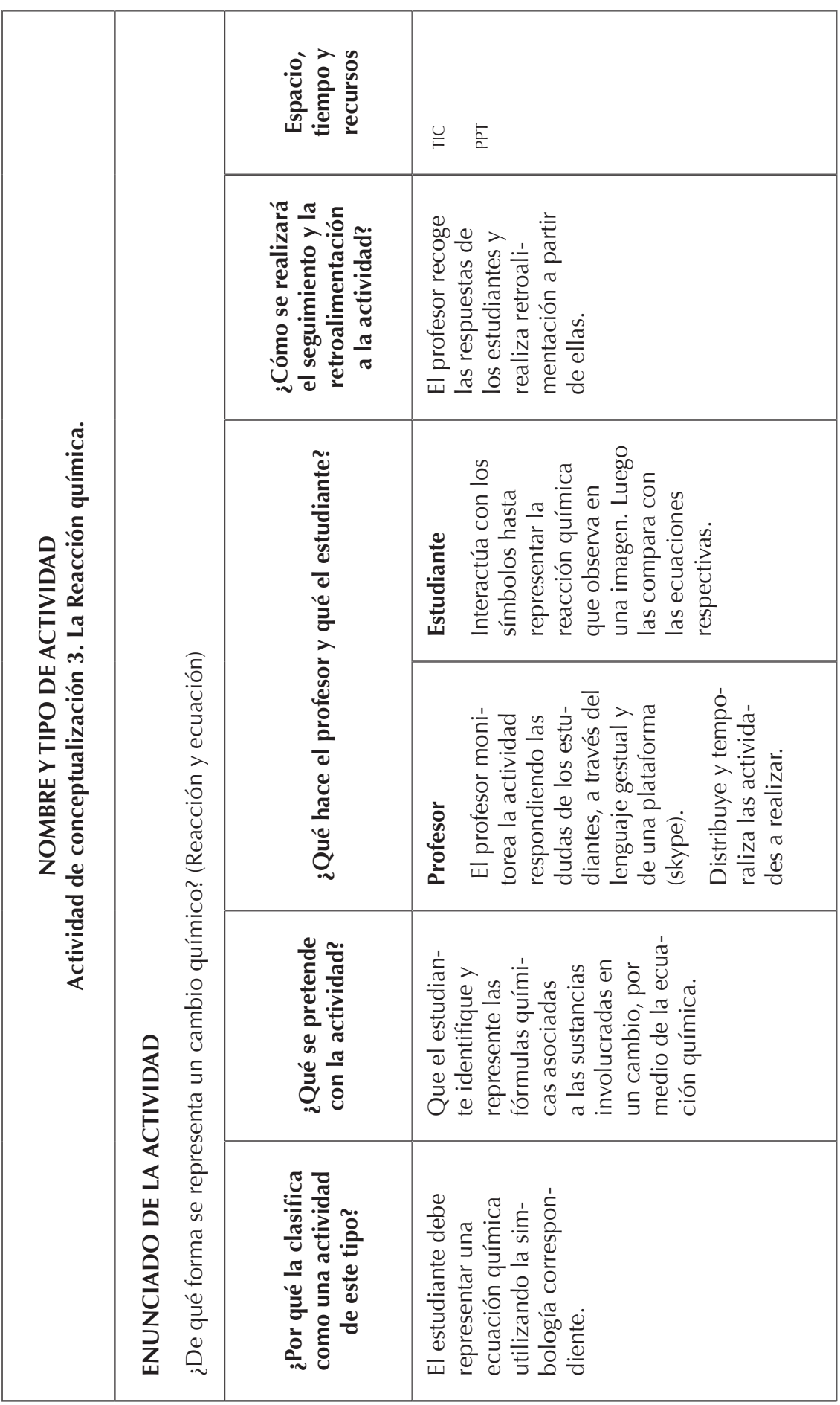




\begin{tabular}{|c|c|c|c|c|}
\hline \multirow{6}{*}{ 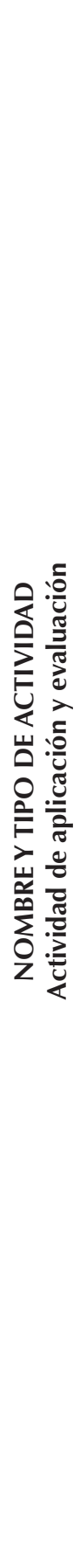 } & \multirow{6}{*}{\multicolumn{2}{|c|}{ 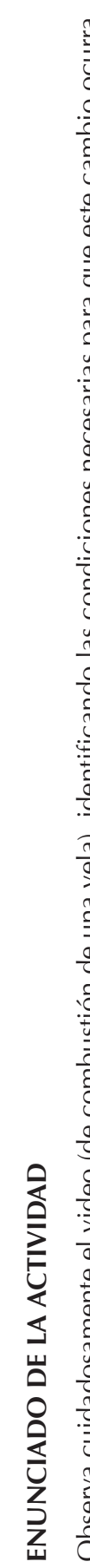 }} & 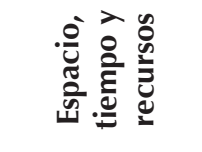 & $\frac{8}{\frac{d}{0}}$ \\
\hline & & & 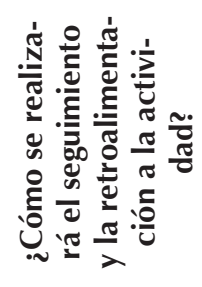 & 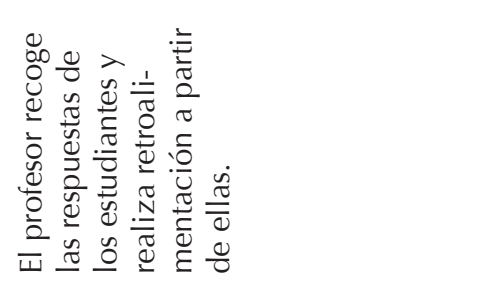 \\
\hline & & & 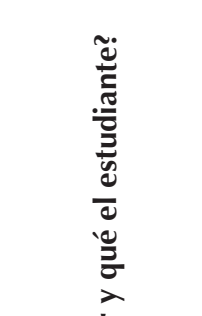 & 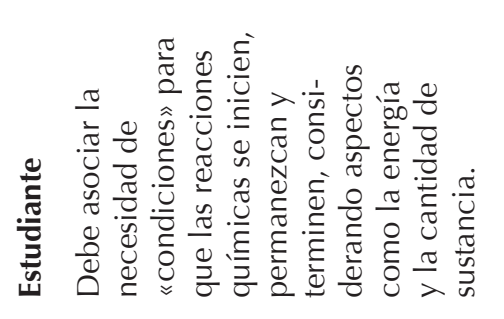 \\
\hline & & & 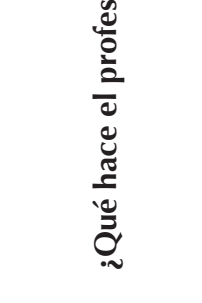 & 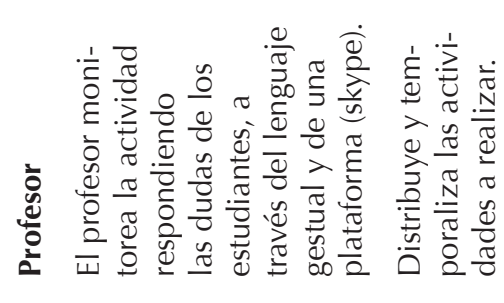 \\
\hline & & & 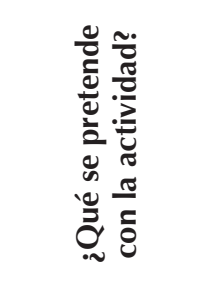 & 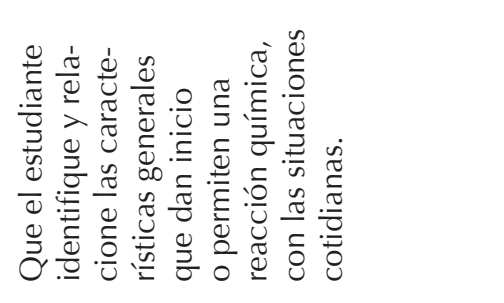 \\
\hline & & & 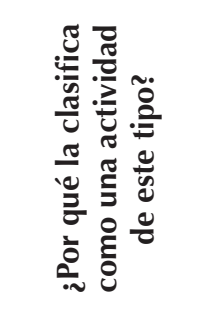 & 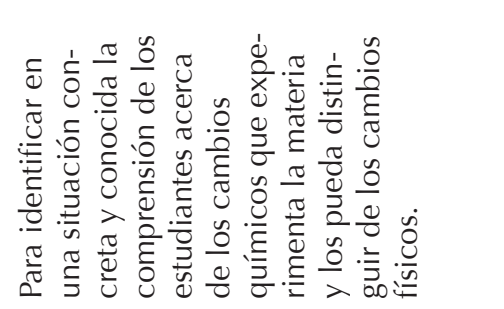 \\
\hline
\end{tabular}




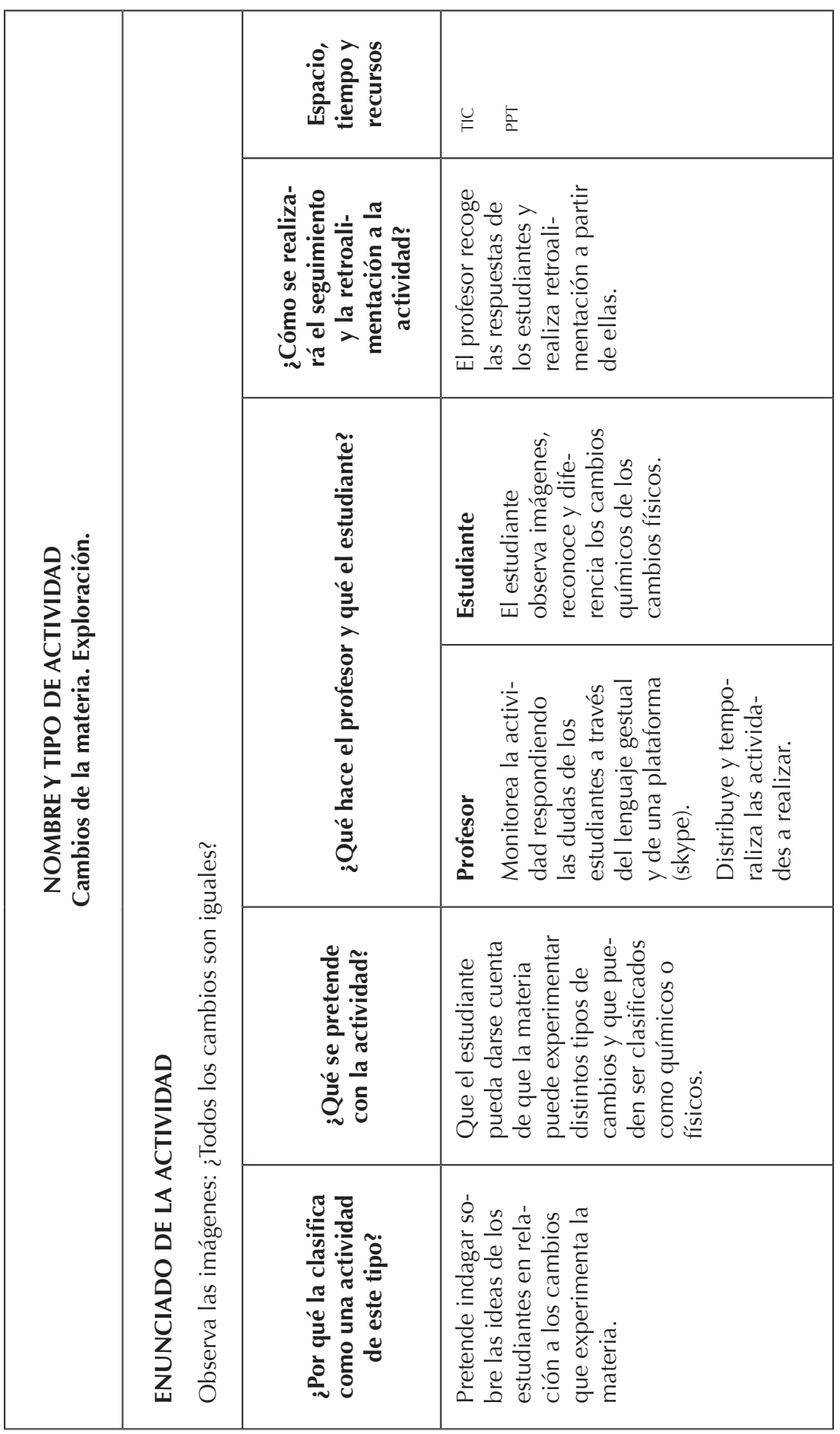




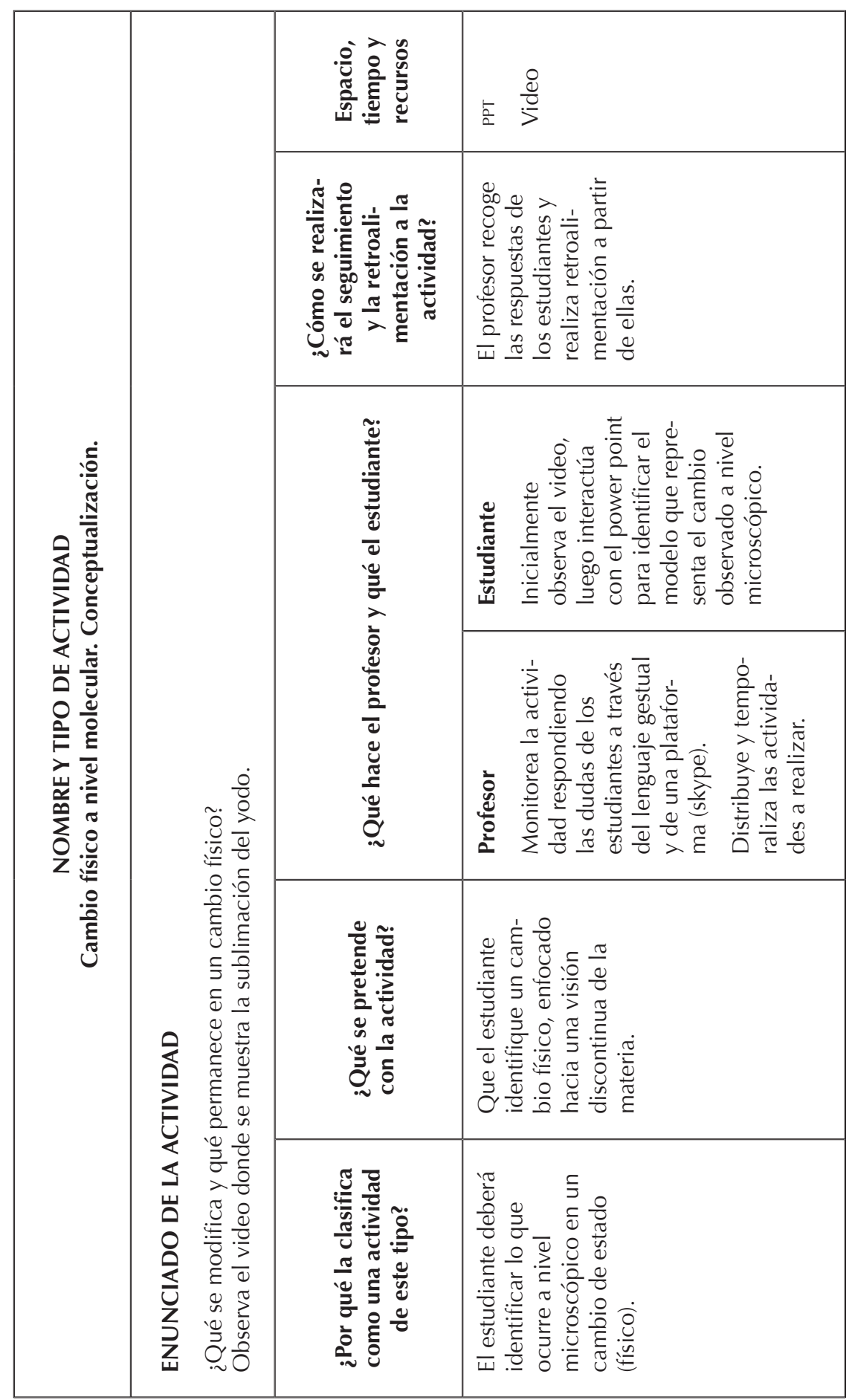




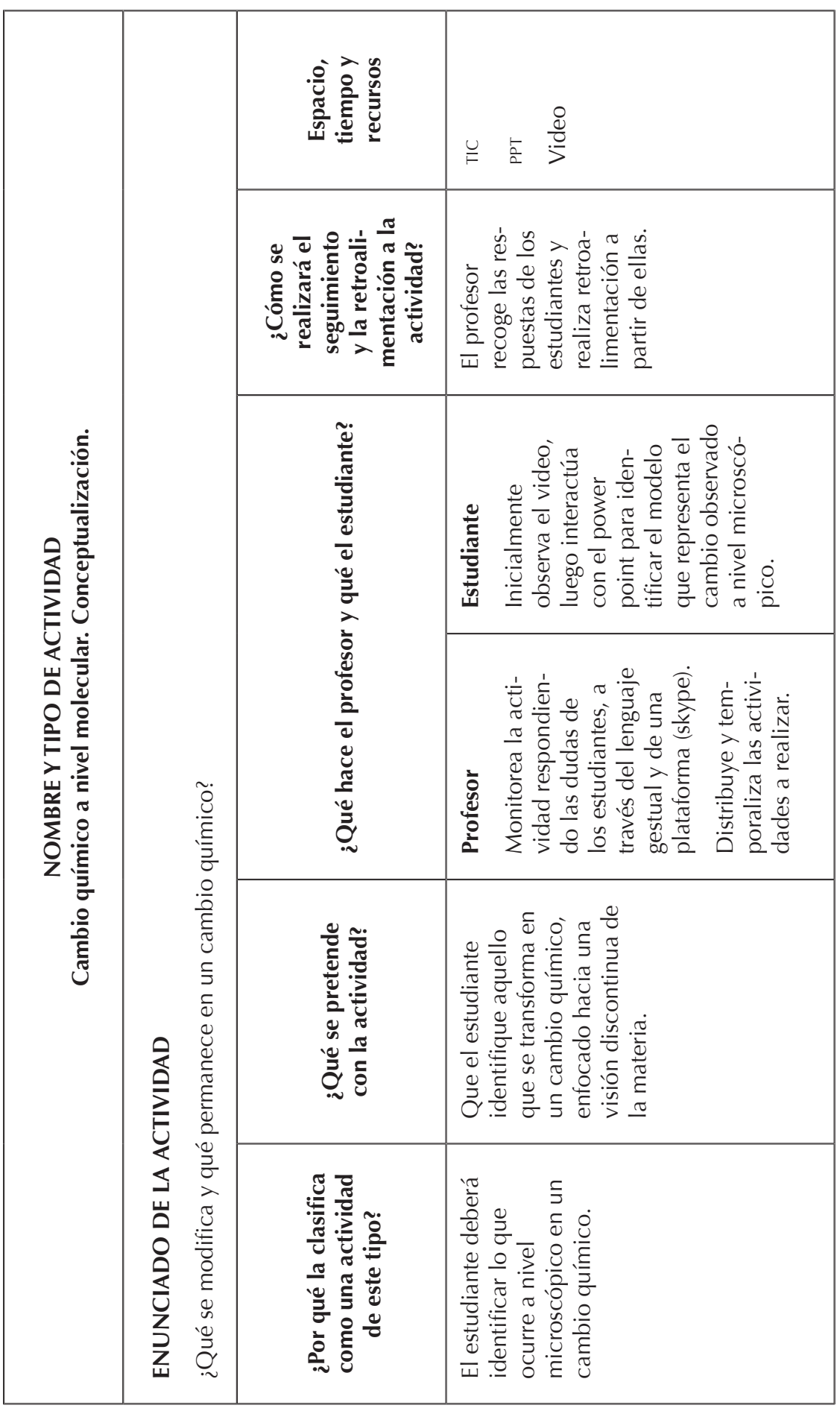




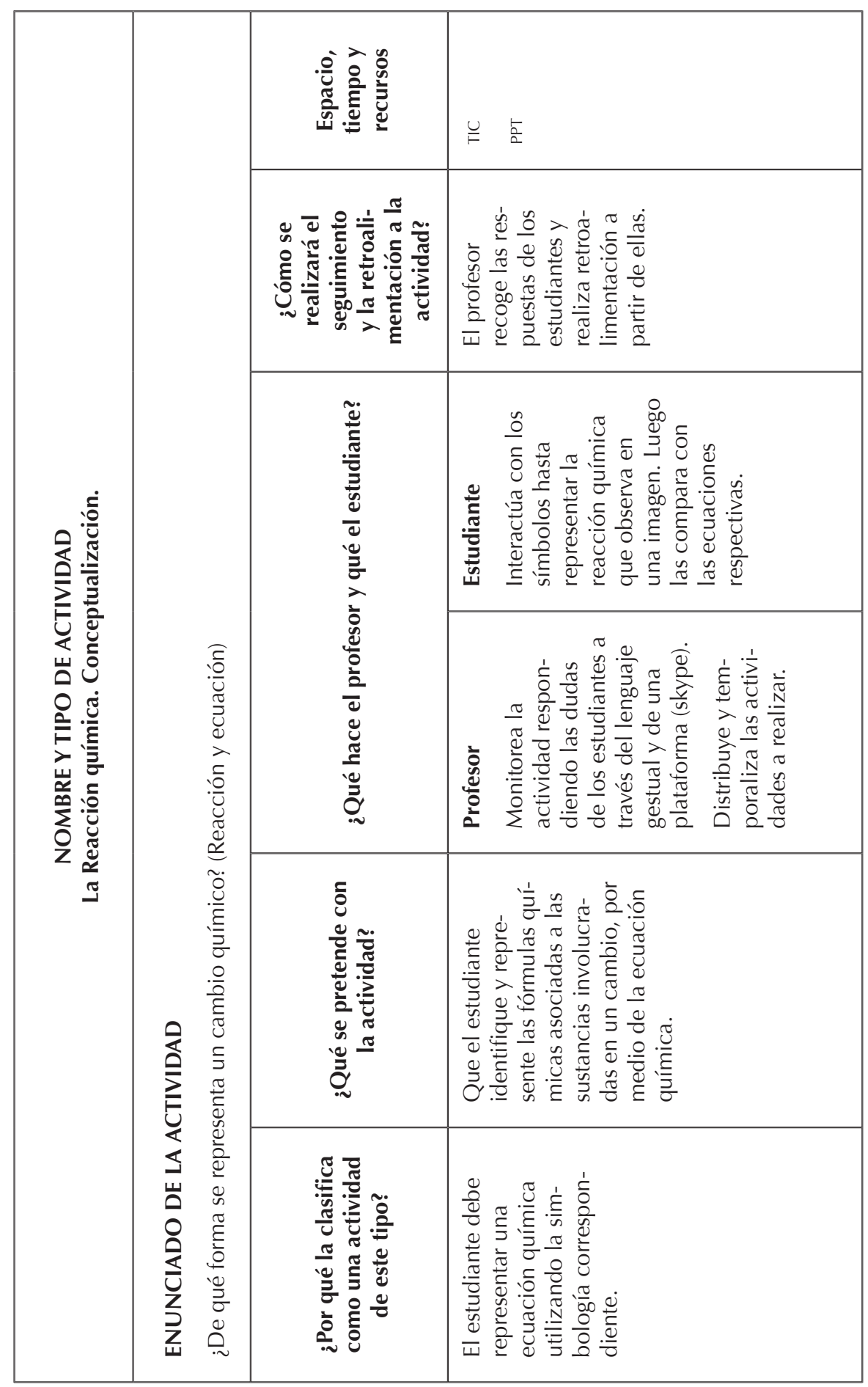




\begin{tabular}{|c|c|c|c|c|}
\hline \multirow{6}{*}{ 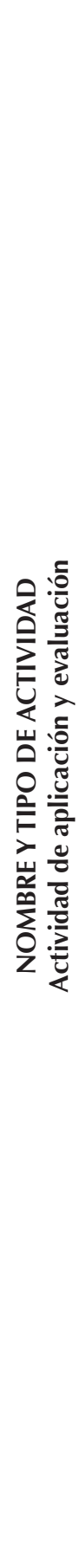 } & \multirow{6}{*}{. } & \multirow{6}{*}{ 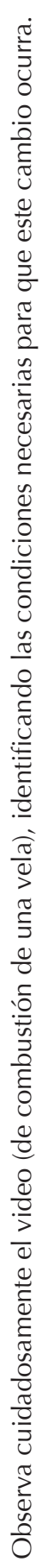 } & 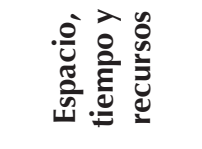 & $\frac{8}{\frac{8}{8}}$ \\
\hline & & & 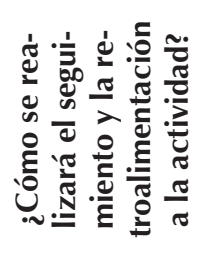 & 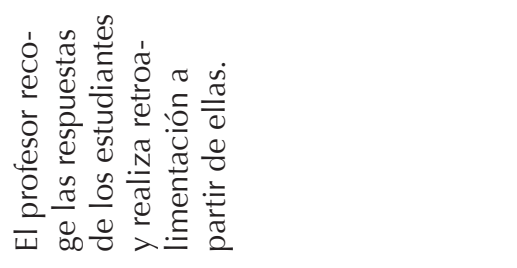 \\
\hline & & & 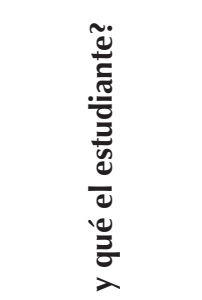 & 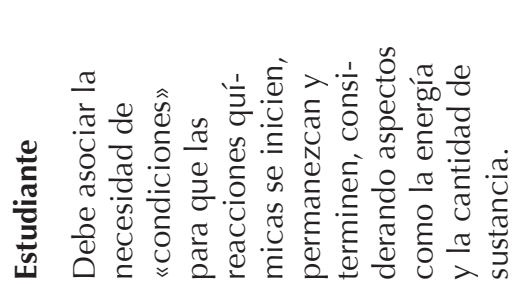 \\
\hline & & & 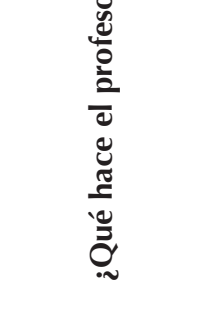 & 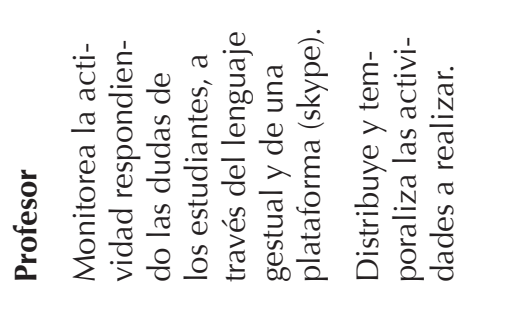 \\
\hline & & & 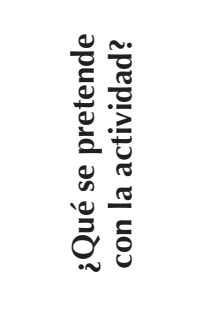 & 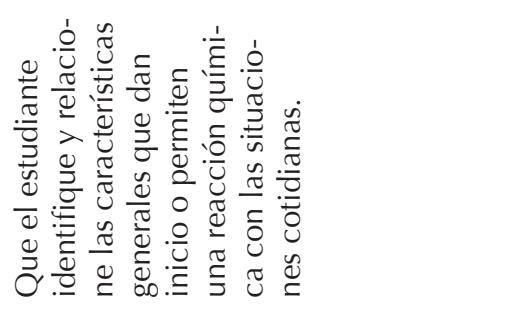 \\
\hline & & & 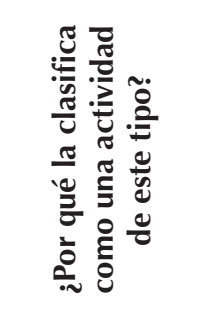 & 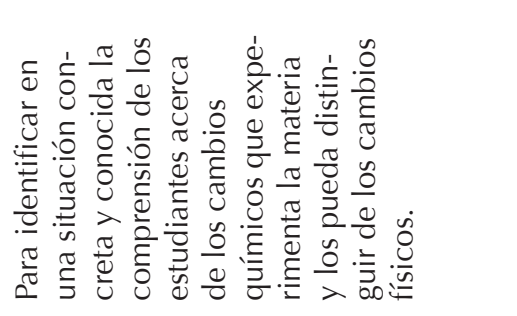 \\
\hline
\end{tabular}


Finalmente, queremos reiterar que para la incorporación de las TIC en procesos de formación de profesores de ciencias naturales en contextos de diversidad, en el marco del reconocimiento de la existencia de una ciencia escolar, no podemos dejar de lado los modelos teóricos de las disciplinas científicas, que dan cuenta del funcionamiento del mundo (Rodríguez et al., 2011), ya que ellos funcionan como referentes para la planificación de las estrategias didácticas, tal como se ha intentado mostrar en los ejemplos anteriores. 


\section{Referencias}

Abell, S. K. \& Lederman, N. G. (2007). Handbook of Research on Science Education. New Jersey: Lawrence Erlbaum Associates.

Allal, L. (1991). Vers une pratique de l'évaluation formative. Bruxelles: De BoeckWesmael.

Alter-Nativa (2012). alter-nativa: Referentes Curriculares con incorporación Tecnológica para Facultades de Educación en las áreas de Lenguaje, Matemáticas y Ciencias, para atender Poblaciones en Contextos de Diversidad. Comisión Europea-Universidad Distrital Francisco José de Caldas, con Referencia DCIALA/19.09.01/10/21526/245-575/ALFAIII.

Anthony, A. B. \& Clark, L. M. (2011). Examining Dilemmas of Practice Associated With the Integration of Technology Into Mathematics Classrooms Serving Urban Students. Urban Education, 46(6), pp. 1300-1331. DOI:10.1177/0042085911416015

Arévalo, I., Pardo, K. \& Vigil, N. (2006). Enseñanza de castellano como segunda lengua en las escuelas EBI del Perú. Perú: Dirección Nacional de Educación Bilingüe Intercultural.

Blanco, R. (1999). Hacia una escuela para todos y con todos. En Proyecto Principal de Educación en América Latina y el Caribe, Boletín 48, pp. 55-72. Santiago de Chile: unESCO-ORELAC. Consultado en:

http://unesdoc.unesco.org/images/0011/001161/116194s.pdf\#page=54

Becerra, C. (2012). Estudiantes indígenas y los usos y apropiación de las tecnologías de información y comunicación. En: Paakat Revista de Tecnología y Sociedad. Año 2, Número 3, septiembre-diciembre. http://www.udgvirtual.udg.mx/ paakat/index.php/paakat/article/view/180/252

Calderón, D. (2005). Dimensión cognitiva y comunicativa de la argumentación en matemáticas. Tesis Doctoral. Cali: Universidad del Valle.

Calderón, D. I. \& León, O. L. (2010). Desarrollo de competencia comunicativa en matemática con estudiantes sordos. Bogotá D.C.: Colciencias-Universidad Distrital Francisco José de Caldas. 
Camargo, E. (2010). A comunicação como barreira à inclusão de alunos com deficiência visual em aulas de mecânica. Em: Ciência \& Educação, 16(1), pp. 259-275 (FLOR).

Camargo, E. \& Da Silva, D. (2006). O ensino de física no contexto da deficiência visual: análise de uma atividade estruturada sobre um evento sonoro-posição de encontro de dois móveis, Em: Ciência e Educação, 12(2), pp. 155-169.

Cochran-Smith, M. (1991). Learning to teach against the grain. In: Harvard Educational Review, 61(3), pp. 279-310.

Cochran-Smith, M., Feiman-Nemser, S., Mclntyre, D. \& Demers, K. (2008). Handbook of Research on Teacher Education: Enduring Questions in Changing Contexts. New York: Routledge-Taylor and Francis.

Costa, L., Neves, D. \& Barone, D. (2006). O ensino de física para deficientes visuais a partir de uma perspectiva fenomenológica. Em: Ciência E Educação, 12(2), pp. 143-153.

Couso, D. (2002). Análisis del contenido del discurso de los profesores de ciencias de secundaria en el diseño de unidades didácticas de forma cooperativa. Tesina de Maestría. Barcelona: Universitat Autònoma de Barcelona.

Fernández, M. (1999). Evaluación y cambio educativo: Análisis cualitativo del fracaso escolar. Madrid: Morata.

Fraser, B. \& Tobin, K. G. (1998). International Handbook of Science Education. London: Kluwer Academic Publisher.

Gabel, D. (1994). Handbook of Research on Science Teaching and Learning. New York: MacMillan Pub.

García-Martínez, A. (2009). Aportes de la Historia de la Ciencia al Desarrollo Profesional de Profesores de Química. Tesis de Doctorado. Barcleona: Departament de Didáctica de la Matemática i les Ciències Experimentals, de la Facultat de Ciències de l'Educació de la Autònoma de Barcelona.

García-Martínez, A., Hernández, R. \& Abella, L. (En prensa). El diseño de unidades didácticas: de la planificación a la acción.

García-Martínez, A. \& Izquierdo Aymerich, M. (2014). Contribución de la Historia de las Ciencias al desarrollo profesional de docentes universitarios. En: Enseñanza de las Ciencias, 32(1), pp. 265-281. 
García-Martínez, A., Merino, C., Rodríguez-Pineda, D., Hernández, R., Flores, M., Molina, A. \& Mosquera, J. (En prensa). Referentes curriculares con incorporación tecnológica para la formación de profesores en el área de Ciencias Naturales para atender poblaciones en contextos de diversidad. México: Universidad Pedagógica Nacional y Universidad Distrital Francisco José de Caldas. Comunidad Europea, ALFA III.

Gil, D., Furió, C. \& Gavidia, V. (1998). El profesorado y la reforma educativa en España. En: Investigación en la Escuela, 36, pp. 49-63.

Hernández, R. (2011). El diseño de una Unidad Didáctica: un ejercicio docente de continua reflexión. En: Revista Entre Comillas. Facultad de Educación, Ciencias Empresariales y Ciencias Aplicadas. 14, pp. 81-92.

Hernández, I. \& Calcagno, S. (2003). Los pueblos indígenas y la sociedad de la información. Revista Argentina de Sociología, 1(1), pp. 110-143. Disponible en: http://lanic.utexas.edu/project/etext/lilas/claspo/workingpapers/indigenas.pdf

Hewson, P. W. (2007). Teacher professional development in science. In: S. K. Abell \& N. G. Lederman (Eds.). Handbook of Research on Science Education (pp. 1177-1203). New Jersey: Lawrence Erlbaum Associates.

Izquierdo, M. (2005). Hacia una teoría de los contenidos escolares. Enseñanza de las Ciencias, 23(1), pp. 111-122.

Izquierdo, M. \& Aduriz-Bravo, A. (2003). Epistemological foundations of school science. In: Science \& Education, 12(1), pp. 27-43.

mineduc (2011). Competencias y Estándares tIC para la Profesión Docente. Red Enlace. Chile: Ministerio de Educación de Chile. Disponible en: http://www. enlaces.cl/libros/docentes/index.html

Marx, R. W., Freeman, J. G., Krajcik, J. S. \& Blumenfeld, P. C. (1998). Professional development of science teachers. In: B. J. Fraser \& K. G. Tobin (Ed.). International Handbook of Science Education (pp. 667-680). London: Kluwer Academic Publishers.

Merino, C., Contreras, D. \& Borja, M. (Ed.) (2013). Orientaciones específicas para la incorporación de tecnología en procesos de Formación de Profesores de Ciencias Naturales, Lenguaje y Comunicación, y Matemáticas en contextos de diversidad para el diseño de secuencias de enseñanza aprendizaje. Valparaíso: Pontificia Universidad Católica de Valparaíso, Universidad Distrital Francisco José de Caldas. Comunidad Europea, ALFA III. 
Mosquera, C. J. y Furió, C. J. (2008). El cambio didáctico en profesores universitarios de química a través de un programa de actividades basado en la enseñanza por investigación orientada. En: Revista Didáctica de las Ciencias Experimentales y Sociales, 22, pp. 115-154.

Perafán, G. (2005). Epistemología del profesor de ciencias sobre su propio conocimiento profesional. En: Enseñanza de las ciencias. Número extra, pp. 1-4. vII Congreso Internacional sobre Investigación en Didáctica de las Ciencias.

Pérez, A. (1998). La evaluación en el nuevo sistema educativo. En: A. Medina, J. Cardona, S. Castillo \& M. C. Domínguez (Coords.). Evaluación de los procesos y resultados del aprendizaje de los estudiantes (pp. 55-82). Madrid: UNED.

Perales, F. \& Cañal, P. (Coord.) (2000). Didáctica de las Ciencias Experimentales. España: Editorial Marfil.

Quero, S. \& Madueño, L. (2006). Süchiki Walekerü: un ejemplo del uso de las TIC en escuelas indígenas, caso Wayuu. En: Educere, 10(34), julio-septiembre, pp. 435-442.

Rodríguez, D. P., Izquierdo, M. \& López, D. M. (2011). ¿Por qué y para qué enseñar ciencias? En: A. D. López-Mota \& M. T. Guerra (Coord.). Las ciencias naturales en educación básica: formación de ciudadanos para el siglo xxı (pp. 7-33). México.

Sánchez, G. \& Valcárcel, M. V. (1993). Diseño de Unidades Didácticas en el Área de Ciencias Experimentales. En: Enseñanza de las Ciencias, 11(1), pp. 33-44.

Sanmartí, N. (2002). Didáctica de las ciencias en la educación secundaria obligatoria. Madrid: Editorial Síntesis Educación.

Santos, M. A. \& De la Rosa, L. (2009). Evaluación y discapacidad. De la concepción técnica a la dimensión crítica. En: Revista de Educación Inclusiva, 2(1), pp. 123-140.

Schön, D. A. (1992). La formación de profesionales reflexivos. Hacia un nuevo diseño de la enseñanza y el aprendizaje de las profesiones. Barcelona: Paidós.

Shulman, L. S. (1986). Those who understand: knowledge growth in Teaching. In: Educational Research, 15(2), pp. 4-14.

Simon, S. \& Campbell, S. (2011). Teacher Learning and professional development in science education. In: B. J. Fraser, K. G. Tobin \& C. J. McRobbie (Eds.). Second International Handbook of Science Education (pp. 307 - 321). London: Springer. 
SITEAL, (2010). Metas educativas 2021: desafíos y oportunidades. Buenos Aires. Disponible en: http://www.siteal.iipe-oei.org/informe_2010

Torres, D. (2009). Kofotecnología. En: Memorias del Congreso Internacional TIC_ disCapacidad CITICA 09. Fundación FREE. Red Especial Iberoamericana para la Cooperación en Educación Especial y Tecnología Adaptativa. México, DF: Instituto Tecnológico de Estudios Superiores de Monterrey campus Ciudad de México.

unESCO (2000). Contacto. Boletín Internacional de la unESCO de Educación Científica, Tecnológica y Ambiental, 25 (pp. 3-4). Disponible en: http://unesdoc. unesco.org/images/0014/001462/146293s.pdf

UNESCO (2005). ¿Cómo promover el interés por la cultura científica?. Una propuesta didáctica fundamentada. Santiago de Chile: OREAL.

Valcárcel, M. V. \& Sánchez, G. (2000). La formación del profesorado en ejercicio. En: F. Perales \& P. Cañal (Coord.). Didáctica de las Ciencias Experimentales (pp. 557-581). España: Editorial Marfil.

Van Driel, J. H., Beijaard, D. \& Verloop, N. (2001). Professional development and reform in science education: The role of teachers' practical knowledge. In: Journal of Research in Science Education, 38(2), pp. 137-158.

Vergel, R., Rocha., P. \& León, O. (2006). El juego, la resolución de problemas y el proyecto de aula como dispositivos en las didácticas de la matemática y de la estadística. Bogotá: Universidad Distrital Francisco José de Caldas.

Wenger, E. (2001). Comunidades de práctica: aprendizaje, significado e identidad. Barcelona: Paidós 


\section{Alvaro García Martínez}

Licenciado en Química, Universidad Distrital Francisco José de Caldas. Magister en Docencia de la Química, Universidad Pedagógica Nacional. Magister en Investigación en Didáctica de las Ciencias Experimentales y Doctor en Didáctica de las Ciencias Experimentales y las Matemáticas, Universidad Autónoma de Barcelona. Ha desarrollado investigaciones con recursos de financiamiento externo, entre ellas: Unión Europea, CONICYT (Chile), COLCIENCIAS, IDEP y Secretaría de Educación de Bogotá. Es Miembro fundador del Grupo de Investigación en Didáctica de la Química, DIDAQUIM, Director del Grupo de Investigación en Educación en Ciencias Experimentales, GREECE, y Miembro de la Red Latinoamericana de Investigadores en Didáctica de las Ciencias. Es autor de publicaciones (artículos, capítulos de libros y libros) en Didáctica de las Ciencias en las siguientes líneas: Relaciones entre historia, filosofía y enseñanza de las ciencias, evaluación, diseño curricular, enseñanza y aprendizaje de las ciencias, TIC y enseñanza de las ciencias y formación de profesores.

\section{Cristian Merino Rubilar}

Licenciado en Educación y Profesor de Química y Ciencias Naturales, Pontificia Universidad Católica de Valparaíso. Doctor en Didáctica de las Ciencias Experimentales, Universidad Autónoma de Barcelona. Es profesor e investigador en Enseñanza de la Química, en diferentes niveles educativos, en el Instituto de Química de la Pontificia Universidad Católica de Valparaíso (Chile). Sus intereses de investigación se centran en la caracte- 
rización de la actividad química escolar para el desarrollo y análisis de actividades de innovación que favorezcan la construcción de explicaciones científicas escolares con énfasis en el tránsito entre el fenómeno y la teoría bajo un enfoque modelizador para la formación de profesores de ciencias (especialmente en química) y además el trabajo experimental y la enseñanza de la química a través de mediaciones tecnológicas.

\section{Diana Patricia Rodríguez Pineda}

Licenciada en Física, Magister en Docencia de la Física. Cuenta con estudios de Maestría en Filosofía con énfasis en Epistemología y Doctora en Educación. Profesora Titular del Cuerpo Académico de Educación en Ciencias de la Universidad Pedagógica Nacional de México; actualmente es la responsable del Doctorado en Educación de la misma Universidad. Es miembro del Sistema Nacional de Investigadores (SNI) y cuenta con el reconocimiento de perfil PROMEP de la Secretaría de Educación Pública. Tiene como líneas de investigación y publicaciones: las concepciones epistemológicas, de aprendizaje y de evaluación; el diseño y desarrollo curricular y la formación de profesores de ciencias. También ha dirigido tesis de Licenciatura, Maestría y Doctorado en las temáticas antes mencionadas.

\section{Rubinsten Hernández Barbosa}

Licenciado en Química y Biología de la Universidad INCCA de Colombia. Realizó estudios de Maestría en Biología en la Pontificia Universidad Javeriana y de Especialización en Lenguaje y Pedagogía de Proyectos en la Universidad Distrital Francisco José de Caldas. Magister en Didáctica de las Ciencias, Universidad Autónoma de Colombia. Ha participado en el proceso de planeación y desarrollo de trabajos de investigación en Enseñanza de las Ciencias Naturales y en Ciencias Básicas y ha formado parte del comité evaluador en diferentes revistas. Actualmente adelanta Estudios de Doctorado en Educación con énfasis en Enseñanza de las Ciencias en la Universidad Distrital Francisco José de Caldas. Es docente Investigador de la Maestría en Didáctica de las Ciencias de la Universidad Autónoma de Colombia.

\section{Flor de María Reyes Cárdenas}

Doctora en Pedagogía, Maestra en Pedagogía e Ingeniera Química, Universidad Nacional Autónoma de México (UNAM). Se ha dedicado a la educación y divulgación de la ciencia desde el año 1992 en contextos informales 
y, posteriormente, desde 1998, en contextos en la educación formal en la educación en ciencias y en matemáticas. Ha colaborado en diversos proyectos e investigaciones para la educación en ciencias y como resultado de esto cuenta con materiales educativos, artículos y capítulos de libro publicados. Ha laborado en diversas organizaciones y programas educativos como la UnAm, la Universidad Pedagógica Nacional de México, el Proyecto Adopte un Talento y el Instituto Latinoamericano de la Investigación Educativa. Actualmente es profesora de la Facultad de Química y su investigación se centra en el saber pedagógico del contenido y la indagación en ciencias naturales con énfasis en química.

\section{Leonardo Enrique Abella Peña}

Licenciado en Química, Universidad Distrital. ICT Certified Teacher del IMOECorea del Sur y Magíster en Docencia de la Química de la Universidad Pedagógica Nacional. Investigador por más de 10 años en el área de tecnologías de la información y la comunicación aplicadas a la enseñanza de las ciencias naturales. Diseñador y evaluador de diversos tipos de software educativo, videojuegos, plataformas de E-learning y SMART learning. Integrante del Grupo de Investigación GREECE, Universidad Distrital. Colaborador de la Oficina de Innovaciones Educativas del Ministerio de Educación Nacional. Docente en ejercicio de la Secretaría de Educación del Distrito Capital - Bogotá.

\section{Juan Carlos Guevara Bolaños}

Ingeniero de Sistemas, Universidad Central. Especialista en Auditoría de Sistema, Universidad Católica. Especialista en Sistemas de Información en la Organización, Universidad de los Andes. Magister en Ciencias, Universidad Distrital. Estudiante del programa de Doctorado en Ingeniería de la Pontificia Universidad Javeriana. Profesor de la Universidad Distrital. Director del Grupo de Investigación METIS, donde ha tenido la oportunidad de participar en el desarrollo de proyectos de investigación en las líneas de Gestión del conocimiento e informática educativa. Sus áreas de interés están en la gestión colaborativa de conocimiento, la interoperabilidad de conocimiento, knowledge awareness, frameworks de gestión del conocimiento, sistemas de gestión del conocimiento, sistemas colaborativos, laboratorios virtuales, simuladores educativos, mundos virtuales y juegos educativos. 


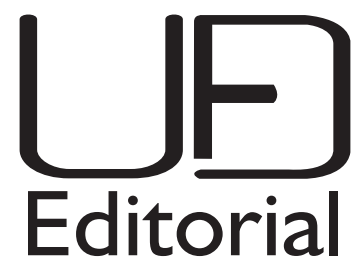

\author{
Este libro fue compuesto en caracteres \\ Optima y Trebuchet MS. \\ Impreso en 2014 en los talleres de Javegraf. \\ Bogotá, Colombia.
}
García Martínez, Álvaro
La formación del profesorado de ciencias en contextos de diversidad : una mirada desde la mediación con las TIC y la construcción de diseños didácticos / Álvaro García Martínez, Cristian Merino Rubliar. -- Bogotá : Universidad Distrital Francisco José de Caldas, 2014.

139 páginas ; $24 \mathrm{~cm}$.

ISBN 978-958-8832-81-4 / ISBN digital: 978-958-8832-82-1

1. Ciencias sociales - Enseñanza - Innovaciones tecnológicas 2. Ciencias sociales - Enseñanza - Metodología 3. Pluralismo (Ciencias sociales) 4. Tecnologías de la información y la comunicación 5. Formación profesional de maestros 6. Pedagogía I. Merino Rubliar, Cristian, autor II. Tít. 300.7 cd 21 ed.

A1456179

CEP-Banco de la República-Biblioteca Luis Ángel Arango 


\section{$\bigsqcup \mathrm{P}$ Editorial}

Las Tecnologías de la Información y de la Comunicación (TIC) se han transformado en un elemento de innovación dentro del conocimiento humano. Aplicadas directamente a la disciplina académica, las TIC se han ganado un espacio debido al creciente interés por este tipo de herramientas de parte de los docentes.

No obstante, al día de hoy, en Latinoamérica el uso de tic no es masivo. Su implementación aún está en una etapa inicial debido a diversos factores: falta de dotación de equipos, problemas con las redes y sistemas limitados de formación docente, aspecto que está íntimamente unido al poco seguimiento al implementar este tipo de tecnologías en las instituciones educativas y a los métodos y procedimientos empleados en la cualificación.

Teniendo en cuenta el contexto anterior, este documento contiene algunas orientaciones para el uso del material desarrollado en el área de Cien- cias Naturales del Proyecto ALTER-NATIVA, el cual va dirigido a la formación de profesores que atienden poblaciones en contexto de diversidad con incorporación de las TIC. 